\title{
4 Kontrafaktik: Eine fiktionstheoretische Perspektive
}

Während die ältere Forschung etwa bis zur Jahrtausendwende dem Fiktionsstatus des literarischen kontrafaktischen Erzählens keine größere Beachtung geschenkt hat, zeichnet sich in neueren Arbeiten eine Entwicklung hin zu einer auch fiktionstheoretisch informierten Perspektive auf das Erzählphänomen ab. ${ }^{208}$ Eine massive Einschränkung bei der Betrachtung faktenvariierender Erzählverfahren ergibt sich dabei jedoch, wie oben bereits ausgeführt wurde, aus der selten hinterfragten Grundentscheidung, ausschließlich das historische kontrafaktische Erzählen als Untersuchungsgegenstand zuzulassen: Ausnahmslos alle bisherigen Monografien zur Kontrafaktik beschäftigen sich schwerpunktmäßig mit der historischen Kontrafaktik, insbesondere in Form des kontrafaktischen historischen Romans. Affinitäten zu anderen faktenvariierenden Erzählverfahren und -genres, wie etwa der Dystopie oder der Satire, sind in der Forschung zwar verschiedentlich konstatiert worden, doch wurden diese Verbindungslinien bisher nicht systematisch weiterverfolgt.

In der vorliegenden Arbeit wird die dominierende Perspektive der bisherigen Kontrafaktik-Forschung gewissermaßen umgekehrt: Anstatt vom Genre des kontrafaktischen historischen Romans auszugehen und dann die etwaigen literarhistorischen, typologischen oder auch fiktionstheoretischen Spezifika dieses Genres aufzuzeigen, soll zunächst die basale Referenzstruktur kontrafaktischer Texte fokussiert werden. Diese Referenzstruktur manifestiert sich im kontrafaktischen historischen Roman zweifellos auf besonders exemplarische Weise, sodass die vorliegende Studie auch in keinem Widerspruch zur bisherigen Forschung steht. Indem jedoch vorderhand von Einschränkungen hinsichtlich des Genres, der Themen und der (impliziten) Epistemologie etwaiger zu behandelnder kontrafaktischer Texte abgesehen wird, eröffnet sich die Möglichkeit, die Struktur der Kontrafaktik zunächst allgemein-fiktionstheoretisch $\mathrm{zu}$ beschreiben, um dann erst in einem zweiten Schritt danach zu fragen, in welchen Genres und Gattungen kontrafaktische Erzählverfahren Verwendung finden, welche Arten von Fakten sich als Ausgangsmaterial der Kontrafaktik eignen und welche epistemologischen Implikationen sich jeweils aus dem konkreten Einsatz kontrafaktischen Erzählens in fiktionalen Medien ergeben.

Die folgenden Ausführungen zur Theorie der Kontrafaktik sind in zwei Großabschnitte unterteilt. Im ersten, mit ,Definition der Kontrafaktik‘ überschriebenen

208 Vgl. Widmann: Kontrafaktische Geschichtsdarstellung; Singles: Alternate History.

Ә Open Access. () 2022 Michael Navratil, publiziert von De Gruyter. (c) BY-NC-ND Dieses Werk ist lizenziert unter einer Creative Commons Namensnennung - Nicht-kommerziell - Keine Bearbeitung 4.0 International Lizenz. https://doi.org/10.1515/9783110763119-005 
Abschnitt wird die grundlegende Referenzstruktur der Kontrafaktik fiktionstheoretisch erläutert. Es wird dabei von einer Minimaldefinition der Kontrafaktik ausgegangen, die in kompakter Weise die zentralen Eigenschaften des Erzählphänomens zusammenfasst. Der fiktionstheoretische Abschnitt besteht im Wesentlichen aus einer sukzessiven Detailerläuterung der Begrifflichkeiten dieser Minimaldefinition, welche am Ende des Kapitels noch einmal in aller Kürze zusammenfassend charakterisiert werden sollen. Angestrebt wird mithin insgesamt eine Explikation des Begriffs der Kontrafaktik. ${ }^{209}$ Im zweiten, mit den Begriffen ,Abgrenzungen, Genres, Eigenheiten‘ überschriebenen Abschnitt wird das Verhältnis der Kontrafaktik zu drei anderen Modi des real-fiktionalen Weltvergleichs - der Realistik, Fantastik und Faktik - erläutert. Ferner werden die Vorteile einer Konzeptualisierung der Kontrafaktik als genreunabhängige Referenzstruktur vorgestellt und, daran anschließend, mehrere Genres diskutiert, in denen diese Referenzstruktur besonders häufig zum Einsatz kommt. Schließlich wird auf das Phänomen der Metafaktizität, also die Reflexion von Lüge und Wahrheit innerhalb kontrafaktischer Erzählwelten, eingegangen. Eine Zwischenbetrachtung am Ende des Theorieteils widmet sich dann noch einmal dem Status der Kontrafaktik als ,Schwellenphänomen', als ein Phänomen also, das in besonderem Maße von bestimmten Kontext- und Rezeptionsbedingungen abhängig ist.

Da es sich bei der Kontrafaktik um ein in hohem Grade kontextsensitives Rezeptionsphänomen handelt, muss von einem Literaturmodell ausgegangen werden, das Faktoren wie den Textrezipienten, bestimmte historische und kulturelle Rezeptionsvoraussetzungen sowie allgemein „extratextuelle[...] Kontext[e]“210 theoretisch zu integrieren vermag. Entsprechend wird Literatur in der vorliegenden Studie grundsätzlich als eine bestimmte Form der Kommunikation beziehungsweise als eine bestimmte Form der Sprachhandlung verstanden ${ }^{211}$ (was freilich nicht bedeutet, dass literarische Kommunikation einfach mit der Alltagskommunikation identisch wäre ${ }^{212}$ ). Kontrafaktik wird also im Folgenden nicht als

209 Zum Verfahren der Explikation siehe Tadeusz Pawłowski: Begriffsbildung und Definition, Berlin / New York 1980, S. 157-198.

210 Als eine von vier literaturwissenschaftlich relevanten Kontextarten bestimmt Lutz Danneberg den „extratextuelle[n] Kontext als Beziehung eines Textes zu nichttextuellen Gegebenheiten, [...] auch ReDeKonstellation“ (Lutz Danneberg: Kontext. In: Harald Fricke (Hg.): Reallexikon der deutschen Literaturwissenschaft. Bd. II. Berlin 2000, S. 333-337, hier S. 334). Siehe Kapitel 4.3.7. Fakten als Kontexte kontrafaktischer Interpretationen.

211 Siehe hierzu ausführlich Zipfel: Fiktion, Fiktivität, Fiktionalität, S. 30-67.

212 Carlos Spoerhase konstatiert: „Die meisten literarischen Texte, die Gegenstand literaturwissenschaftlicher Beschäftigung sind, sind vom Standpunkt der Alltagskommunikation anomal, weil sie hermeneutisch äußerst anspruchsvoll sind. Charakteristisch ist für den literarischen Text ein ,das verstehe ich nicht', das nach weiteren interpretativen Anstrengungen verlangt.“ 
ein bloß semantisches oder textstrukturelles Phänomen aufgefasst - was, wie noch zu zeigen sein wird, auch gar nicht möglich wäre -, sondern vielmehr als Ergebnis eines Aktes literarischer Kommunikation, der auf bestimmten textuellen, aber eben auch auf epistemischen, kulturellen, historischen und individuellen Voraussetzungen beruht - und der folglich immer auch scheitern kann.

\subsection{Minimaldefinition der Kontrafaktik}

Große Theoriegebäude haben den offenkundigen Nachteil, dass man sich leicht in ihnen verläuft. Wofern ein primär theoretisches Interesse verfolgt wird, mag man dieses Problem in Kauf nehmen. Für eine Literaturtheorie jedoch, die ihrem künstlerischen Gegenstand, dem literarischen Text, verpflichtet bleiben will - die also selbst nicht Epistemologie, Textontologie oder Ethik werden möchte -, stellt ein großes theoretisches Abstraktionsniveau ein Problem dar. Eine allzu voraussetzungsreiche Text- oder Interpretationstheorie läuft Gefahr, zur theoretischen Idiosynkrasie zu geraten und für die eigentliche Textdeutung nicht mehr produktiv gemacht werden zu können (während sich auf der anderen Seite die hermeneutische Praxis - ungeachtet aller wechselnder theoretischer Moden - gegenüber starren theoretischen Beschränkungen als erstaunlich immun erwiesen hat ${ }^{213}$ ). Im Zusammenhang der Entwicklung einer Theorie der Kontrafaktik erscheint dieses Problem besonders relevant, da es sich hier einerseits um ein fiktionstheoretisch anspruchsvolles Phänomen handelt, das eine umsichtige theoretische Erläuterung erfordert. Andererseits soll die Entwicklung einer Theorie der Kontrafaktik aber auch nicht als Selbstzweck betrieben werden, sondern letztlich in den Dienst einer Erhellung der in Frage stehenden künstlerischen Phänomene gestellt werden. Bei aller theoretischer Ambition sollte die Erhellung und Deutung literarischer Texte die regulative Idee literaturwissenschaftlichen Arbeitens bleiben.

(Carlos Spoerhase: Autorschaft und Interpretation. Methodische Grundlagen einer philologischen Hermeneutik. Berlin 2007, S. 414).

213 So konstatiert Andreas Kablitz, „daß noch die engagierteste Kritik an der Texthermeneutik, daß kein Appell Against Interpretation ihr den Garaus hat machen können. Textinterpretationen sind noch immer das Hauptgeschäft der Literaturwissenschaft; und nichts deutet darauf hin, daß sich das bald ändern wird. [...] Jedenfalls in pragmatischer Hinsicht scheint es so etwas wie eine Unvermeidlichkeit der Interpretation zu geben.“ (Andreas Kablitz: Theorie der Literatur und Kunst der Interpretation. $\mathrm{Zu}$ einigen Blindstellen literaturwissenschaftlicher Theoriebildung. In: Poetica 41/3-4 (2009), S. 219-231, hier S. 221). 
In der vorliegenden Studie wird zwecks einer Vermittlung zwischen Theorie und Textdeutung von einer kompakten Minimaldefinition der Kontrafaktik ausgegangen. Diese lautet:

\section{Minimaldefinition der Kontrafaktik}

Kontrafaktik bezeichnet signifikante Variationen realweltlichen Faktenmaterials innerhalb fiktionaler Medien.

Die vorgeschlagene Definition fungiert als Strukturierungshilfe für die folgenden theoretischen Überlegungen ebenso wie als kondensierte Version derselben. Der praktische Nutzen der Minimaldefinition entspricht dabei in etwa demjenigen einer mathematischen Formel: Sie kann zur konkreten Problemlösung herangezogen werden, ohne jedes Mal aufs Neue hergeleitet zu werden.

Anhand einer ausführlichen Erläuterung der zentralen Begriffe der Minimaldefinition soll im Folgenden das Erzählphänomen der Kontrafaktik theoretisch eingehegt und die Möglichkeit einer Identifikation und Analyse kontrafaktischer Elemente eröffnet werden. Zwar werden im Laufe der Erläuterung der Minimaldefinition auch einige Begriffe kommentiert, die in der Minimaldefinition selbst nicht auftauchen, etwa diejenigen der Referenz oder der Markierung; in diesen Fällen soll dann jedoch stets deutlich gemacht werden, weshalb diese Begriffe respektive Konzepte in der Minimaldefinition gewissermaßen mitgemeint sind und entsprechend bei ihrer Erläuterung mitberücksichtigt werden sollten.

Eine Bemerkung zur Darstellungsform der folgenden Erläuterungen sei vorausgeschickt: Da die einzelnen begrifflichen Teile der Minimaldefinition der Kontrafaktik konzeptionell eng miteinander verzahnt sind, erweist sich eine streng systematisch-sukzessive Entwicklung ihrer Terminologie als nicht vollständig durchführbar. Die einzelnen systematischen Aspekte der Kontrafaktik, die in der Minimaldefinition angezeigt werden, weisen keine logische Hierarchisierung untereinander auf, sondern sind jeweils auf komplexe Weise voneinander abhängig. Es wird sich entsprechend als unumgänglich erweisen, bei den folgenden Erläuterungen einzelner Termini gelegentlich auf Begriffe und Konzepte vorzugreifen, die erst im weiteren Verlauf der Argumentation erläutert werden. Die bedeutendsten theoretischen Vor- und Rückverweise werden dabei jeweils in den Fußnoten angezeigt. 


\subsection{Fiktionalität}

Wie bereits zu Beginn des Theorieteils erwähnt, bezeichnet Kontrafaktik das kontrafaktische Erzählen oder Denken speziell in fiktional-künstlerischen Medien. Angesichts der Vielzahl der möglichen Definitionen von Fiktionalität ${ }^{214}$ soll im Folgenden dasjenige Fiktionalitätsverständnis vorgestellt werden, das für die hier vorgestellte Theorie der Kontrafaktik maßgeblich ist. ${ }^{215}$

Die vorliegende Studie folgt einem institutionellen Fiktionalitätsverständnis, sie schließt also an Positionen an, die Fiktionalität an einen bestimmten Aussagemodus binden. Diesen Positionen zufolge konstituiert Fiktionalität sich nicht (allein) über die Ontologie der beschriebenen Sachverhalte - etwa über die Erfundenheit (Fiktivität) der Aussagegegenstände - oder über spezifische textuelle Merkmale sogenannte Fiktionssignale -, sondern über eine bestimmte Art des pragmatischen Umgangs mit Texten (was nicht bedeutet, dass bestimmte Eigenschaften der Erzählgegenstände oder Textmerkmale hier gar keine Rolle spielen würden ${ }^{216}$ ). Ein Text wird diesem Verständnis zufolge dadurch fiktional, dass er den Regeln einer bestimmten gesellschaftlichen Institution, eben der ,Institution Fiktionalität ${ }^{\star}$ gemäß behandelt wird. In ihrer einflussreichen Studie Truth, Fiction, and Literature von 1994 definieren Peter Lamarque und Stein Haugom Olsen eine institutionelle Praxis folgendermaßen:

An institutional practice, as we understand it, is constituted by a set of conventions and concepts which both regulate and define the actions and products involved in the practice. [...] An institution, in the relevant sense, is a rule-governed practice which makes possible certain (institutional) actions which are defined by the rules of the practice and which could not exist as such without those rules. ${ }^{217}$

Fiktionalität bezeichnet entsprechend eine bestimmte kommunikationspragmatische Haltung, die gegenüber Texten und anderen Medien eingenommen werden kann und die Modalitäten des Umgangs mit diesen Texten und Medien reguliert.

214 Vgl. zum Überblick Tilmann Köppe / Tobias Klauk (Hg.): Fiktionalität. Ein interdisziplinäres Handbuch. Berlin / Boston 2014.

215 Zur den basalen Unterscheidungen Fiktionalität/Faktualität sowie Fiktivität/Realität siehe Kapitel 2. Vorbereitendes.

216 Zipfel weist darauf hin, „daß es zur theoretischen Deutung literarischer Fiktion mehrschichtiger Beschreibungen bedarf.“ (Zipfel: Fiktion, Fiktivität, Fiktionalität, S. 167) Danneberg bemerkt: „Was man auch immer mit ,Wahrhaftigkeit‘, ,Fiktionalität‘ und ähnlichen Konzepten meint und über sie weiß: Immer scheinen es komplexe, mehrwegige Klassifikatoren zu sein.“ (Danneberg: Weder Tränen noch Logik, S. 40).

217 Peter Lamarque / Stein Haugom Olsen: Truth, Fiction, and Literature. A Philosophical Perspective. Oxford 1994, S. 256. 
Auch die Rede von ,Fiktions-Kompetenz ${ }^{218}$ oder vom ,Fiktionsvertrag“, wie sie sich in der Forschung mitunter findet, stellt letztlich eine (metaphorische) Charakterisierung der ,Institution ${ }^{219}$ Fiktionalität dar. ${ }^{220}$ Mit Blick auf den aktuellen Stand der Forschung ist $\mathrm{zu}$ bemerken, dass konventionalistische, pragmatische oder eben institutionelle Fiktionalitätstheorien zu einer gewissen Dominanz gelangt sind. ${ }^{221}$ Im Folgenden sollen die zentralen Implikationen und Vorteile eines solchen institutionellen Fiktionalitätsverständnisses knapp umrissen werden.

Tilmann Köppe fasst die Grundannahme institutioneller Theorien der Fiktionalität folgendermaßen zusammen:

Was einen Text fiktional macht, ist [...] die Tatsache, dass der Text mit der Absicht hervorgebracht wurde, gemäß den Konventionen der Fiktionalitätsinstitution rezipiert zu werden. Für diese Rezeption ist wesentlich, dass Leser den Text einerseits zur Grundlage einer imaginativen Auseinandersetzung mit dem Dargestellten nehmen und andererseits von bestimmten Schlüssen vom Text auf Sachverhalte in der Wirklichkeit absehen; so darf man insbesondere nicht davon ausgehen, dass die Sätze des Werkes wahr sind oder vom Autor der Werkes für wahr gehalten werden. ${ }^{222}$

Der Aufruf zur Befolgung der Regeln der Institution Fiktionalität kann beispielsweise über Paratexte erfolgen, etwa durch Gattungszuordnungen wie ,Roman“ oder ,Erzählung‘ auf dem Bucheinband, aber auch durch die Zugehörigkeit eines Textes zu einem bestimmten Autorenwerk oder durch textimmanente Fiktionssignale wie etwa den Einsatz eines allwissenden Erzählers. ${ }^{223}$

Einem institutionellen Fiktionalitätsverständnis zufolge lässt sich die Fiktionalität eines Textes letztlich allein über den pragmatischen Umgang mit diesem Text zuverlässig bestimmen - nicht aber über bestimmte textuelle Eigenschaften. So formuliert Marc Chinca: „Pragmatische Ansätze definieren die Fiktionalität

218 Jean-Marie Schaeffer etwa schreibt: „[L]a compétence fictionnelle nécessite l'apprentissage d'un ensemble d'attitudes intentionnelles d'une grande complexité.“ [Die Fiktions-Kompetenz erfordert das Erlernen eines Ensembles institutioneller Haltungen von großer Komplexität. - Übersetzung M. N.] (Jean-Marie Schaeffer: Pourquoi la fiction? Paris 1999, S. 16).

219 Vgl. etwa Umberto Eco: Im Wald der Fiktionen. Sechs Streifzüge durch die Literatur. München ${ }^{2} 1999$, S. 103.

220 Vgl. Zipfel: Fiktion, Fiktivität, Fiktionalität, S. 284.

221 Vgl. Tobias Klauk / Tilmann Köppe: Bausteine einer Theorie der Fiktionalität. In: Tilmann Köppe / Tobias Klauk (Hg.): Fiktionalität. Ein interdisziplinäres Handbuch. Berlin / Boston 2014, S. 3-31, hier S. 7.

222 Tilmann Köppe: Die Institution Fiktionalität. In: Ders. / Tobias Klauk (Hg.): Fiktionalität. Ein interdisziplinäres Handbuch. Berlin / Boston 2014, S. 35-49, hier S. 35.

223 Vgl. Klein / Martínez: Wirklichkeitserzählungen, S. 3f. „Die Klassifikation eines Textes als fiktional oder faktual ist eine Entscheidung, die letztlich auf textpragmatischer Ebene getroffen wird.“ (Ebd., S. 4). 
von ihrem ,Sitz im Leben“ her, als Funktion der Relation zwischen dem Sprechakt und seiner Gebrauchssituation. Diese Situation, und nicht etwa linguistische Merkmale des Textes, ist letzten Endes entscheidend““.224 Damit wird zwar nicht prinzipiell ausgeschlossen, dass es auch bestimmte Texteigenschaften geben kann, die einen Text tendenziell eher in Richtung fiktionalen Schreibens rücken $^{225}$ - etwa die Schilderung von Gedanken in der dritten Person Singular oder die Verwendung des epischen Präteritums ${ }^{226}$-; nur reichen diese Texteigenschaften allein nicht aus, um das Vorliegen fiktionaler Rede sicherzustellen, da Sprache an und für sich eine Übertragung fiktionaler Rede in faktuale Kontexte nicht zuverlässig auszuschließen vermag. ${ }^{227}$ Lutz Danneberg bemerkt hierzu: „Eine aufgrund eines bestimmten Wissens als nichtfiktional klassifizierte Darstellung läßt sich grundsätzlich (bei verändertem oder als irrelevant erklärtem Wissen) auch wie eine fiktionale behandeln - und umgekehrt.“228

Für das kontrafaktische Erzählen erweist sich diese prinzipielle Übertragbarkeit sprachlich identischer Äußerungen von einem fiktionalen und in einen faktualen Kontext und vice versa als besonders bedeutsam, hat man es hier doch mit einem Erzählverfahren zu tun, das sowohl in fiktionalen wie auch in faktualen Kontexten Verwendung findet - und dies zum Teil in sprachlich ähnlicher Form. Faktual-kontrafaktische Szenarien der Historiografie und fiktional-kontrafaktische Szenarien des literarischen Alternate History-Genres etwa können mit Blick auf den manifesten Text mitunter kaum voneinander unterschieden werden. Dieser potenzielle sprachliche Isomorphismus sollte allerdings nicht dazu verleiten, fiktionale und faktuale Äußerungskontexte zu vermischen oder beide auf dieselben Regeln und Standards zu beziehen, wie es in der bisherigen Kontrafaktik-

224 Marc Chinca: Mögliche Welten. Alternatives Erzählen und Fiktionalität im Tristanroman Gottfrieds von Straßburg. In: Poetica 35 (2003), S. 307-333, hier S. 313.

225 Siehe etwa Dorrit Cohn: Signposts of Fictionality. A Narratological Perspective. In: Poetics Today 11 (1990), S. 775-804.

226 Vgl. Käte Hamburger: Die Logik der Dichtung. Wien 1980, S. 60-121.

227 So konstatiert John Searle in seinem klassischen Aufsatz zur Fiktionstheorie: „The utterance acts in fiction are indistinguishable from the utterance acts of serious discourse, and it is for that reason that there is no textual property that will identify a stretch of discourse as a work of fiction.“ (John R. Searle: The Logical Status of Fictional Discourse. In: New Literary History 6/2 (1975), S. 319-332, hier S. 327) Simone Winko konstatiert mit Blick auf die neuere Diskussion rund um ,Poetizität‘ und ,Literarizität‘ als Bestimmungsmerkmale von ,Literatur‘: „Als gescheitert kann der Versuch angesehen werden, die textinternen Kriterien als notwendige und hinreichende Bedingungen für Literatur zu postulieren“ (Simone Winko: Auf der Suche nach der Weltformel. Literarizität und Poetizität in der neueren literaturtheoretischen Diskussion. In: Dies. / Fotis Jannidis / Gerhard Lauer (Hg.): Grenzen der Literatur. Zu Begriff und Phänomen des Literarischen. Berlin 2009, S. 374-396, hier S. 391).

228 Danneberg: Weder Tränen noch Logik, S. 40. 
Forschung vielfach geschehen ist. Stattdessen muss - zumindest aus heuristischen Gründen - eine möglichst strenge Trennung von fiktionalen und faktualen Äußerungskontexten angestrebt werden, da nur auf diese Weise der unterschiedliche Einsatz desselben Erzählverfahrens im Rekurs auf diejenigen Lizenzen und Beschränkungen bewertet werden kann, die für den jeweiligen Äußerungszusammenhang auch tatsächlich gelten. ${ }^{229}$

Ein pragmatisches oder institutionelles Verständnis von Fiktionalität bietet eine ganze Reihe von Vorteilen gegenüber einem Fiktionalitätsverständnis, das sich auf bestimmte Textmerkmale oder auf ontologische Eigenschaften der erzählten Welt bezieht. ${ }^{230}$ Da in einem institutionellen Verständnis Fiktionalität an bestimmte soziale Konventionen gebunden ist, vermag diese Theorie auch zu beschreiben, weshalb sich der Fiktionalitätsstatus ein und desselben Textes mitunter im Laufe der Zeit verändert. Ein naheliegendes Beispiel wären die antiken Mythen, die in ihrem Entstehungskontext vermutlich nicht als fiktional betrachtet wurden, heute aber durchaus als fiktional angesehen werden können. Mit einer institutionellen Fiktionalitätstheorie lässt sich erklären, unter welchen sozialen, epistemischen oder sonstigen Rahmenbedingungen Texte einen Status als fiktionale Texte gewinnen oder diesen Status auch wieder verlieren können. Diese historisch und sozial variable pragmatische Einbindung ist auch für eine Bestimmung der Kontrafaktik von Belang, da es sich bei der Kontrafaktik erstens per definitionem um eine fiktionale Ausprägung kontrafaktischen Erzählens handelt und weil das kontrafaktische Erzählen zweitens notwendigerweise ein rezeptionsabhängiges und also kontextsensitives Erzählphänomen darstellt. Wird also einem Text aufgrund veränderter Rahmenbedingungen sein Fiktionalitätsstatus abgesprochen - etwa weil ein kontrafaktischer Text als faktuale Verschwörungstheorie, als Fake News oder Lüge gedeutet wird -, so kann er nicht mehr länger der Kontrafaktik zugeschlagen werden.

Ein weiterer Vorteil institutioneller Fiktionalitätstheorien besteht in ihrer besonderen Eignung zur Diskussion solcher Texte, die Fiktionalität mit einem deutlichen Weltbezug kombinieren, fiktionaler Textgattungen also, in denen

229 Der Unterschied zwischen einem hinsichtlich seines Wortlauts identischen Textes, der einmal in einem fiktionalen und einmal in einem faktualen Äußerungskontext verwendet wird, ließe sich aus der Sicht einer sprachhandlungstheoretisch fundierten Fiktionstheorie unter anderem dahingehend beschreiben, dass im Falle einer fiktionalen Sprachhandlungssituation die Rolle des ,Senders ‘ verdoppelt ist: Hier müsste zwischen Autor und Erzähler unterschieden werden, während in faktualen Sprachhandlungssituationen eine solche Trennung nicht üblich oder zulässig ist. Vgl. Dorrit Cohn: Signposts of Fictionality, S. 793; Zipfel: Fiktion, Fiktivität, Fiktionalität, S. 120 f.; Singles: Alternate History, S. 95, Anm. 131.

230 Vgl. Köppe: Die Institution Fiktionalität, S. 45-48. 
der Versuch unternommen wird, „Einsichten über die Wirklichkeit zu vermitteln. $\mathrm{Zu}$ diesen Gattungen gehören etwa Fabeln, der historische Roman, der Schlüsselroman oder der roman à thèse, zum erweiterten Kreis gehören aber auch der psychologische Roman oder der Entwicklungsroman“231 - und, so könnte ergänzt werden, auch die Texte der Kontrafaktik und Formen politischen Schreibens, lassen sich doch sowohl kontrafaktische als auch politische Texte einzig in Bezug auf eine bestimmte gesellschaftliche und zeitliche Konstellation analysieren. Diese Notwendigkeit des Weltbezugs besteht natürlich a fortiori bei Beispielen politischer Realitätsvariationen, wie sie im Zentrum der vorliegenden Studie stehen, also bei Kombinationen von Kontrafaktik und politischem Schreiben.

Institutionelle Fiktionalitätstheorien bieten sich darüber hinaus in besonderem Maße als Grundlage medienübergreifender Kunsttheorien an. Ein Fiktionalitätsbegriff, der eng an die spezifischen Bedingungen literarischer Werke gebunden ist, kann nur eingeschränkt bei film- oder bildwissenschaftlichen Untersuchungen zur Anwendung kommen. Institutionelle Fiktionalitätstheorien, die ihr Augenmerk primär auf die Konventionen der Produktion und Rezeption künstlerischer Werke legen, erlauben es hingegen, kunsttheoretische Überlegungen auch medienübergreifend nutzbar zu machen - freilich immer unter der Voraussetzung entsprechender Anpassungen an das jeweilige künstlerische Medium. $^{232}$

Ein letzter Vorteil institutioneller Fiktionalitätstheorien besteht in ihrer relativ einfachen Handhabbarkeit. Noch einmal sei Tilmann Köppe zitiert:

[F]ür den Literaturwissenschaftler [ist] ein grundsätzliches Verständnis der Fiktionalität literarischer Texte zentral; man kann aber nicht erwarten, dass sich Literaturwissenschaftler mit den Subtilitäten philosophischer Semantik, Modallogik oder Ontologie auseinandersetzen. Während solche Theorien weitab von literaturwissenschaftlichen Kerninteressen liegen und entsprechend im Ruf einer nur geringen Anschlussfähigkeit stehen, bieten institutionelle Theorien der Fiktionalität zahlreiche Möglichkeiten, literaturwissenschaftliche Kernfragen wie etwa die nach literaturspezifischen Konventionen, Gattungen, literaturgeschichtlichen Entwicklungen sowie nach den Funktionen fiktionaler Literatur zu thematisieren und zu beantworten. ${ }^{233}$

Gerade das Phänomen der Kontrafaktik, das ohnehin stark zum theoretischen Ausfransen neigt, kann nur davon profitieren, wenn bei der Bestimmung seiner

231 Köppe: Die Institution Fiktionalität, S. 46.

232 Köppe: Die Institution Fiktionalität, S. 47.

233 Köppe: Die Institution Fiktionalität, S. 47 f. 
definierenden Merkmale philosophische Spezialprobleme soweit wie möglich hintangehalten werden und das Augenmerk stattdessen auf das, literaturwissenschaftliche Kerninteresse' gerichtet bleibt.

Jene literarischen Texte, die das Korpus dieser Arbeit bilden, sowie auch der fiktionale Film - etwa Tarantinos Inglourious Basterds - und der fiktionale Comic etwa Alan Moores und Dave Gibbons' Watchmen - werden von dem vorgeschlagenen institutionellen Fiktionalitätsverständnis zweifellos abgedeckt. Einen Grenzfall der Kontrafaktik bildet demgegenüber der (eher seltene, wiewohl theoretisch reizvolle) Fall fiktionaler Medien, die keinen dezidiert künstlerischen Anspruch erheben. $\mathrm{Zu}$ nennen ist hier insbesondere die Werbung, welche, zumindest in ihrer audiovisuellen Ausprägung, zwar medial-formal mit dem fiktionalen Film übereinstimmt, sich aufgrund ihrer offenkundig außerästhetischen Zweckgebundenheit nämlich der Absatzsteigerung des beworbenen Produkts - allerdings nicht problemlos als künstlerische Gattung bezeichnen lässt.

Ein diskussionswürdiges Beispiel kontrafaktischer ,Werbung' stellt der fingierte Werbespot MCP - Collision Prevent für den Mercedes Benz, genauer: für dessen Bremsassistenten dar, der im Jahre 2013 auf YouTube veröffentlicht und bis Anfang des Jahres 2020 fast anderthalb Millionen Mal aufgerufen wurde. ${ }^{234}$ Jens Jessen fasst in einem Zeit-Artikel, welcher den Clip gegen Kritik der Öffentlichkeit sowie des Autoherstellers verteidigt, die Handlung des Spots wie folgt zusammen:

Der Mercedes, der dort offenbar auf einer Zeitreise in ein Dorf des späten 19. Jahrhunderts gelangt ist, bremst ein erstes Mal vorbildlich vor spielenden Kindern - ein zweites Mal aber, als ihm noch ein kleiner Junge vor den Kühler läuft, bremst es nicht, „Adolf“, schreit die entsetzte Mutter, und wenig später sieht man den Buben tot in Form eines Hakenkreuzes auf der Fahrbahn liegen. Das Ortsschild, von dem tüchtigen Mercedes wenig später passiert, trägt die Aufschrift Kronland: Oberösterreich, Ortschaft: Braunau am Inn. Dann, triumphierend, der große Satz „Erkennt Gefahren, bevor sie entstehen“. 235

Der Spot greift eines der prominentesten Themen der Kontrafaktik auf, nämlich die veränderte Lebensgeschichte Adolf Hitlers. Allerdings tut er dies in einer ungewöhnlichen Variante: Nicht die Biografie des erwachsenen Politikers erfährt eine Modifikation, sondern Adolf Hitler wird bereits als Kind - unter bewusster Inkaufnahme eines technisch-historischen Anachronismus - von einem Merce-

234 Mercedes Benz ADOLF Spot (German/Deutsch) - 2013 HD. Quelle: https://www.youtube.com/ watch?v=bEME9licodY (Zugriff: 01.01.2020).

235 Jens Jessen: Für Hitler wird nicht gebremst. Ein Video parodiert die neue Fahrhilfe von Mercedes Benz. In: Die Zeit, 29.08.2013. 
des Benz überfahren. Die ,Gefahren' seines weiteren politischen Werdegangs werden somit ausgeräumt, noch ,bevor sie entstehen‘.

Der fingierte Werbespot, bei dem es sich um die Abschlussarbeit des Regisseurs Tobias Haase an der Filmakademie Ludwigsburg handelt, lässt sich als Metakommentar auf das Pathos und die fragwürdigen Versprechungen echter Werbespots verstehen, welche hier formal meisterlich imitiert respektive anzitiert werden, um dann jedoch in einem weiteren Schritt mittels einer absurden kontrafaktischen Volte und einer verfremdenden Verwendung des Werbeslogans satirisch unterhöhlt zu werden. Man könnte bei diesem Spot geradezu von einer Poetizität der Werbung - durchaus im Sinne Roman Jakobsons sprechen, die dadurch entsteht, dass die weithin bekannte ,Sprache“ der Werbung reflexiv auf sich selbst rückbezogen und damit in eine autosubversive Schleife hineingedreht wird. In Verbindung mit der ostentativ respektlosen, kontrafaktischen Behandlung eines der düstersten Kapitel deutscher Geschichte - eine Negativwertung, die es im konkreten Fall kurioserweise ermöglicht, selbst noch das Überfahren-Werden eines Kindes lustig zu finden -, stellt der fingierte Werbespot die Falschheit kommerzieller Werbeversprechen mit satirischer Deutlichkeit heraus. ${ }^{236}$

Das Beispiel zeigt, dass Kontrafaktik auch in Medien zum Einsatz kommen kann, die zwar fiktional, nicht aber literarisch oder allgemein künstlerisch sind (wenngleich es sich bei Tobias Haases Pseudo-Spot natürlich sehr wohl um ein Kunstwerk handelt, das sich auch mitnichten als realer Werbespot eignen würde). Allerdings dürften derartige Fälle eine Ausnahme bilden: Für gewöhnlich erfüllen kontrafaktische Werke sowohl das Kriterium der Fiktionalität als auch dasjenige der Literarizität (oder auch Poetizität). ${ }^{237}$ Entsprechend erscheint, zumindest in einem etwas vereinfachenden Sprachgebrauch, die Aussage legitim: Kontrafaktik bezeichnet das kontrafaktische Erzählen in der Kunst.

236 Siehe zum Provokationspotenzial des Spots auch Rhein / Schumacher / Wohl von Haselberg: Einleitung, S. $7 \mathrm{f}$.

237 Literarizität, Poetizität und ,Kunstcharakter` auf der einen und Fiktionalität auf der anderen Seite weisen zwar eine große Schnittmenge untereinander auf, sind aber nicht deckungsgleich. So gibt es sowohl literarische Werke, die nicht fiktional sind (wie etwa dadaistische Lautgedichte), als auch fiktionale Werke, die keinen Kunstcharakter beanspruchen können (wie etwa Werbespots). Vgl. Lutz Rühling: Fiktionalität und Poetizität. In: Heinz Ludwig Arnold / Heinrich Detering (Hg.): Grundzüge der Literaturwissenschaft. München 1996, S. 25-51. 


\subsection{Fakten und fiktionale Welten}

Dass Texte der Kontrafaktik auf Fakten bezogen sind, ist bereits dem Begriff abzulesen. Keinen Aufschluss gibt der Begriff hingegen darüber, welche Arten von Fakten hier genau vorausgesetzt werden müssen, was den Status dieser Fakten begründet und bis zu welchem Grade sie intersubjektiv verbindlich sein sollten. Zu klären bleibt also vorderhand das, was man die, Epistemologie der Kontrafaktik' nennen könnte.

Im Folgenden sollen Status und Bedeutung der realweltlichen Fakten für die Kontrafaktik erläutert werden. Hierbei wird zunächst zu klären sein, was die relevanten Fakten überhaupt als solche konstituiert und wie sich das Verhältnis eines Faktums zu seiner kontrafaktischen Variation bestimmen lässt. Daran anschließend werden der realweltliche Status der Fakten der Kontrafaktik sowie ihre Referenzstruktur näher erläutert. Schließlich soll drei naheliegenden Einwänden begegnet werden, die gegen die These vorgebracht werden könnten, kontrafaktische Texte würden indirekt auf realweltliches Faktenmaterial referieren: Es wird zu klären sein, ob die Theorie der Kontrafaktik mit konstruktivistischen Wahrheitstheorien vereinbar ist (um es vorwegzunehmen: sie ist es), ob sich die Kontrafaktik an Theorien,ästhetischer Wahrheit' anschließen lässt (sie tut es nicht) und wie der Status von Informationen einzuschätzen ist, die in der fiktionalen Erzählung oder in Paratexten, also innerhalb des kontrafaktischen Werkes selbst geliefert werden.

\subsubsection{Kontrafaktik, Wahrheit, Fiktionalität}

Das Verhältnis von Dichtung und Wahrheit bildet seit der Antike eine der Grundfragen der abendländischen Ästhetik. Hans Blumenberg hat gar die - wohl ein wenig überzogene - These aufgestellt: „Die Tradition unserer Dichtungstheorie seit der Antike läßt sich unter dem Gesamttitel einer Auseinandersetzung mit dem antiken Satz, daß die Dichter lügen, verstehen.“238 Trotz einer prinzipiellen gesellschaftlichen Anerkennung der Praxis fiktionalen, also nicht unmittelbar wahrheitserheischenden Erzählens in der Moderne und der weitgehenden Anerkennung der - nicht zuletzt epistemischen - Autonomie der Kunst hat die Frage nach dem Zusammenhang von Literatur und Wahrheit auch im 20. und 21. Jahr-

238 Hans Blumenberg: Wirklichkeitsbegriff und Möglichkeit des Romans. In: Hans Robert Jauß (Hg.): Nachahmung und Illusion. Poetik und Hermeneutik I. München 1964, S. 9-27, hier S. 9. 
hundert nichts an Relevanz verloren: In den letzten Jahrzehnten wurden die teils deutlich älteren, einschlägigen Diskussionen in Ästhetik, (analytischer) Philosophie und Fiktionstheorie in der Literaturwissenschaft aufgenommen und fortgeführt. Zugleich wurde das Verhältnis von Wahrheit und Literatur im Rahmen der kulturwissenschaftlichen Erweiterung der Literaturwissenschaft, in der Diskursanalyse und anderen Diskurstheorien, in der Poetologie des Wissens sowie in der ,Literatur und Wissen'-Forschung eingehend und teils programmatisch thematisiert. Dabei darf mittlerweile als Konsens gelten, dass der Versuch einer starren, etwa streng typologischen Kopplung von Wahrheit und Literatur nur scheitern kann, und zwar sowohl an den vielfältigen Definitionsmöglichkeiten der beiden in Frage stehenden Begriffe als auch an den zahllosen Möglichkeiten ihrer wechselseitigen Konfiguration. Den Zusammenhang von Wahrheit und Literatur wird man nicht deduktiv-abstrakt, sondern nur induktiv, für einzelne Untergruppen von Texten, wenn nicht gar nur für Einzeltexte sinnvoll erörtern können. ${ }^{239}$

Die Kontrafaktik nun bildet den Fall eines Erzählphänomens, für das ein präzises Verständnis des Verhältnisses von Literatur und Wahrheit nicht nur von generellem ästhetischen oder poetologischen Interesse ist, sondern als zentrales Bestimmungskriterium des Erzählphänomens angesehen werden kann (ähnlich etwa wie im Falle der Fantastik oder bei den meisten Lesarten des Realismus). Die Frage nach dem Status der Fakten in der Kontrafaktik führt dabei zur Diskussion der Fiktionalität zurück. Eine, wenn nicht die zentrale Eigenschaft fiktionaler Texte besteht nämlich darin, dass es sich dabei um „nicht-behauptende Rede ohne unmittelbare Referenz in der Wirklichkeit“ handelt. ${ }^{240}$ Platons bekannter Vorwurf, dass die Dichter lügen, erweist sich - zumindest im Rahmen eines modernen Fiktionalitätsverständnisses - bereits a priori als haltlos, da die fiktionale Rede der Dichter gar keine unmittelbare Aussage über die reale Welt zu machen versucht und somit weder zu realweltlich wahren noch zu realweltlich falschen Behauptungen führt. Christian Klein und Matías Martínez bringen diesen Umstand auf die Formel: „Unter allen möglichen Verfassern lügen die Dichter am wenigsten, weil sie - im Gegensatz z. B. zu den Geschichtsschreibern - in ihren Werken gar nichts selbst behaupten, sondern einen imaginären Erzähler erfinden, der immer nur etwas in Bezug auf seine fiktive Welt behauptet.“241

Nun weist die These von der Wahrheitsindifferenz als Definitionskriterium fiktionaler Rede zweifellos einen hohen Grad an Plausibilität auf. Allerdings lassen sich Beispiele fiktionale Literatur anführen, welche an der Gültigkeit

239 Vgl. Tilmann Köppe: Wahrheit. In: Roland Borgards u. a. (Hg.): Literatur und Wissen. Ein interdisziplinäres Handbuch. Stuttgart u. a. 2013, S. 231-235.

240 Martínez / Scheffel: Einführung in die Erzähltheorie, S. 16.

241 Klein / Martínez: Wirklichkeitserzählungen, S. 3. 
dieser These - zumindest in einer verabsolutierten Lesart - Zweifel aufwerfen. Die Behauptung, der primäre Effekt der Fiktionalität literarischer Texte bestehe in der, wie Andreas Kablitz schreibt, „Vergleichgültigung gegenüber dem Wahrheitswert ihrer Sätze“ respektive in der „Belanglosigkeit der Falsifikation“242, ist insofern irreführend, als damit impliziert wird, dass Wahrheitswerte für fiktionale Texte grundsätzlich keine Rolle spielen würden. Gerade an der Kontrafaktik wird allerdings deutlich, dass fiktionale Texte durchaus in bedeutungskonstitutiver Weise von Wahrheitswerten faktualer Annahmen abhängig sein können. Die spezifische Interpretationsleistung, zu der kontrafaktische Texte aufrufen, beruht ja gerade darauf, dass Abweichungen von realweltlichen Fakten innerhalb eines fiktionalen Werks erkannt und für deutungsrelevant befunden werden.

Der Versuch, Fiktionalität allein an den Wahrheitswert von Aussagen beziehungsweise an die Suspendierung der Notwendigkeit eines solchen Wahrheitswertes $\mathrm{zu}$ binden, greift also zu kurz. Zwar ist fiktionale literarische Rede nicht in ähnlicher Weise auf faktische Richtigkeit verpflichtet wie faktuale Rede (auch nicht im Falle solcher faktenaffiner Genres wie etwa dem historischen Roman oder der Dokufiktion); zugleich scheint es jedoch wenig plausibel anzunehmen, eine konkrete, offenkundig faktisch richtige oder eben faktisch falsche Textaussage etwa die Variation eines allgemein bekannten historischen Datums - sei für die Bedeutungsgenese des Textes grundsätzlich irrelevant, wird diese Textaussage doch vom Leser erkannt und mitunter auch in die Textinterpretation miteinbezogen. Die „willinge suspension of disbelief “243, die Samuel Taylor Coleridge bekanntlich als Grundvoraussetzung für die Rezeption fiktionaler Werke ansetzte, gilt zwar auch für kontrafaktische Werke; auch hier wäre es keine adäquate Leserreaktion, zu sagen: „Der Dichter lügt!“ Die Besonderheit der Rezeptionsstruktur der Kontrafaktik besteht allerdings darin, dass der Leser bei der Lektüre gleichsam in einem zweiten Rezeptionsschritt, welcher sich auf die reale Welt bezieht, genau das sagen muss - „Der Dichter“, oder vielmehr: „Der Text lügt!“ (respektive macht eine realweltlich unzutreffende Aussage) -, um den fiktionalen Text überhaupt als kontrafaktischen Text interpretieren $\mathrm{zu}$ können. ${ }^{244}$

Ein Heraustreten aus einer primär epistemischen Betrachtungsweise der Kontrafaktik, wie es in dieser Studie vorgeschlagen wird, kann und darf also

242 Andreas Kablitz: Kunst des Möglichen. Theorie der Literatur. Freiburg i. Brsg. 2013, S. 191, S. 169, Anm. 39.

243 Samuel Taylor Coleridge: Biographia Literaria: Or, Biographical Sketches of My Literary Life and Opinions. New York / Boston 1834, S. 174.

244 Kommunikationspragmatisch handelt es sich bei kontrafaktischen Aussagen freilich niemals um Lügen, da kontrafaktische Aussagen per definitionem offenkundig falsch sind und mithin auch keine Täuschungsabsicht verfolgen. Vgl. Navratil: Lying in Counterfactual Fiction. 
keine vollständige Indifferenz gegenüber Fragen des Wissens und der objektiven Richtigkeit von Textaussagen nach sich ziehen; mit dem Begriff des ,Fakts ist schließlich bereits auf terminologischer Ebene eine Kategorie gegeben, die keine vollständige epistemische Indifferenz erlaubt. Die Kontrafaktik bindet sich zwar nicht in der Art einer wahren Aussage innerhalb eines faktualen Diskurses unmittelbar an die Fakten, wie terminologisch ja wiederum bereits der Begriff Kontrafaktik anzeigt; sie sieht aber auch nicht vollständig von den Fakten ab, etwa im Sinne einer Nonfaktizität. Vielmehr liegt hier der Fall eines fiktionalen Erzählens vor, bei welchem realweltliche Fakten auf ganz bestimmte Weise im Rahmen eines fiktionalen Mediums verwendet werden. Wie alle fiktionalen Texte treffen auch kontrafaktische Texte keine unmittelbaren Wahrheitsaussagen über die reale Welt; damit ist jedoch nicht ausgeschlossen, dass sich kontrafaktische Texte realweltlicher Faktenannahmen in einer bestimmten Weise - nämlich qua erkennbarer und signifikanter Variation - bedienen können, um ästhetische, affektive oder normative Effekte zu erzielen.

Die Feststellung, dass in kontrafaktischen Texten realweltlichen Wahrheitsannahmen widersprochen wird, zwingt dabei keineswegs dazu, das Fiktionalitätskriterium für die Kontrafaktik einzuschränken. Eine solche Einschränkung wäre lediglich dann geboten, wenn man erwarten würde, dass Texte der Kontrafaktik, da sie in irgendeiner Weise mit Fakten zu tun haben, selbst Aussagen über Faktisches machen wollten. Bei dieser Forderung allerdings würde es sich wiederum um eine Variante der oben erläuterten epistemischen Übergeneralisierungen handeln: Die relevanten Textelementen der Kontrafaktik sind fiktive Elemente innerhalb eines fiktionalen Mediums; nichts berechtigt dazu, diese Elemente für unmittelbare Aussagen über reale Sachverhalte heranzuziehen, auch wenn diese Elemente auf realen Sachverhalten beruhen oder indirekt auf diese verweisen mögen. ${ }^{245}$ Tatsächlich vermitteln Werke der Kontrafaktik weniger selbst Wissen über die Welt, sondern bedürfen vielmehr realweltlicher Fakten in ihrer Funktion als inferentielles Wissen: Relevant für Werke der Kontrafaktik ist also „nicht in erster Linie das Wissen in Literatur oder aus Literatur, sondern vielmehr das Wissen, das von Texten vorausgesetzt wird, damit ihre Bedeutung verstanden werden kann.“ ${ }^{246}$ Grundsätzlich ist die kontrafaktische Faktenvaria-

245 Zipfel bemerkt in Bezug auf George Orwells (kontrafaktische) Fabel Animal Farm: „Die in Animal Farm erzählte Geschichte ist fiktiv, d. h. sie hat sich so nicht auf einem Bauernhof zwischen Tieren zugetragen. Die Besonderheit, daß mittels der fiktiven Geschichte auf reale historische Begebenheiten Bezug genommen wird, spielt für die Feststellung der Fiktivität der Geschichte keine Rolle.“ (Zipfel: Fiktion, Fiktivität, Fiktionalität, S. 76f., Anm. 41).

246 Simone Winko / Fotis Jannidis: Wissen und Inferenz. Zum Verstehen und Interpretieren literarischer Texte am Beispiel von Hans Magnus Enzensbergers Gedicht Frühschriften. In: Jan 
tion zunächst im Kontext der fiktionalen Welt zu bewerten. Allenfalls in einem zweiten Schritt kann sie für Aussagen über die reale Welt, aus der die Fakten stammen, herangezogen werden, etwa für politische Positionierungen zu bestimmten Aspekten der Realität.

\subsubsection{Kompositionalismus und kontrafaktische Elemente als real-fiktive Hybridobjekte}

Da für die Kontrafaktik qua Begriff Fakten eine Rolle spielen, es sich bei der Kontrafaktik aber zugleich um eine Form fiktionalen Erzählens handelt, wird hier die grundsätzliche Frage berührt, ob und in welcher Form Fakten oder Wissen über die reale Welt überhaupt in ein fiktionales Werk integriert werden können. Auch über die Kontrafaktik hinaus bildet das Problem des ,Weltwissens in der Fiktion“ eine zentrale Frage der Fiktionstheorie. Lässt man die panfiktionalistische Option, dass überhaupt alles Fiktion ist, aus unplausibel außen vor ${ }^{247}$, so können die in dieser Frage vertretenen Positionen grob in zwei Gruppen unterteilt werden, für die sich in der Forschung die Begriffe Autonomismus und Kompositionalismus durchgesetzt haben. ${ }^{248}$ Autonomistische Positionen nehmen an, dass Sprachverwendung und Ontologie der Erzählgenstände in fiktionalen Texten kategorisch von Sprachverwendung und Ontologie in nichtfiktionalen Äußerungskontexten unterschieden seien. Kunstwerke werden dabei tendenziell von allen außerliterarischen Bezügen autonomisiert (wobei häufig ein, wie Peter Blume schreibt, „In-Dienst-Nehmen der Fiktionsfrage für die Zwecke der Autonomieästhetik“249 erkennbar ist ${ }^{250}$ ). Demgegenüber wird auf kompositionalistischer Seite die Position vertreten, dass auch fiktionale Texte niemals ganz ohne Anleihen bei der realen Welt auskommen können. So betont etwa Umberto Eco,

Borkowski u. a. (Hg.): Literatur interpretieren. Interdisziplinäre Beiträge zur Theorie und Praxis. Münster 2015, S. 221-250, hier S. 225.

247 Vgl. Konrad: Panfiktionalismus, S. $236 \mathrm{f}$.

248 Für eine Abwägung autonomistischer und kompositionalistischer Positionen siehe Peter Blume: Fiktion und Weltwissen. Der Beitrag nichtfiktionaler Konzepte zur Sinnkonstitution fiktionaler Erzählliteratur. Berlin 2004, S. 16-34.

249 Blume: Fiktion und Weltwissen, S. 17.

250 So schreibt beispielsweise Eberhard Lämmert: „Es macht geradezu das Wesen des Dichterischen aus, daß alle benutzten Realien ihres transliterarischen Bezugssystems entkleidet werden und innerhalb der fiktiven Wirklichkeit der Dichtung neuen Stellenwert und eine neue, begrenzte Funktion erhalten. Deshalb kann jede Geschichte einer Erzählung grundsätzlich aus sich selbst heraus verstanden werden.“ (Eberhard Lämmert: Bauformen des Erzählens. Stuttgart 1955, S. 27). 
daß wir selbst bei der unmöglichsten aller Welten, um von ihr beeindruckt, verwirrt, verstört oder berührt zu sein, auf unsere Kenntnis der wirklichen Welt bauen müssen. Mit anderen Worten, auch die unmöglichste Welt muß, um eine solche zu sein, als Hintergrund immer das haben, was in der wirklichen Welt möglich ist.

Dies aber bedeutet: Die fiktiven Welten sind Parasiten der wirklichen Welt. ${ }^{251}$

Vertreter kompositionalistischer Ansätze gehen davon aus, dass die Welten fiktionaler Texte aus einer Kombination realweltlicher Elemente mit solchen Elementen bestehen, die von der literarischen Fiktion eigenständig gesetzt werden. ${ }^{252}$ Für den Kompositionalismus spricht unter anderem die Überlegung, dass fiktionale Texte gar nicht verständlich wären, wenn sie keinerlei Bezug zur realen Welt unterhielten ${ }^{253}$, sowie die damit verbundene Beobachtung, dass Leser, um einen fiktionalen Text zu verstehen, keine neue Sprache lernen müssen, sodass die Sätze in fiktionalen Texten auch keine generell andere Bedeutung haben können als dieselben Sätze in realweltlichen Kontexten. ${ }^{254}$ Nicht zuletzt dürften die Annahmen des Kompositionalismus dem spontanen Lektüreverhalten der meisten Leser entsprechen, die intuitiv und unbeschadet ihrer Beherrschung der Konventionen der Fiktionalitätsinstitution eine gewisse Kontinuität zwischen der realen Welt und etwaigen fiktionalen Welten annehmen. ${ }^{255}$

Gegen Vertreter kompositionalistischer Positionen wurde der Vorwurf vorgebracht, sie würden den Fiktionalitätsstatus literarischer Werke einschränken und damit letztlich den Grundsatz der Kunstautonomie in Frage stellen. ${ }^{256}$ Bei der Annahme jedoch, eine Integration realweltlicher Wissensele-

251 Eco: Im Wald der Fiktionen, S. 112.

252 Daraus folgt, dass fiktionale Welten ontologisch niemals streng abgeschlossen sind. Fotis Jannidis konstatiert: „Man kann aber diese Sprechweise [i. e. die Sprechweise von ,fiktionalen“ oder ,narrativen Welten'] nicht so wörtlich nehmen, daß man tatsächlich von ontologisch selbständigen Welten spricht, da diese nicht nur von der Textpoiesis abhängig sind, sondern ebenso von der jeweiligen Situation, in der die Texte kommuniziert werden.“ (Fotis Jannidis: Figur und Person. Beiträge zu einer historischen Narratologie. Berlin / New York 2004, S. 73).

253 Vgl. Blume: Fiktion und Weltwissen, S. 50.

254 Vgl. Searle: The Logical Status of Fictional Discourse, S. 324; Jan C. Werner: Fiktion, Wahrheit, Referenz. In: Tilmann Köppe / Tobias Klauk (Hg.): Fiktionalität. Ein interdisziplinäres Handbuch. Berlin / Boston 2014, S. 125-158, hier S. 145. Eco spricht in diesem Zusammenhang von „grammatikalische[r] Kompetenz“ (Umberto Eco: Lector in fabula. Die Mitarbeit der Interpretation in erzählenden Texten. München ${ }^{2} 1990$, S. 61).

255 David Lewis betont in seinem einflussreichen Aufsatz Truth in Fiction: „Most of us are content to read a fiction against a background of well-known fact, 'reading into' the fiction content that is not there explicitly but that comes jointly from the explicit content and the factual background." (Lewis: Truth in Fiction, S. 41).

256 So behauptet etwa Uwe Durst in Bezug auf die historische Kontrafaktik: „Entscheidend ist allein die Struktur der historischen Entwicklung, die innerhalb der fiktionalen Erzählung als 
mente in fiktionale Texte würde automatisch den Fiktionalitätsstatus dieser Texte unterminieren, handelt es sich um ein Missverständnis. Kompositionalisten plädieren nicht notwendigerweise für eine Einebnung von Fiktionalität und Faktualität, sondern weisen lediglich darauf hin, dass ursprünglich faktische Elemente auch in fiktionalen Texten verwendet werden können, da fiktionale Äußerungskontexte prinzipiell offen sind sowohl für fiktive Elemente als auch für realweltliche Wissensbestände, was umgekehrt auf faktuale Äußerungskontexte nicht zutrifft. ${ }^{257}$ Beatrix van Dam beschreibt diese Asymmetrie wie folgt: „Faktische Elemente stören [...] den fiktionalen Text nicht, während fiktive Elemente im faktualen Text dessen Glaubwürdigkeit unterlaufen. Eine fiktionale Erzählung ,funktioniert' auch ohne konkreten Wirklichkeitsbezug, kann diese Ebene jedoch nach Belieben ,hinzufügen“.“258 Entsprechend sind Kompositionalisten auch nicht gezwungen, von unterschiedlichen ,Graden der Fiktionalität‘ auszugehen, nur weil fiktionale Texte mehr oder weniger reale (also realweltlich referentialisierbare) Elemente enthalten. ${ }^{259}$ Auch Texte, die eine relativ hohe

eigentliche, ,wirkliche', angeblich nicht-fiktionale Historie konstituiert wird. Jede andere Betrachtungsweise ignoriert das literarische Faktum." (Uwe Durst: Zur Poetik der parahistorischen Literatur. In: Neohelicon 31/2 (2004), S. 201-220, hier, S. 211).

257 Dirk Niefanger hält fest: „Die Analyse von Realitätsreferenzen stellt den Status der Fiktionalität und die Zuordnung dieser Texte zur Dichtung oder Literatur nicht in Frage. Sie kann aber für das tiefere Verständnis der Texte und Einzelfragen der Interpretation [...] sehr wohl herangezogen werden. Erkannte Realitätsreferenzen erzeugen zweifellos einen hermeneutischen Mehrwert.“ (Dirk Niefanger: Realitätsreferenz im Gegenwartsroman. Überlegungen zu ihrer Systematisierung. In: Birgitta Krumrey / Ingo Vogler / Katharina Derlin (Hg.): Realitätseffekte in der deutschsprachigen Gegenwartsliteratur. Schreibweisen nach der Postmoderne? Heidelberg 2014, S. 35-62, hier S. 56 f.).

258 Dam: Geschichte erzählen, S. 64. Siehe auch Bunia: Faltungen, S. $155 \mathrm{f}$.

259 So betont etwa Danneberg, dass der Begriff ,fiktional“ eine „Makroeigenschaft von Darstellungsgesamtheiten bezeichnet, die auch jedem ihrer Bestandteile zukommt. [...] Es gibt keine Formen von ,Semifiktionalität‘. [...] Das schließt freilich nicht aus, daß sich fiktionale Darstellungen (und Welten) vergleichen lassen und daß auf eine Vergleichsbasis bezogen sich grundsätzlich verschiedene komparative Begriffe bilden lassen - etwa auch ,realistischer als'; nur eben nicht beim Begriff der Fiktionalität.“ (Danneberg: Weder Tränen noch Logik, S. 45f.) Siehe zum Problem der ,Grade von Fiktionalität‘ auch Zipfel: Fiktion, Fiktivität, Fiktionalität, S. 292-297; Köppe: Die Institution Fiktionalität, S. 47. Unbeschadet der Tatsache, dass, wie Henrike Manuwald bemerkt, „die Unterscheidung zwischen fiktionalen wahrheitsindifferenten Texten und faktualen Texten, bei denen das nicht der Fall ist, binär ist“, muss nicht prinzipiell die Möglichkeit ausgeschlossen werden, dass „generell neben faktual und fiktional noch eine dritte Kategorie angesetzt werden“ könnte (Henrike Manuwald: Der Drache als Herausforderung für Fiktionalitätstheorien. Mediävistische Überlegungen zur Historisierung von ,Faktualität‘. In: Johannes Franzen u. a. (Hg.): Geschichte der Fiktionalität. Diachrone Perspektiven auf ein kulturelles Konzept. Baden-Baden 2018, S. 65-82, hier S. 81f. Siehe auch ebd. für weitere Literaturangaben). Im Folgenden wird auf 
Dichte konkreter, realweltlicher Realitätsreferenzen aufweisen - wie etwa der historische Roman, Dokumentardramen oder eben die Texte der Kontrafaktik können einem kompositionalistischen Verständnis nach problemlos in ihrer Gänze als fiktional klassifiziert werden.

Demgegenüber erscheinen autonomistische Ansätze für eine Beschreibung der Kontrafaktik schon deshalb ungeeignet, weil sie einen Bezug fiktionaler Texte auf realweltliche Fakten, wie er für die Kontrafaktik ja gerade konstitutiv ist, ausschließen. Das Phänomen der Kontrafaktik lässt sich aber einzig aus dem Umstand heraus erklären, dass einzelne Elemente in fiktionalen Texten in unterschiedlicher Weise - und mitunter auch gar nicht - auf die reale Welt zu referieren in der Lage sind. ${ }^{260}$ Bezüglich der Eigennamen in fiktionalen Texten etwa bemerkt Catherine Gallagher:

Many of us hold that fictional characters appeal to readers on the basis of their distinctive ontological lack, their freedom from individual extra-textual historical reference. It does not necessarily follow from such a view, however, that one takes every proper name in a fiction to indicate a "Nobody"; for modes of reference often vary widely within works, and just as we usually read names in novels differently from the way we read them in newspapers or history books, we sometimes - especially in historical novels - engage in a dialectically differential reading within a work.

Bei der Kontrafaktik handelt es sich um genau einen solchen dialektisch-differentiellen Rezeptionsvorgang, welcher Elementen der fiktionalen Welt, die realweltliches Faktenmaterial variieren, und solche Elemente, bei denen dies nicht der Fall ist, interpretatorisch miteinander vermittelt. Auch Franz Zipfel hält fest, dass es sich „[f]ür die literaturwissenschaftliche Beschreibung unterschiedlicher Arten von fiktiven Geschichten und unterschiedlicher Formen ihres Wirklichkeitsbezugs [als] sinnvoll [erweist], an einer Unterscheidung verschiedener Arten von in fiktionalen Texten erwähnten Gegenständen festzuhalten. “261 Autonomistische Ansätze vermögen derartige Differenzen nicht zu greifen, da sie die einzelnen Elemente eines fiktionalen Textes im Hinblick auf ihren Realitätsbezug untereinander nivellieren.

Akzeptiert man also - in Kontinuität mit den Positionen des Kompositionalismus -, dass sich Elemente innerhalb fiktionaler Texte hinsichtlich ihres fiktions-

die Möglichkeit eines solchen dreigliedrigen Fiktionskonzepts allerdings nicht weiter eingegangen.

260 Fiktionale Texte referieren zwar immer, aber nicht notwendigerweise auf die reale Welt, wie insbesondere am Beispiel der fantastischen Literatur deutlich wird. Siehe Kapitel 4.3.5. Transfiktionale Doppelreferenz, sowie Kapitel 5.1. Realistik, Fantastik, Kontrafaktik, Faktik. 261 Zipfel: Fiktion, Fiktivität, Fiktionalität, S. 95. 
theoretischen Status unterscheiden können, so kann man die Frage stellen, was denn nun der genaue Status kontrafaktischer Elemente ist. Zur Beantwortung dieser Frage kann auf eine fiktionstheoretische Unterscheidung von Terence Parsons und dessen Modifikation durch Thomas Pavel zurückgegriffen werden: In seinem Buch Nonexistent Objects unterscheidet Parsons zwischen zwei Klassen von Objekten in fiktionalen Texten: „objects native to the story versus objects that are immigrants to the story. “262 Das Lieblingsbeispiel der englischsprachigen Fiktionsdiskussion aufgreifend, erläutert Parsons seine Unterscheidung anhand der Sherlock Holmes-Geschichten: Während Sherlock Holmes, als vollständig fiktive Figur ohne direktes Vorbild in der realen Welt, in Arthur Conan Doyles Romanen als native object anzusehen ist, bildet London ein immigrant object, da die Stadt London auch realweltlich existiert und den Lesern der Sherlock Holmes-Geschichten bekannt sein dürfte. Parsons hat darüber hinaus darauf hingewiesen, dass immigrant objects in fiktionalen Texten manchmal so behandelt werden, als handele es sich dabei um native objects, dass also auf realweltliche Elemente Bezug genommen wird, welche innerhalb der fiktionalen Welt gleichwohl erkennbar modifiziert werden. In diesem Fall könne man von surrogate objects sprechen. ${ }^{263}$ Allerdings eröffnet Parsons damit strenggenommen keine dritte Kategorie von Objekten in Erweiterung zu den Kategorien der immigrant und native objects; vielmehr wird mit dem Term ,surrogate objects“ eine gewandelte Sichtweise auf die (variierten) immigrant objects angezeigt: "[I]t would definitely be wrong to hold that both an immigrant object and its surrogate occur in a novel; when we say that, according to the novels, Holmes lived in London, we refer to the real London or to its surrogate, but not to both. ${ }^{\text {264 }}$ Letztlich hat man es in Parsons' Theorie also immer mit nur zwei Klassen von Objekten zu tun, wobei eine dieser Klassen eben unterschiedliche Deutungen erlaubt.

Thomas Pavel hat nun (eigentlich in einer Fehllektüre Parsons, ${ }^{265}$ ) in seinem Buch Fictional Worlds die drei genannten Begriffe aufgenommen, bezeichnet damit allerdings drei gleichberechtigte Klassen von Objekten, wobei er surrogate objects wie folgt definiert: „Surrogate objects are fictional counterparts of real objects in those fictional texts that substantially modify their descriptions“. ${ }^{266}$ Die Gruppe der surrogate objects kommt dabei kontrafaktischen Elementen in fiktionalen Texten sehr nahe: Beide variieren in signifikanter Weise realweltliche Sachverhalte. Aufgrund

262 Terence Parsons: Nonexistent Objects. New Haven / London 1980, S. 51.

263 Parsons: Nonexistent Objects, S. 57-59.

264 Parsons: Nonexistent Objects, S. 58f.

265 Vgl. Zipfel: Fiktion, Fiktivität, Fiktionalität, S. 97f., Anm. 112.

266 Pavel: Fictional Worlds, S. 29. 
ihrer konstitutiven Faktenbeugung sind surrogate objetcs oder kontrafaktische Elemente unausweichlich als fiktiv anzusehen. ${ }^{267}$ Zugleich bleiben sie jedoch, um überhaupt als surrogate objects respektive als kontrafaktische Elemente erkennbar zu sein, weiterhin auf jene Fakten bezogen, welche sie variieren. Die Grundannahme des Kompositionalismus, dass nämlich eine Kombination realweltlicher mit originär literarischen Elementen im Rahmen fiktionaler Texte möglich sei, lässt sich also auch auf surrogate objects und kontrafaktische Elemente beziehen.

Im Falle der Kontrafaktik werden nun allerdings nicht einfach reale und fiktive Elemente über den Text hinweg verteilt; vielmehr findet innerhalb ein und desselben Elements eine real-fiktive Komposition statt: Eine partielle Übereinstimmung des fiktionalen Elements mit dem realen Sachverhalt, auf dem dieses Element beruht, schafft allererst die Möglichkeit einer konkreten Verbindung zwischen Realität und Fiktion, wie sie für die Kontrafaktik charakteristisch ist; andererseits wird der reale Sachverhalt eben nicht einfach in den fiktionalen Text übernommen, sondern erscheint dort auf signifikant - also deutungsrelevant - variierte Weise. ${ }^{268}$ Bei kontrafaktischen Elementen handelt es sich mithin um real-fiktive Hybridobjekte.

Als Beispiel kann hier auf Robert Harris' Fatherland verwiesen werden (theoretisch aber ebenso gut auf jeden anderen kontrafaktischen Text). In diesem Roman referieren gewisse Lebensereignisse sowie der Figurenname ,Hitler` eindeutig auf die realhistorische Person Adolf Hitler. Zugleich jedoch weicht die Geschichte des politischen Wirkens Hitlers in Harris' Roman signifikant von derjenigen seines realweltlichen Vorbilds ab, sodass es sich nicht um den realen Hitler, sondern um ein fiktives Doppel desselben handeln muss. ${ }^{269}$ Der kon-

267 Zipfel betont, dass „Personen oder Orte, die zwar den Namen von realen Objekten tragen, deren Beschreibung jedoch in signifikanter Weise nicht mit den realen Gegebenheiten übereinstimmt, [...] letztlich als fiktive Objekte zu betrachten [sind]“ (Zipfel: Fiktion, Fiktivität, Fiktionalität, S. 113).

268 Hilary Dannenberg charakterisiert die Dekodierung kontrafaktischer Texte entsprechend als „a successive process of differentiation and identification. In order to successfully negotiate the emergent structure of a counterfactual blend, the reader must correctly identify each of its components as being either different from or identical to real-world history. “ (Hilary Dannenberg: Fleshing Out the Blend: The Representation of Counterfactuals in Alternate History in Print, Film, and Television Narratives. In: Ralf Schneider / Marcus Hartner (Hg.): Blending and the Study of Narrative. Berlin / Boston 2012, S. 121-145, hier S. 129f.).

269 Rodieks mehr technische Beschreibung desselben Sachverhalts am Beispiel Napoleons lautet: „Der Name ,Napoleon“ referiert prinzipiell auf die reale Person Napoleon, also auf jenes Individuum der empirischen Realität, das zum enzyklopädischen Wissensbestand des Lesers gehört. Dort, wo der kontrafaktische Napoleon $\left(\mathrm{N}_{\mathrm{k}}\right)$ hinsichtlich bestimmter Eigenschaften mit dem realen Napoleon $\left(\mathrm{N}_{\mathrm{r}}\right)$ nicht vereinbar erscheint, werden bei der Lektüre die entsprechenden $\mathrm{N}_{\mathrm{r}}$ Merkmale dergestalt neutralisiert, daß ein homogener $\mathrm{N}_{\mathrm{k}}$ als fiktionale Gestalt zustande kommt. 
trafaktische Hitler in Harris' Roman bildet somit - wie alle kontrafaktischen Elemente - ein real-fiktives Hybridobjekt. ${ }^{270}$

Nun ist die realweltliche Teilreferenz kontrafaktischer Elemente keineswegs auf das Problem der Eigennamen historischer Figuren in der Literatur beschränkt, welches in der Fiktionstheorie unter dem Begriff ,Napoleon-Problem bekannt ist. ${ }^{271}$ Kontrafaktische Texte können auf jeden beliebigen Aspekt realweltlichen Faktenwissens referieren: So treten in Houellebecqs Unterwerfung zwar kontrafaktische Variationen der realen Politikerpersönlichkeiten Marine Le Pen oder François Hollande auf, die unter anderem über ihre Eigennamen eindeutig identifizierbar sind. Für die Interpretation des Romans relevanter dürfte allerdings eine Reihe von Themen sein, die nicht mit realweltlichen Eigennamen in Verbindung stehen: namentlich der kontrafaktische Entwurf einer Islamisierung Frankreichs, samt der anhängigen Fragen der demografischen Entwicklung, des transnationalen Lobbyismus sowie der Geschlechterverhältnisse.

\subsubsection{Die reale Welt}

Bei den Fakten der Kontrafaktik - jenen Fakten also, die kontrafaktischen Werken zugrunde liegen - handelt es sich laut der Minimaldefinition um realweltli-

Einerseits ist die, Verschmelzung 'von $\mathrm{N}_{\mathrm{k}}$ und $\mathrm{N}_{\mathrm{r}}$ nur eine Als-Ob-Verschmelzung, andererseits gilt sie nur für die Dauer der Lektüre.“ (Rodiek: Prolegomena zu einer Poetik des Kontrafaktischen, S. 273) Siehe für einen ähnlichen Formalisierungsvorschlag fiktionaler, Gegenstücke‘ zu realweltlichen Sachverhalten Danneberg: Weder Tränen noch Logik, S. 59, Anm. 56.

270 Diese Sichtweise ist mit Parsons' Zwei-Klassen-Modell fiktionaler Objekte durchaus vereinbar: Das, was Pavel surrogate objects nennt, ließe sich im Rahmen von Parsons' Theorie reformulieren als ein Objekt mit mehreren Teileigenschaften, von denen man manche als native objects (oder besser: native properties) und andere als immigrant objects (immigrant properties) bezeichnen kann. So führt der kontrafaktische Hitler in Harris' Roman zwar seinen realweltichen Namen (immigrant property), erhält aber eine deutlich veränderte Biografie (native property). Bei ausreichender Segmentierung der Objekteigenschaften erweist sich mithin die dritte Kategorie der surrogate objects, wie Pavel sie versteht, strenggenommen als überflüssig. Für die Beschreibung kontrafaktischer Elemente, von Elementen also, bei denen gerade der Mischcharakter von Eigenschaften zweier Klassen signifikant ist, erscheint es allerdings deutlich naheliegender, auf Pavels dreigliedriges Modell anstatt auf das zweigliedrige Modell von Parsons zurückzugreifen. Ein situativ-pragmatisches Vorgehen bei der Begrenzung von Elementen innerhalb fiktionaler Werke ist insofern sinnvoll und sogar unvermeidlich, als es „,keine allgemeingültige Segmentierung von Wirklichkeit gibt“ (Wilef Hoops: Fiktionalität als pragmatische Kategorie. In: Poetica 11 (1979), S. 280-317, hier S. 302).

271 Vgl. Bunia: Faltungen, S. 150-172; Gallagher: What would Napoleon do? Zur Geschichte und Theorie fiktionaler Biografien siehe Ina Schabert: In Quest of the Other Person. Fiction as Biography. Tübingen 1990, S. 9-84. 
ches Faktenmaterial: Die indirekten Referenzen der Kontrafaktik beziehen sich also stets auf die reale Welt oder auf die Realität (beide Begriffe werden im Rahmen dieser Studie synonym zueinander verwendet). Was nun genau fiktionale Welten von der realen Welt unterscheidet, was den Status fiktiver Gegenstände ausmacht und in welchem Sinne, wenn überhaupt, fiktionale Welten ,existieren' - diese und ähnliche Fragen führen in die Bereiche der Epistemologie, Ontologie, Metaphysik und der analytischen Sprachphilosophie und werden in diesen Forschungsfeldern teils überaus kontrovers diskutiert. Für eine literaturwissenschaftliche - das heißt im gegebenen Kontext: eine fiktionstheoretisch sowie hermeneutisch orientierte - Theorie der Kontrafaktik spielen derartige philosophische Spezialprobleme allerdings nur eine untergeordnete Rolle. So kommt Frank Zipfel in seiner einflussreichen Studie Fiktion, Fiktivität, Fiktionalität zu dem Schluss, dass „man aus literaturwissenschaftlicher Sicht große Teile der (onto)logischen Diskussion über fiktive Gegenstände getrost überspringen [kann]“. ${ }^{272}$ Diejenige Version der Realität, auf die sich Texte der Kontrafaktik - und überhaupt fiktionale Texte - beziehen, ist tendenziell nicht diejenige von Sprachphilosophen oder Verschwörungstheoretikern. Es mögen daher einige knappe Hinweise zu Status und Relevanz der realen Welt innerhalb einer Theorie der Kontrafaktik genügen.

Die Annahme, dass die Fakten der Kontrafaktik aus der realen Welt stammen müssen, ließe sich reformulieren zu der Forderung, dass die Fakten der Kontrafaktik selbst nicht literarischer Natur - beziehungsweise nicht von der literarischen Fiktion gesetzt - sein dürfen. Die Fakten der Kontrafaktik ,wandern“ also stets von der realen in die fiktionale Welt und nicht umgekehrt. Selbstredend postuliert jeder fiktionale Text Sachverhalte, welche innerhalb seiner fiktionalen Welt gültig sind: In Kafkas Erzählung Die Verwandlung - bei der es sich im Übrigen nicht um einen kontrafaktischen, sondern um einen fantastischen Text handelt ${ }^{273}$ - wird Gregor Samsa in ein ungeheures Ungeziefer verwandelt, und dieser Sachverhalt ist innerhalb der erzählten Welt ebenso wahr wie die Umstände, dass Gregor Samsa eine Schwester hat und dass die Familie in einer Wohnung lebt. ${ }^{274}$ Bei all dem han-

272 Zipfel: Fiktion, Fiktivität, Fiktionalität, S. 104.

273 Vgl. Simon Spiegel: Theoretisch phantastisch. Eine Einführung in Tzvetan Todorovs Theorie der phantastischen Literatur. Murnau am Staffelsee 2010, S. 141-152.

274 Diese ,diegetische Wahrheit‘ ist dabei sogar sehr viel stabiler als die faktuale Wahrheit der realen Welt, da letztere durch zusätzlich hinzukommende Informationen ja stets destabilisiert werden könnte. Umberto Eco vermutet, „daß wir Romane lesen, weil sie uns das angenehme Gefühl geben, in Welten zu leben, in denen der Begriff der Wahrheit nicht in Frage gestellt werden kann, während uns die wirkliche Welt sehr viel tückischer vorkommt. [...] Streng epistemologisch genommen können wir nicht sicher sein, daß die Amerikaner wirklich auf dem 
delt es sich allerdings um Informationen, die allein für die erzählte Welt Gültigkeit beanspruchen können. Diese ,diegetischen Fakten‘ oder ,fiktionalen Wahrheiten' können zwar werkimmanent wieder abgewandelt oder variiert werden. ${ }^{275}$ Allerdings würde es sich dann nicht um Kontrafaktik, sondern um eine Lüge innerhalb der fiktionalen Welt, um einen Fall unzuverlässigen Erzählens, um eine Parallelweltgeschichte oder ähnliches handeln. Aber auch im Falle, dass ein anderer fiktionaler Text variierend auf die diegetischen Fakten von Kafkas Erzählung Bezug nähme, läge keine Kontrafaktik vor. Stattdessen würde es sich dann um einen Fall von Intertextualität, beispielsweise um eine literarische Persiflage, handeln. ${ }^{276}$

Wie aber lassen sich fiktionale Welten und reale Welt - respektive die in diesen Welten jeweils gültigen Wahrheiten - überhaupt voneinander unterscheiden? Eine simple, aber implikationsreiche Möglichkeit der Unterscheidung zwischen der als real designierten Welt und fiktionalen Welten hat Lutz

Mond waren (während wir sicher sind, daß Flash Gordon auf dem Planeten Mongo war).“ (Eco: Im Wald der Fiktionen, S. 121-123).

$275 \mathrm{Im}$ Anschluss an Kendell Waltons Make-Believe-Theorie bemerkt J. Alexander Bareis zum Konzept der fiktionalen Wahrheit: „Dass Sherlock Holmes in der Baker St 221B wohnt, ist eine fiktionale Wahrheit, denn dieser Sachverhalt wird so mehrmals in den Geschichten von Conan Doyle geschildert und ist somit ein Teil der Fiktion der Sherlock-Holmes-Geschichten. In Bezug auf die historische Richtigkeit fehlt dieser Aussage ein Wahrheitswert, denn zu der Zeit, in denen [sic] sich die Sherlock-Holmes-Geschichten abspielen sollen, hat es in London keine Adresse Baker St 221B gegeben.“ (J. Alexander Bareis: Fiktionen als Make-Believe. In: Tilmann Köppe / Tobias Klauk (Hg.): Fiktionalität. Ein interdisziplinäres Handbuch. Berlin / Boston 2014, S. 50-67, hier S. 57).

276 Richard Saint-Gelais charakterisiert Romanadaptionen wie Seth Grahame-Smiths Pride and Prejudice and Zombies als „counterfiction“, die er wie folgt definiert: „, text that sets out to modify the diegesis of a former fictional narrative." Die Parallele zu kontrafaktischen Texten sieht Saint-Gelais darin, dass derartige „fictional text sets out to offer a counterfactual version, not of a real state of affairs, but of a pre-existing fiction. Negations of known facts may also be, after all, negotiations of known novelistic facts." (Richard Saint-Gelais: How To Do Things With Worlds: From Counterfactuality to Counterfictionality. In: Dorothee Birke / Michael Butter / Tilmann Köppe (Hg.): Counterfactual Thinking - Counterfactual Writing. Berlin 2011, S. 240-252, hier S. 241f., 244) Beim beschriebenen Phänomen handelt es sich letztlich allerdings schlicht um eine Spielart von Intertextualität. Die „novelistic facts“ eines fiktionalen Texts - also etwa die Eigenschaften der Figuren in Jane Austens Pride and Prejudice - sind Fakten nur innerhalb der fiktionalen Welt des Textes, während die Fakten der Kontrafaktik immer aus der realen Welt stammen. Dass auch fiktionale Wahrheiten - also Wahrheiten über fiktionale Welten - innerhalb der realen Welt gewusst werden, ist für die Unterscheidung von Intertextualität und Kontrafaktik bedeutungslos, da dieser Umstand ja ohnehin auf jedwedes Wissen zutrifft. Danneberg bemerkt hierzu: „Fiktionale Welten sind nicht Teil der als real angesehenen Welt, nur das Wissen über sie ist Teil der realen Welt.“ (Danneberg: Weder Tränen noch Logik, S. 81). 
Danneberg in seinem Aufsatz Weder Tränen noch Logik. Über die Zugänglichkeit fiktionaler Welten vorgestellt:

Zu fiktionalen Welten gibt es immer nur einen einzigen Zugang, nämlich über die Interpretation der als fiktional angesehenen Darstellungsgesamtheit - oder anders formuliert: Jede Welt, die wir als nichtfiktional, also als reale Welt auffassen, ist multivial, hat also mindestens zwei Zugänge. ${ }^{277}$

Sachverhalte in der realen Welt sind also derart, dass sie mehrere verschiedene Zugangsweisen erlauben. So kann man beispielsweise die realen Alpen selbst besteigen, sie von fern betrachten, über sie lesen, sie auf Fotografien ansehen etc.; dass hingegen Marcel „[l]ange Zeit [...] früh schlafen gegangen [ist]““278, kann man eben nur anhand einer Lektüre von Prousts Roman Auf der Suche nach der verlorenen Zeit erfahren. In letzterem Fall liegt mithin eine, wie Danneberg es ausdrückt, „Autodeterminiertheit des Zugangs zur fiktionalen Welt““279 vor. Dass fiktionale Welten, im Gegensatz zur realen Welt, nicht ,multivial‘ sind, bedeutet dabei nicht, dass das, was über sie gewusst werden kann, explizit im Text ausgedrückt sein müsste. Durch die Erwähnung der ,Darstellungsgesamtheit‘ weist Danneberg vielmehr darauf hin, dass die, wenn man so will, Gesamteinrichtung der fiktionalen Welt sich nur über eine Interpretation des jeweiligen kompletten Werkes erschließen lässt. ${ }^{280}$

Für die Kontrafaktik folgt daraus, dass die Fakten der realen Welt, die kontrafaktisch variiert werden, an und für sich stets multivial zugänglich sein müssen, dass sie also nicht allein über eine einzelne Darstellung vermittelt sein dürfen; die kontrafaktische Variation hingegen - beziehungsweise die fiktionale Welt, in der sie sich ereignet - kann einzig über die Interpretation der fiktionalen Darstellungsgesamtheit des kontrafaktischen Werkes erschlossen werden. So lassen sich Informationen über das realgeschichtliche Ende des Zweiten Weltkriegs auf viel-

277 Danneberg: Weder Tränen noch Logik, S. 65.

278 Marcel Proust: Unterwegs zu Swann. Auf der Suche nach der verlorenen Zeit. Bd. 1. Frankfurt a. M. 1994, S. 7.

279 Danneberg: Weder Tränen noch Logik, S. 65.

280 Entsprechend können isolierte Aussagen über eine fiktionale Welt, die beispielsweise in einem Roman getätigt werden, sich schlussendlich sogar als falsch erweisen: Anhand einer Interpretation der als fiktional angesehenen Darstellungsgesamtheit lässt sich mitunter erschließen, dass es sich beim Bericht eines unzuverlässigen Erzählers um einen Täuschungsversuch handelt, sodass nicht allen seinen Sätzen derselbe Wahrheitswert zukommt. Vgl. Danneberg: Weder Tränen noch Logik, S. 68-71. 
fältige Weise gewinnen; die fiktionale Welt von Harris’ Roman Fatherland, in welcher der Kriegsverlauf ab 1942 von der Realhistorie abweicht, ist hingegen einzig über den Roman selbst zugänglich. ${ }^{281}$

Bei der Unterscheidung von Weltwissen und diegetischem Wissen sowie bei der Annahme, dass Fakten immer nur von der realen Welt in die fiktionale Welt wandern können und nicht umgekehrt, handelt es sich selbstverständlich um Tendenzaussagen und heuristische Vereinfachungen. Fälle sind denkbar, in denen literarische Fiktionen, im Sinne einer „Applikation“ ${ }^{282}$, selbst wieder in die reale Welt zurückwirken und dabei neue Fakten entstehen lassen, die dann wiederum zur Basis einer kontrafaktischen Variation in der Literatur werden können (etwa wenn eine fiktionale Satire auf die realen Werther-Selbstmorde geschrieben würde, welche ihrerseits in Nachahmung der Handlung von Goethes Roman begangen wurden). ${ }^{283}$ Derartige Rückkopplungseffekte der fiktionalen Literatur mit der Realität sind zwar nicht prinzipiell auszuschließen, dürften aber realiter eher eine Ausnahme darstellen. Eine Modifikation der hier vorgestellten Theorie der Kontrafaktik würden derartige Spezialfälle aber ohnehin nicht erzwingen, da auch in diesen Fällen eine fiktionale Wahrheit allererst $\mathrm{zu}$ einem realweltlichen Faktum werden respektive ein solches produzieren müsste, ehe dieses dann wiederum kontrafaktisch variiert werden könnte.

281 Dass es auch Sachverhalte in der realen Welt gibt, die unter Umständen nicht multivial zugänglich sind - etwa persönliche Erinnerungen an biografische Ereignisse oder Träume -, bestätigt dabei nur das vorgeschlagene Modell, da realweltlich nicht-multiviale Sachverhalte eben auch keinen Faktenstatus erreichen können und sich somit auch nicht als Material der Kontrafaktik eignen.

282 Laut Jürgen Link „fungiert [bei der Applikation] der literarische Text als ein Ensemble nicht von Abbildern, sondern von Vor-Bildern für Realität im Sinne von realer Praxis.“ (Jürgen Link: ,Wiederkehr des Realismus “ - aber welches? Mit besonderem Bezug auf Jonathan Littell. In: kultuRRevolution. zeitschrift für angewandte diskurstheorie 54 (2008), S. 6-21, hier S. 16).

283 Unter den Produktions- und Rezeptionsbedingungen der Massenmedien dürften gerade populäre, fiktionale Repräsentationen von Wissen - beispielsweise aus dem Bereich der Geschichte - einen nicht zu unterschätzenden Einfluss auf das enzyklopädische Wissen eines Großteils der empirischen Leserschaft ausüben. Rosenfeld bemerkt hierzu: „Given the millions of people who are exposed to historical films, television broadcasts, and novels, it is highly likely that mass-market historical narratives are shaping popular historical awareness to a much greater extent than the histories produced by professional historians. “ (Rosenfeld: The World Hitler Never Made, S. 14) Siehe auch Barbara Korte / Sylvia Paletschek (Hg.): History Goes Pop. Zur Repräsentation von Geschichte in populären Medien und Genres. Bielefeld 2009. 


\subsubsection{Das Faktenverständnis der Kontrafaktik}

Für gewöhnlich referieren kontrafaktische Texte - wie die meisten Texte, die sich auf die reale Welt beziehen (also die allermeisten Texte!) - auf diejenige Version der Realität, die von einer durchschnittlichen Leserschaft als verbindlich anerkannt wird, man könnte auch sagen: auf die „Alltagswirklichkeit“. ${ }^{284}$ Diese, wenn man so will, pragmatische Durchschnittsenzyklopädie konstituiert sich für den einzelnen Menschen einerseits durch persönliche Erfahrungen, andererseits durch die Übernahme von Wissen aus für vertrauenswürdig befundenen Quellen: Mitglieder einer Sprach- und Wissensgemeinschaft können jeweils nur einen kleinen Ausschnitt des enzyklopädischen Wissens dieser Gemeinschaft durch eigene Anschauung überprüfen und auch dies nur, wofern unmittelbare Anschauung überhaupt möglich ist (eine Bedingung, die etwa im Falle des Wissens über geschichtliche Ereignisse nur selten gegeben ist). Für den Großteil der Enzyklopädie sind die Mitglieder dieser Sprach- und Wissensgemeinschaft hingegen - im Sinne einer ,sprachlichen Arbeitsteilung ${ }^{625}$ (Hilary Putnam) - auf die Übernahme von Expertenwissen angewiesen. Mit Umberto Eco kann man die Enzyklopädie einer bestimmten Gruppe entsprechend verstehen als

die Gesamtheit des Wissens, von der ich nur einen Teil besitze, aber zu der ich, wenn nötig, Zugang habe, da sie so etwas wie eine riesige Bibliothek darstellt [...].

Die Erfahrung und eine lange Reihe von Entscheidungen, bei denen ich Vertrauen in die menschliche Gemeinschaft gesetzt hatte, haben mich überzeugt, daß das, was die Gesamt-Enzyklopädie beschreibt (nicht selten mit etlichen Widersprüchen), ein zufriedenstellendes Bild dessen darstellt, was wir die reale Welt nennen. ${ }^{286}$

Es ist dieses ,zufriedenstellende Bild der realen Welt', auf das in kontrafaktischen Texten kontrastierend Bezug genommen wird. Kontrafaktik - so könnte eine geringfügige Modifikation der Minimaldefinition lauten - variiert also As-

284 Laut Zipfel ist die „Alltagwirklichkeit [...] wohl die einzige Konzeption von Wirklichkeit, die als Bezugspunkt für eine Beschreibung der Fiktivität in literarischen Texten relevant ist.“ (Zipfel: Fiktion, Fiktivität, Fiktionalität, S. 75) Auch Hoops hält fest: „Als kommunikativ relevante Bezugsebene [fiktionaler Texte] kommt [...] weder ,Empirie، im naturwissenschaftlichen Sinne (wie bei van Dijk) noch ,Wirklichkeit‘ in irgendeinem fachphilosophischen Sinne (wie bei Blumenberg und Landwehr) in Frage, sondern ausschließlich die Erfahrungswirklichkeit eines bestimmten textproduzierenden oder -rezipierenden Individuums bzw. die gemeinsame Praxis bestimmter Gruppen, Epochen usw.“ (Hoops: Fiktionalität als pragmatische Kategorie, S. 301).

285 Vgl. Hilary Putnam: The meaning of 'meaning'. In: Ders.: Mind, Language and Reality. Philosophical Papers Vol. 2. Cambridge 1975, S. 215-271, hier S. 228.

286 Eco: Im Wald der Fiktionen, S. 120. 
pekte der (faktualen) Enzyklopädie auf erkennbare und signifikante Weise innerhalb eines fiktionalen Mediums.

Entsprechend ist der Begriff der ,realweltlichen Fakten', von dem diese Arbeit ausgeht, vorderhand ein pragmatischer oder konventionalistischer; epistemologisch und ontologisch soll er möglichst implikationsarm gehalten werden. Unter den Begriffen ,Fakt‘ oder ,wahre Aussage‘ wird zunächst in etwa das verstanden, was der durchschnittliche Mitteleuropäer des frühen 21. Jahrhunderts - bei dem es sich freilich um eine heuristische Hilfsannahme handelt - als Fakt oder wahre Aussage akzeptieren würde. Die Aussage „Der Zweite Weltkrieg hat stattgefunden“ ist in diesem Sinne wahr - und zwar unbeschadet der Tatsache, dass der Wahrheitswert dieser Aussage von einem konstruktivistischen Historiker, einem Panfiktionalisten, einem Holocaustleugner, einem Sprachphilosophen oder etwaigen anderen ,fakto-exzentrischen“ Individuen als fragwürdig angesehen werden könnte. Für die intendierten Leser der zur Diskussion stehenden literarischen Texte - ebenso wie für die Leserschaft dieser Studie - darf vorausgesetzt werden, dass es sich bei dem Satz „Der Zweite Weltkrieg hat stattgefunden“ und ähnlichen Aussagen um wahre Aussagen respektive um Fakten handelt - unabhängig davon, wie genau man den Wahrheitswert dieser Aussagen oder Fakten begründen mag.

Im Rahmen dieser Studie werden die Begriffe Wissen, Wahrheit und Fakten in enger Abhängigkeit voneinander verwendet: Dieselbe Annahme - etwa die Kenntnis eines historischen Datums - kann gleichzeitig Teil des Wissens einer Person sein, als Fakt angesehen werden sowie für wahr gehalten werden. ${ }^{287}$ Von größerer Bedeutung als eine präzise Abgrenzung der Begriffe voneinander ist im gegebenen Kontext der Umstand, dass sich alle drei - wofern nicht anders definiert - auf die reale Welt beziehen. Wenn also beispielsweise von den ,Fakten der Kontrafaktik die Rede ist, so sind damit stets jene Fakten der realen Welt gemeint, auf die sich eine kontrafaktische Variation bezieht - und nicht das binnenfiktionale Ergebnis dieser Variation, also bestimmte, fiktionale Wahrheiten“ innerhalb der fiktionalen Welt eines kontrafaktischen Textes.

Von einem möglichst allgemeinen, gewissermaßen normalsprachlichen Verständnis der Fakten auszugehen und weitergehende Problematisierungen dieser Kategorie vorderhand hintanzustellen, erscheint auch deshalb sinnvoll, weil man anderenfalls Gefahr liefe, sich vorschnell auf ein spezifisches, enges Verständnis von Fakten festzulegen. Damit würde das Untersuchungsspektrum der kontrafaktischen Literatur jedoch von vornherein beschnitten: Die Frage nämlich, was

287 Siehe zum Verhältnis von Literatur und Wissen, Wahrheit und Fakten die folgenden Überblicksdarstellungen: Tilmann Köppe (Hg.): Literatur und Wissen. Theoretisch-methodische Zugänge. Berlin / New York 2011; Roland Borgards u. a. (Hg.): Literatur und Wissen. Ein interdisziplinäres Handbuch. Stuttgart u. a. 2013. 
genau Fakten als solche konstitutiert beziehungsweise welche Art von Fakten für die Kontrafaktik zulässig sind, kann nicht beantwortet werden, ohne damit zugleich auch das Korpus der potenziell zu untersuchenden Texte einzuschränken. So unterscheiden sich die Fakten, die in einem alternativgeschichtlichen Text verhandelt werden, in aller Regel sehr weitgehend von denjenigen, die für einen satirischen Text ausschlaggebend sind, und diese wiederum sind mitunter verschieden von den Bezugsfakten des dystopischen Schreibens etc. Es erscheint insofern sinnvoll, für eine allgemeine Theorie der Kontrafaktik zunächst von einem möglichst offenen Faktenverständnis auszugehen.

Eine zumindest tentative Vermittlung zwischen allgemeiner Fiktionstheorie, mit ihrem möglichst inklusiven Faktenverständnis, und einer Deduktion des Faktenbegriffs qua Einzelwerk kann über eine Diskussion der verschiedenen kontrafaktischen Genres geleistet werden. Zwar geben auch die kontrafaktischen Genres - Alternate History, Utopie, kreativer Dokumentarismus etc. - nicht mechanistisch eine ganz bestimmte Konzeption der Fakten vor; allerdings können die kontrafaktischen Genres als eine Art Relaisstelle zwischen allgemeiner Theorie und Einzelwerk fungieren, indem sie, eben relativ zum Genre, eine etwas genauere Bestimmung der Faktenbasis erlauben, als es allein anhand einer allgemeinen Theorie der Kontrafaktik möglich wäre. ${ }^{288}$ So müssen sich etwa Werke des Alternate History-Genres selbstverständlich auf historische Fakten beziehen, Autofiktionen auf biografische Informationen etc.

Aus der Forderung eines möglichst offenen Faktenverständnisses folgt nicht zuletzt, dass die Fakten der Kontrafaktik nicht immer und überall mit Propositionen im Sinne der analytischen Sprachphilosophie gleichgesetzt werden können. Zwar lassen sich die Fakten, die im Rahmen kontrafaktischer Szenarien variiert werden, sehr häufig als Propositionen formulieren (etwa: In der realen Welt stirbt Hitler im Jahre 1945, während er in Robert Harris' Roman Fatherland im Jahre 1964 noch lebt). Jedoch sind unter Umständen auch Ausprägungen von Fakten literarisch oder allgemein künstlerisch variationsfähig, die sich im Rahmen einer propositionalen Aussagenlogik nicht greifen lassen. $\mathrm{Zu}$ denken wäre etwa an Weltwissen in Form von Frames und Scripts, an das sinnliche Wiedererkennen gewisser Töne oder Farben, an die Identifikation bestimmter Sprachmuster oder an Formen der Bildevidenz. Eine allgemeine Theorie der Kontrafaktik sollte in der Lage sein, auch diese nicht-propositionalen Faktenformen zu integrieren.

Die besonderen Herausforderungen und Möglichkeiten einer nicht-propositionalen Kontrafaktik seien anhand einiger einschlägiger Beispiele angedeutet. Abbildung 1 zeigt die beiden Coverabbildungen der amerikanischen und der

288 Siehe Kapitel 17. Versuch eines politischen Vergleichs: Kracht, Röggla, Zeh, Randt. 
deutschen Erstausgabe von Richard J. Evans' Altered Pasts. Auf dem amerikanischen Coverbild ist ein Astronaut zu sehen, der auf einer grauen, verödeten Fläche - vermutlich der Oberfläche des Mondes - steht. Links neben ihm im Bild steckt ein etwa mannshoher Mast mit einer chinesischen Flagge im Boden. ${ }^{289}$ Es handelt sich hierbei um eine Bildmontage auf der Basis einer bekannten Fotografie der Apollo 11 Mission, die Neil Armstrong neben der amerikanischen Flagge zeigt. Das deutsche Coverbild des Buches hingegen zeigt einen in die Ferne blickenden Adolf Hitler, in Uniform und mit Hakenkreuzbinde am Arm. Im Bildhintergrund ist die Freiheitsstatue zu sehen. Es wird somit suggeriert, dass Hitler im Rahmen seines Welteroberungsfeldzugs bis nach Amerika gelangt sei, was realhistorisch bekanntlich unzutreffend ist.
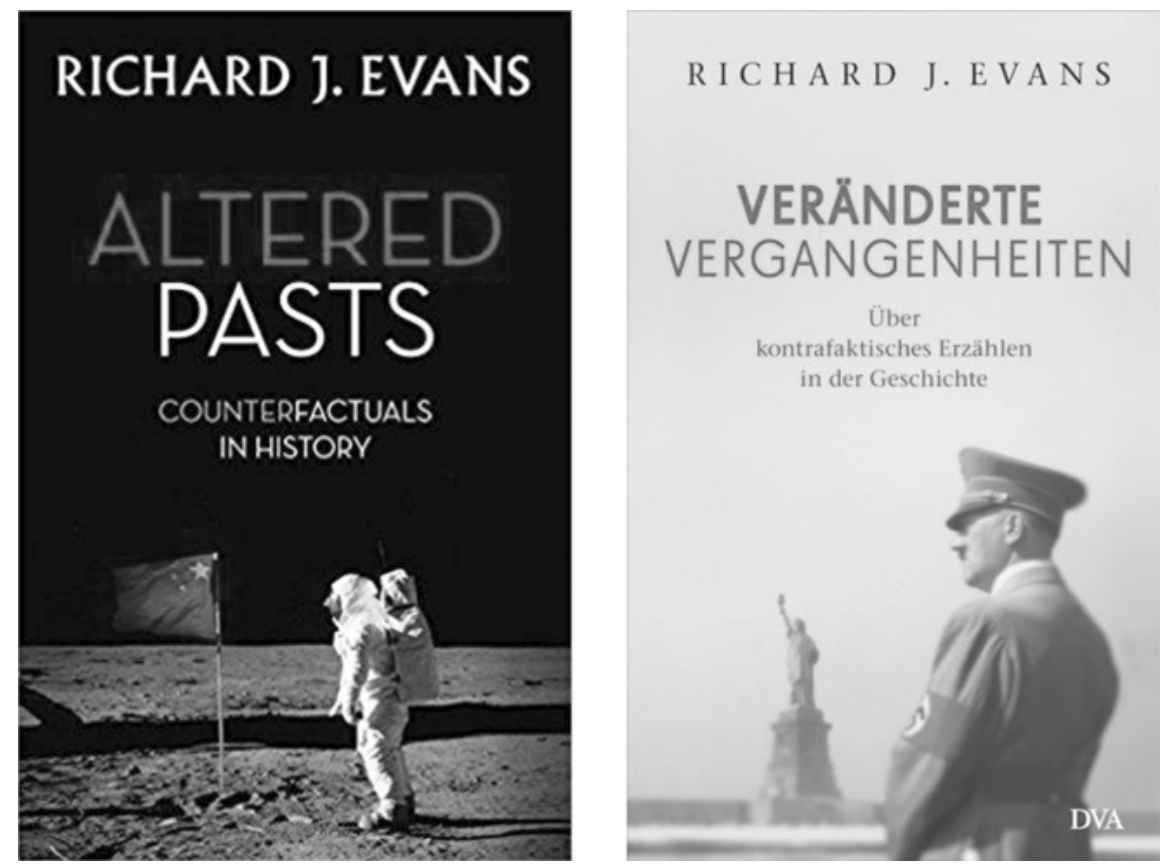

Abbildung 1: Buchcover der amerikanischen und der deutschen Ausgabe von Richard J. Evans' Altered Pasts.

289 Ein weiteres interessantes Bilddetail besteht darin, dass die abgebildete chinesische Flagge dieselbe rostrote Farbe hat, mit der auch das Wort „Altered“ im Haupttitel gedruckt ist. Durch die transsemiotische Verbindung des Begriffs der ,Veränderung‘ mit einem konkreten pikturalen Element wird die kontrafaktische Variation zusätzlich markiert. 
So verschieden die Motive der beiden Coverabbildungen auch sein mögen, das zugrundeliegende Bildverfahren ist in beiden Fällen dasselbe: Ein weithin bekannter Aspekt der Geschichte wird qua Bild aufgerufen und dann auf signifikante Weise variiert. (Die unterschiedlichen Covergestaltungen dürften dabei nicht zuletzt auf nationalspezifische Ausformungen des kollektiven Gedächtnisses zurückzuführen sein. Während die Mondlandung im kollektiven Gedächtnis des deutschen Sprachraums eine sehr viel geringere Rolle spielt als der Zweite Weltkrieg, ist sie im kollektiven Gedächtnis der USA fest verankert.) Wofern man von einer künstlerischen Ambition und nicht von dem Versuch der Geschichtsfälschung ausgehen will, liegt hier Kontrafaktik ganz ohne propositionale Aussage, ja sogar ganz ohne Sprache vor. Man könnte hier von einem Fall ,pikturaler Kontrafaktik' sprechen.

Nun mag an dieser Stelle der Einwand vorgebracht werden, dass das Weltwissen, auf das die Bilder implizit rekurrieren, in Teilen ja durchaus sprachlichpropositionaler Natur ist oder dass sich zumindest die kontrafaktische ,Aussage“ der Bilder sprachlich reformulieren lässt, etwa in der Form: „Während in Wahrheit amerikanische Astronauten als erste auf dem Mond gelandet sind, sind es im Bild chinesische.“ Allerdings sind auch Beispiele denkbar, bei denen eine solche Rückübersetzung in sprachliche Propositionen nicht möglich ist: Man stelle sich einen Film vor, in dem eine bekannte Violinistin ihre Geige in die Hand nimmt, mit dem Bogen kraftvoll darüberstreicht, und es ertönt - ein Trompetenton. Man könnte zwar auch in diesem Fall formulieren: Während in der realen Welt eine Geige wie eine Geige klingt, klingt sie im Film wie eine Trompete. Was aber genau ,wie eine Trompete klingen' bedeutet, lässt sich seinerseits nicht befriedigend in Form von Propositionen ausdrücken. ${ }^{290}$ Die für die Kontrafaktik konstitutive Inkongruenz zwischen Weltwissen und fiktionaler Welt ist in diesem Fall nicht auf der Ebene des explizit Ausgesagten anzusetzen, sondern hängt eher mit

290 In vergleichbarer Weise betont Andrea Albrecht mit Blick auf die Repräsentation von Wissen in Platons Dialog Menon: „Diese nicht-propositionalen, vom Text exemplifizierten oder gezeigten Wissensgehalte können teilweise in eine propositionale Form ,übersetzt' werden [...]. Andere im Dialog exemplifizierte Wissensgehalte hingegen [...] entziehen sich der Propositionalisierung auf grundsätzlichere Weise. Obwohl diese Formen des Wissens benannt und thematisiert werden können, lassen sie sich nicht - oder zumindest nicht vollständig - in einen propositionalen Klartext überführen. In ihrer Eigenart können sie vielmehr prinzipiell nur gezeigt, praktisch nachgeahmt, performativ präsentiert und der Leserin und dem Leser durch die formalen (und das heißt auch: durch die gemeinhin als ästhetisch bezeichneten) Gestaltungselemente eines Textes auf indirektem Wege vermittelt werden.“ (Andrea Albrecht: Zur textuellen Repräsentation von Wissen am Beispiel von Platons Menon. In: Tilmann Köppe (Hg.): Literatur und Wissen. Theoretisch-methodische Zugänge. Berlin / New York 2011, S. 140163, hier S. 162). 
Prozessen des sinnlichen Wiedererkennens, möglicherweise auch mit Skript- und Framewissen (,Konzertbesuch', ,übende Musikerin' etc.) zusammen. ${ }^{291}$ Generell könnte man die Frage stellen, ob sich der Aspekt des Weltwissens, der hier variiert wird, überhaupt mit der Kategorie der ,Wahrheit' fassen lässt oder ob bei Prozessen des sinnlichen Wiedererkennens nicht doch eher ,Richtigkeit‘ die angemessene Kategorie wäre. ${ }^{292}$

Da es sich bei der Literatur um ein sprachliches Medium handelt, werden hier selbstverständlich meist sprachlich vermittelbare Fakten im Vordergrund stehen. ${ }^{293}$ Insbesondere in künstlerischen Medien jedoch, die selbst nicht (ausschließlich) sprachlich verfasst sind - etwa in Film oder Comic -, sollten in Abhängigkeit von der jeweiligen medialen Präsentation mitunter auch nicht-sprachliche oder nicht-propositionale Wissensformen berücksichtigt werden. Prinzipiell ist Kontrafaktik nicht an Sprachlichkeit gebunden, sondern an Referenz. In allen Medien, die eine Referenzfunktion aufweisen - also etwa sprachliche Texte, Filme, nicht-abstrakte Bilder, vermutlich aber nicht die Musik (zumindest nicht die reine Instrumentalmusik) -, können theoretisch auch kontrafaktische Realitätsreferenzen zum Einsatz kommen.

Trotz der prinzipiellen Offenheit des Faktenbegriffs gibt es zumindest ein allgemeines, gewissermaßen formales Kriterium, das alle Fakten der Kontrafaktik erfüllen müssen und das sich bereits im Begriff der Kontrafaktik selbst andeutet: Der Aspekt des Weltwissens, welcher in der Kontrafaktik variiert wird, muss sol-

291 Siehe zu den Grundbegriffen der kognitiven Semantik Blume: Fiktion und Weltwissen, S. 31-62.

292 Nelson Goodman bemerkt hierzu: „Keine Rolle spielt Wahrheit [...] in nicht-verbalen Versionen sowie in verbalen Versionen ohne Aussagen. Verwirrung droht, wenn wir von Bildern oder Prädikaten sagen, sie seien ,wahr von' dem, was sie abbilden oder worauf sie zutreffen; sie haben keinen Wahrheitswert und können einige Dinge darstellen oder denotieren und andere nicht, während eine Aussage einen Wahrheitswert hat und, wenn überhaupt von etwas, von allem wahr ist. [...] Gleichwohl ist Zeigen oder Exemplifizieren ebenso wie das Denotieren eine Referenzfunktion; und Bilder werden unter ganz ähnlichen Gesichtspunkten erwogen wie die Begriffe und Prädikate einer Theorie; auf ihre Relevanz und auf die Aufschlüsse hin, die sie geben; auf ihre Kraft und ihre Angemessenheit - kurz, ihre Richtigkeit.“ (Nelson Goodman: Weisen der Welterzeugung. Frankfurt a. M. 1990, S. 33).

293 Ein Faktenverständnis, das nicht allein auf sprachlich vermittelbare Informationen oder auf propositionale Aussagen beschränkt ist, lässt sich dabei gut an holistische Ansätze in der kognitiven Semantik anschließen. So betont Monika Schwarz, dass „[e]ine strikte Trennung zwischen sprachlichen Bedeutungen und nichtsprachlichem Weltwissen [...] beim heutigen Kenntnisstand über die mentale Repräsentation und Verarbeitung von Bedeutungen im Gedächtnis wohl nicht mehr aufrecht zu erhalten [sei]“ (Monika Schwarz: Kognitive Semantik - State of the Art und Quo vadis? In: Dies. (Hg.): Kognitive Semantik/Cognitive Semantics. Ergebnisse, Probleme, Perspektiven. Tübingen 1994, S. 9-24, hier S. 12). 
cherart sein, dass er eine erkennbare und möglichst unmissverständliche Abweichung erlaubt. Hieraus folgt, dass die jeweils in Frage stehenden Fakten für die intendierte Rezipientengruppe einen hinreichenden Grad an Eindeutigkeit sowie an Konventionalität besitzen müssen, um eine etwaige Abweichung überhaupt erkennbar werden zu lassen. So mögen Ansichten etwa über soziale Gerechtigkeit oder die Natur der Liebe zwar partiell auf Fakten oder faktennahen Annahmen beruhen; doch bestehen über diese Themen derart disparate Ansichten, dass sie sich zur Basis der Kontrafaktik schwerlich anbieten. Bei solchen Themen wäre gar nicht klar, von welchem Faktenkonsens ein kontrafaktischer Text überhaupt abweichen sollte. Auch das Vorkommen von Leben in fernen Galaxien oder das Wesen der Zeit vor dem Urknall - an und für sich durchaus ,faktenfähige“ Themen - eignen sich nicht als Faktenmaterial der Kontrafaktik, einfach deshalb, weil das relevante Wissen hier (noch) nicht zur Verfügung steht.

Jenseits der Kriterien der Bekanntheit und weitgehenden Akzeptanz müssen die Fakten der Kontrafaktik auch das Kriterium der hinreichenden Spezifität erfüllen. Spezifität von Fakten ist notwendig, damit eine Variation dieser Fakten zugleich eine eindeutige Falsifikation zur Folge hat. ${ }^{294}$ Annahmen über die Realität hingegen, denen nicht mit einiger Eindeutigkeit widersprochen werden kann, können auch nicht zur Basis kontrafaktischer Variationen werden, da derartige Annahmen bereits in ihrem ursprünglichen, faktualen Äußerungskontext gar nicht den Status von Fakten in einem engeren Sinne erlangt haben. ${ }^{295}$ So sind etwa unspezifische - wenn auch möglicherweise wahre - Aussagen wie „Gerechtigkeit ist ein hoher Wert“ oder „Irren ist menschlich“ als Ausgangsmaterial kontrafaktischer Variationen unbrauchbar.

294 Helbig bemerkt: „Conditio sine qua non und somit zentrales Definitionskriterium parahistorischer Literatur ist folglich eine eindeutig falsifizierbare historische Aussage.“ (Helbig: Der parahistorische Roman, S. 146).

295 Hier berührt sich die Theorie der Kontrafaktik mit der Grundannahme des Falsifikationismus, dass nämlich Wahrheit niemals zuverlässig positiv formuliert werden kann, Unwahrheit hingegen sehr wohl. Umberto Eco betont in diesem Zusammenhang, „dass Gesetze gerade als Antworten auf die Entdeckung von Grenzen formuliert werden. Worin diese Grenzen aber bestehen, kann man mit Gewissheit überhaupt nicht sagen; abgesehen davon, dass es sich dabei um Gesten der Zurückweisung handelt, um eine Verneinung, die sich einem ab und an aufdrängt. [...] [D]er bescheidene Negative Realismus [...] [steht] in deutlicher Nähe zu den Annahmen Poppers, denen zufolge die einzige Prüfung, deren wissenschaftliche Theorien unterzogen werden können, jene der Falsifizierbarkeit ist. So kann man niemals mit Sicherheit sagen, ob eine Interpretation richtig ist, aber man kann sie sehr wohl ausschließen, wenn sie es nicht ist.“ (Umberto Eco: Gesten der Zurückweisung. In: Markus Gabriel (Hg.): Der neue Realismus. Berlin 2014, S. 33-50, hier S. 49). 
Zentrales Kriterium für die Fakten der Kontrafaktik ist somit die Möglichkeit einer eindeutigen Abweichung von Einzelaspekten des Weltwissens, man könnte auch sagen: von konkreten realweltlichen Informationen. Diese Eignung zur eindeutigen Abweichung lässt sich geradezu als Test für das Faktenmaterial der Kontrafaktik ansetzen: Um festzustellen, ob ein einzelnes Element des Weltwissens sich zur fiktionalen kontrafaktischen Variation eignet, kann man dieses Element probeweise in einem faktualen Äußerungskontext versetzen und dort zu variieren versuchen. Nur solche spezifischen Ausschnitte des Weltwissens, deren Veränderung in einem faktualen Kontext eindeutig als Lüge oder als Verfälschung wahrgenommen würde, eignen sich zum Material der Kontrafaktik. ${ }^{296}$

\subsubsection{Transfiktionale Doppelreferenz}

Um von realweltlichem Wissen abweichen zu können, müssen kontrafaktische Elemente in fiktionalen Texten überhaupt fähig sein, sich auf dieses Wissen zu beziehen; sie müssen also auf realweltliche Sachverhalte referieren. Das postmoderne ,Moratorium der Referenzfrage“ (Thomas Pavel) ${ }^{297}$ sollte für die Kontrafaktik entsprechend ausgesetzt werden. Eine postmoderne Referenzleugnung ist mit der Theorie der Kontrafaktik schlicht unvereinbar. ${ }^{298}$

Definieren lässt sich Referenz mit Dirk Niefanger als „Akt oder [...] Objekt sprachlicher Bezugnahme auf Gegenstände, Wahrnehmungen, Handlungen, Kulturformationen, mentale Repräsentationen (sogenannte Frames) oder Konzepte. “299 Legt man nun ein kommunikationstheoretisches Sprachverständnis zugrunde, so kann davon ausgegangen werden, dass sprachliche Äußerungen grundsätzlich Referenzen produzieren. Andreas Kablitz konstatiert in diesem

296 Auch fantastische Texte weichen eindeutig von Weltwissen ab, nur handelt es sich bei der Wissensbasis der Fantastik um allgemeines Weltwissen und nicht, wie im Falle der Kontrafaktik, um konkrete, mehr oder weniger kontingente Einzelinformationen. Siehe Kapitel 5.1. Realistik, Fantastik, Kontrafaktik, Faktik.

297 Vgl. Pavel: Fictional Worlds, S. 10.

298 Siehe allgemein zur Referenz literarischer Texte sowie zur Kritik an postmodernen Versuchen der Referenztilgung literarischer Sprache Zipfel: Fiktion, Fiktivität, Fiktionalität, S. 5056. Zipfel schreibt dort: „Der linguistisch durchaus fruchtbare Ansatz, Sprache als differentielles Zeichensystem zu betrachten, schließt jedoch nicht aus, Sprache auch als Mittel sprachlicher Handlungen und damit als Mittel zur Bezugnahme auf Außersprachliches zu beschreiben. [...] Die Verbannung der Referenz aus der Beschreibung sprachlicher Zeichen führt zu einer unnötigen Verengung der Betrachtung von Sprache und basiert auf einer Vernachlässigung funktionaler und pragmatischer Beschreibungen.“ (ebd., S. 56).

299 Niefanger: Realitätsreferenz im Gegenwartsroman, S. 37. 
Sinne: „Es gibt keine sprachlichen Äußerungen, die nicht Referenz produzieren würden. Anders gesagt: Sprachliche Äußerungen kommen ohne Behauptungen nicht aus. “300 In ähnlicher Weise betont Jean-Marie Schaeffer, dass Aussagen in fiktionalen und faktualen Texten ganz prinzipiell referieren: „Il faut [...] abandonner l'idée selon laquelle il existerait deux modalités de représentation, l'une qui serait fictionnelle et l'autre qui serait référentielle: il n'en existe qu'une seule, à savoir la modalité référentielle.“301 Der Referenzcharakter sprachlicher Äußerungen ist dabei nicht nur unabhängig davon, ob diese sprachlichen $\ddot{u}$ ßerungen in fiktionalen oder faktualen Kontexten verwendet werden, sondern auch unabhängig davon, ob die Gegenstände, auf die referiert wird, in der realen Welt tatsächlich vorkommen. Der Term ,Einhorn' referiert auch dann auf ein Einhorn, wenn in der realen Welt keine Einhörner existieren. Lubomír Doležel charakterisiert diesen Sachverhalt am Beispiel von Shakespeares Hamlet wie folgt: „While Hamlet is not a man to be found in the actual world, he is an individualized possible person inhabiting an alternative world, the fictional world of Shakespeare's play. The name Hamlet is neither empty nor self-referential; it refers to an individual of a fictional world."302

Kontrafaktische Texte referieren nun allerdings auf besondere Weise, insofern die realweltlichen Sachverhalte, auf die hier Bezug genommen wird, im Text selbst nicht (korrekt) genannt, sondern eben in variierter Form wiedergegeben werden; die nicht-variierte, realweltliche Faktenform ist dabei allerdings stets mitgemeint. Kontrafaktische Elemente in fiktionalen Texten zeichnen sich also durch eine spezifische Referenzstruktur aus: Das kontrafaktische Element respektive ,Zeichen' referiert einerseits direkt oder explizit auf den durch dieses Zeichen dargestellten Sachverhalt innerhalb der fiktionalen Welt (in Harris' Fatherland also etwa: den Sieg der Nazis im Zweiten Weltkrieg); zugleich referiert dieses Zeichen aber auch auf jenen realweltlichen Sachverhalt, der von dem erstgenannten, fiktionalen Sachverhalt variiert wird (im genannten Beispiel also den realen Kriegsverlauf, inklusive der Niederlage von Nazi-Deutschland). Diese zweite Referenz ist indirekt oder implizit, insofern sie mit dem, was vom kontrafaktischen Zeichen expressis verbis bezeichnet wird - also mit der direkten oder

300 Andreas Kablitz: Kunst des Möglichen. Prolegomena zu einer Theorie der Fiktion. In: Poetica 35 (2003), S. 251-273, hier S. 266.

301 [Wir müssen die Idee aufgeben, der zufolge es zwei Modi der Repräsentation gäbe, einen fiktionalen und einen referentiellen: Es gibt nur einen einzigen, nämlichen den referentiellen Modus. - Übersetzung M. N.] Schaeffer: Pourquoi la fiction?, S. 153.

302 Doležel: Heterocosmica, S. 16. 
expliziten Referenz dieses Zeichens - konfligiert. $^{303}$ Gleichwohl muss diese indirekte Referenz auf die realweltlichen Fakten mitberücksichtigt werden, wenn das entsprechende Element als kontrafaktisches Element identifiziert und gedeutet werden soll. Werke der Kontrafaktik bedienen sich also einer spezifischen Form der Doppelreferenz: Bei der Interpretation eines kontrafaktischen Werkes müssen sowohl seine direkten Referenzen auf Elemente der fiktionalen Welt (das, was im Werk selbst ausgesagt wird) als auch seine indirekten Referenzen auf eine extratextuelle Realität (das, wovon diese Aussagen abweichen oder womit sie konfligieren, in dem Falle, dass sie auf die reale Welt angewandt würden) miteinbezogen werden. Genau diese Spannung zwischen expliziter-fiktionaler und impliziter-realweltlicher Referenz setzt den spezifisch kontrafaktischen Interpretationsprozess in Gang. ${ }^{304}$

Nun ist die Kontrafaktik nicht das einzige Verfahren, das Doppelreferenzen ausbildet. Auch manche Formen der uneigentlichen Rede, etwa die Metapher, bedienen sich mehrgliedriger Referenzstrukturen. Eine Besonderheit der Kontrafaktik liegt allerdings darin, dass sich ihre direkte und ihre indirekte Referenz jeweils auf unterschiedliche Welten bezieht. Der Begriff ,Welt' hat sich in der Fiktionstheorie seit geraumer Zeit als Bezeichnung für die Gesamtheit all dessen durchgesetzt, was von einem fiktionalen Text als binnenfiktional wahr, richtig oder existent postuliert wird; bedarfsweise können zum Begriff ,Welt‘ qualifizierende Attribute wie fiktiv, fiktional, möglich etc. hinzutreten. ${ }^{305}$ Fiktionale Texte produzieren grundsätzlich Welten, die sich mehr oder weniger von der als real designierten Welt unterscheiden. Darüber hinaus kann der Begriff ,Welt‘ selbstverständlich auch die reale Welt, also die geteilte Realität der Leser, bezeichnen, sodass sich die Möglichkeit eines Vergleichs zwischen der realen Welt und etwaigen fiktionalen

303 Auch Neal J. Roese und Mike Morrison schreiben „counterfactual statements“ eine „conditional structure and implicit reference to a parallel factual statement“ $\mathrm{zu}$ (Roese / Morrison: The Psychology of Counterfactual Thinking, S. 19 - Hervorhebung M. N.).

304 Für Phänomene (wie die Kontrafaktik), bei denen eine Spannung zwischen fiktionaler und realweltlicher Wahrheit vorliegt, spricht Benjamin Hrushovski von einer „tension between the two referential directions.“ (Benjamin Hrushovski: Fictionality and Fields of Reference. In: Poetics Today 5/2 (1984), S. 227-251, hier S. 247).

305 Bereits Wolfgang Kayser konstatiert in seiner erstmals 1948 erschienenen Studie Das sprachliche Kunstwerk: „In der Epik dient das Erzählen dem Erschaffen von Welt.“ (Wolfgang Kayser: Das sprachliche Kunstwerk. Eine Einführung in die Literaturwissenschaft. Tübingen / Basel ${ }^{20} 1992$, S. 352). Vgl. auch Thomas Anz: Textwelten. In: Ders. (Hg.): Handbuch Literaturwissenschaft. Bd. 1: Gegenstände und Grundbegriffe. Stuttgart 2007, S. 111-130; Andreas Kablitz: Erzählung und Beschreibung. Überlegungen zu einem Merkmal fiktionaler erzählender Texte. In: Romanistisches Jahrbuch 23 (1982), S. 67-84, hier S. 77 f.; Zipfel: Fiktion, Fiktivität, Fiktionalität, S. 82-90. 
Welten ergibt. Da nun bei der Kontrafaktik ein konkreter realweltlicher (realer) Sachverhalt und seine literarische (fiktionale und fiktive) Variation miteinander verglichen werden, kann man behaupten, dass kontrafaktische Elemente gleichzeitig auf zwei Welten referieren. ${ }^{306}$

Die Kontrafaktik zeichnet sich mithin durch eine Spielart dessen aus, was Wolfgang Künne in seinem Buch Abstrakte Gegenstände als ,Transfiktionalität‘ bezeichnet hat. Den Term „transfiktional“ definiert Künne wie folgt: „[W]ir verwenden jeweils zwei konkrete singuläre Terme, und (nur) einer von ihnen ist fiktional.“307 Der Begriff ,transfiktional‘ deutet also einen Vergleich an, entweder zwischen Elementen zweier fiktionaler Welten oder - und allein dieser zweite Fall ist für die Theorie der Kontrafaktik relevant - zwischen einem Faktum in der realen Welt und einem Tatbestand innerhalb der Diegese. ${ }^{308}$ Ein Beispiel für eine solche transfiktionale Aussage wäre etwa der von mir, dem realen Autor dieses Textes als empirische Person geäußerte Satz: „Ich bin kleiner als Sherlock Holmes.“ Künnes Konzept der Transfiktionalität hebt vorderhand auf eine Vermittlung disparater Informationen ab: Bei dem anvisierten fiktionalen Sachverhalt handelt es sich um einen beliebigen, lediglich lose kategorial mit dem Faktum in der realen Welt verwandten Sachverhalt, wie eben der, dass Sherlock Holmes und ich Wesen sind, die eine Körpergröße haben. (Zum Vergleich: Ein Satz wie „Ich bin

306 In ähnlicher Weise bemerkt Gallagher zur Alternate History: „the meaning of the fabula is interdiegetic, contained in the contrast between what happens in the diegesis and what the reader knows to be uncontroversial facts." (Gallagher: What Would Napoleon Do?, S. 322) Brian McHale konstatiert in Bezug auf den kontrafaktischen Roman The Man in the High Castle von Philip K. Dick: „Inevitably, such a story invites the reader to compare the real state of affairs in our world with the hypothetical state of affairs projected for the parallel world; implicitly it places our world and the parallel world in confrontation." (Brian McHale: Postmodernist Fiction. London / New York 1987, S. 61).

307 Wolfgang Künne: Abstrakte Gegenstände. Semantik und Ontologie. Frankfurt a. M. 1983, S. 295. Vgl. auch ders.: Fiktion ohne fiktive Gegenstände: Prolegomena zu einer Fregeanischen Theorie der Fiktion. In: Johannes L. Brandl / Alexander Hieke / Peter M. Simons (Hg.): Metaphysik. Neue Zugänge zu alten Fragen. Sankt Augustin 1995, S. 141-161, hier S. 155-161.

308 Künnes Begriff der Transfiktionalität unterscheidet sich somit von Begriff der Transfiktionalität, wie er von Richard Saint-Gelais und Marie-Laure Ryan verwendet wird und ausschließlich die Überführung eines Elements aus einem fiktionalen Text in einen anderen fiktionalen Text bezeichnet (glücklicher wäre dieses Phänomen möglicherweise als ,Interfiktionalität‘ bezeichnet gewesen). Vgl. Richard Saint-Gelais: Transfictionality. In: David Herman / Manfred Jahn / Marie-Laure Ryan (Hg.): Routledge Encylopedia of Narrative Theory. London / New York 2008, S. 612f.; Marie-Laure Ryan: Transfictionality Across Media. In: John Pier / José Ángel García Landa (Hg.): Theorizing Narrativity. Berlin 2008, S. 385-417, bes. S. 387. Diese Form der Transfiktionalität/,Interfiktionalität‘ spielt eine Rolle im Zusammenhang intertextueller Erzählverfahren, nicht aber für die Kontrafaktik. 
kleiner als Toleranz“ wäre schlicht sinnlos.) Im Falle der Kontrafaktik liegt nun ein spezifischer Fall von Transfiktionalität vor, insofern es sich bei realweltlichem Fakt und fiktionalem Sachverhalt gewissermaßen zweimal um dieselbe Information handelt - nur dass diese Information innerhalb der fiktionalen Welt eben als Kontrafakt, also in variierter Form, vorkommt. Die Vergleichsbezüge der Kontrafaktik konstituieren also eine spezifische Untergruppe transfiktionaler Bezüge, jene Untergruppe nämlich, bei der ein realweltlicher Sachverhalt mit einer Variation desselben Sachverhalts innerhalb der fiktionalen Welt verglichen wird.

Anhand von Abbildung 2 seien drei basale Möglichkeiten der Vermittlung eines fiktionalen Elements mit Elementen außerhalb des Textes verdeutlicht:
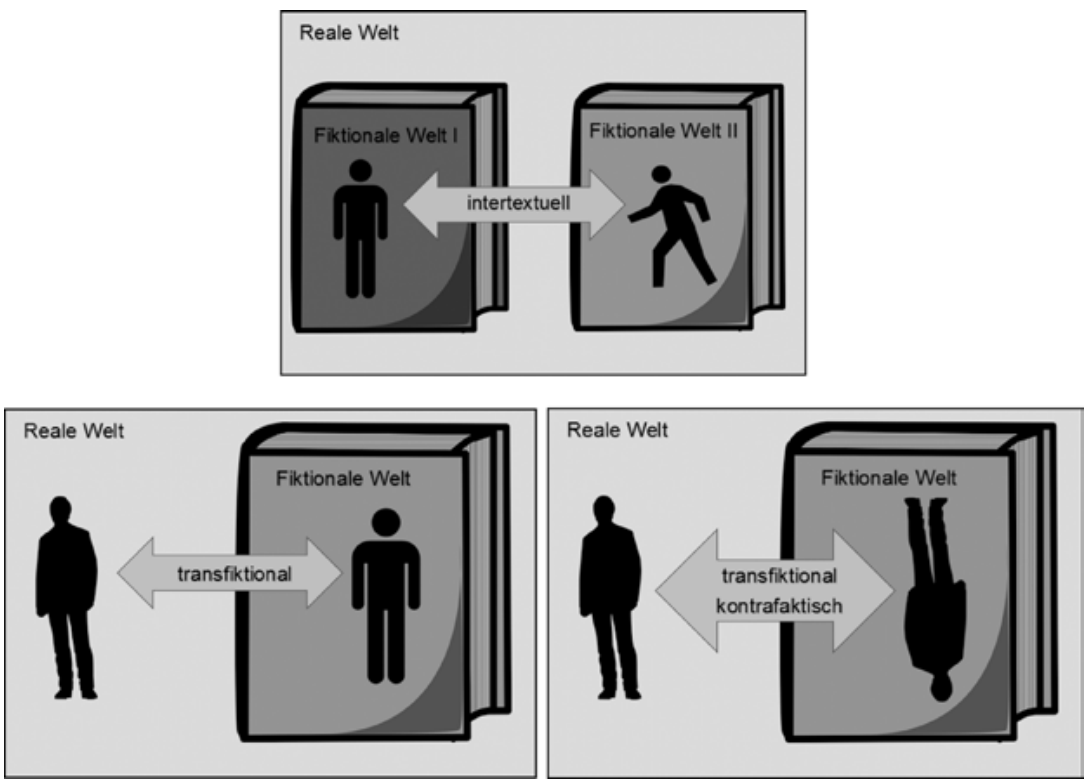

Abbildung 2: Intertextuelle Referenz, transfiktionale Referenz, transfiktionale kontrafaktische Referenz.

Im Falle literarischer Intertextualität wird ein Element eines fiktionalen Textes mit einem Element eines anderen, typischerweise ebenfalls fiktionalen Textes in Beziehung gesetzt. Eine die Intertextualität betreffende Aussage wäre etwa: „Leopold Bloom in James Joyces Roman Ulysses ist eine moderne Version des Odysseus in Homers Odyssee.“ Im Falle der Transfiktionalität hingegen wird ein Sachverhalt innerhalb einer fiktionalen Welt mit einem realweltlichen Sachverhalt verglichen, etwa: „Ich bin kleiner als Sherlock Holmes.“ Im Gegensatz zur Intertextualität wird bei der Transfiktionalität der Bereich der Fiktion in Richtung der Realität über- 
schritten. Bei der Kontrafaktik schließlich wird ebenfalls ein Sachverhalt innerhalb einer fiktionalen Welt mit einem realweltlichen Sachverhalt verglichen, allerdings unter der zusätzlichen Bedingung, dass es sich bei diesem fiktionalen Sachverhalt gerade um eine Variation des primären realweltlichen Sachverhalts handelt, etwa: „Während Adolf Hitler in der Realität 1945 stirbt, lebt er in Robert Harris’ Roman Fatherland im Jahre 1964 immer noch.“ Kontrafaktisch erzählte Texte verweisen also mittels des in ihnen bearbeiteten Faktenmaterials auf einen realen Referenten; allerdings wird dieser reale Referent innerhalb der fiktionalen Welt gerade nicht reproduziert, sondern vielmehr abgewandelt, satirisch übersteigert oder auf erkennbare Weise ausgelassen. Es ergibt sich damit eine Referenzstruktur, bei der Elemente in fiktionalen Texten auf reale Referenten - scheinbar paradox - nicht dadurch verweisen, dass letztere im Text vorkommen, sondern gerade dadurch, dass sie im Text nicht beziehungsweise nur in abgewandelter Form vorkommen. Kontrafaktische Elemente sind also genau solche, die unter Berücksichtigung ihrer faktenvariierenden, transfiktionalen Doppelreferenz zu interpretieren sind.

Setzt man nun voraus, dass kontrafaktische Elemente in fiktionalen Texten sich durch die spezifische Referenzstruktur faktenvariierender, transfiktionaler Doppelreferenzen auszeichnen, so sollte offenkundig sein, dass Kontrafaktik sich niemals allein werkimmanent, also unter alleiniger Berücksichtigung der fiktionalen Welt, wird bestimmen lassen. Kontrafaktik erfordert notwendigerweise einen Vergleich zwischen Fakt und Kontra-Fakt und mithin eine Überschreitung der Grenze zwischen Fiktion und Realität.

Der einzige Vorschlag eines Immanenz-Modells der Kontrafaktik stammt von Uwe Durst, der in seinem Aufsatz Zur Poetik der parahistorischen Literatur den Versuch unternimmt, das alternativgeschichtliche Erzählen allein über die immanente Verweisstruktur literarischer Texte zu bestimmen. Durst zufolge stellt im parahistorischen Erzählen

die Literatur die ,reale‘ Geschichte erst her, die gleichfalls eine eigengesetzliche, unhistorische Struktur aufweist. Für die Analyse parahistorischer Literatur ist die Formation der ,Historie‘ von ebenso großem Interesse wie ihre Deformation. Eine genologische Kategorisierung anhand eines direkten Vergleichs von Wirklichkeit und Fiktion bagatellisiert die Eigengesetzlichkeit der Literatur. Sie bringt das literarische Faktum zum Verschwinden. ${ }^{309}$

So sympathisch der (offensichtlich strukturalistisch motivierte) Verweis auf die ,Eigengesetzlichkeit der Literatur' auch erscheinen mag: Durch sein dogmatisches Festhalten an einer immanenten Kunstdeutung verfehlt Durst gerade die Eigentümlichkeit der parahistorischen oder allgemein der kontrafaktischen Literatur, die

309 Durst: Zur Poetik der parahistorischen Literatur, S. 220. 
ja eben nicht auf einem Vergleich zweier fiktionaler Szenarien miteinander beruht, sondern vielmehr dadurch charakterisiert ist, dass die literarische Fiktion kontrastierend auf ein von ihr unabhängiges Faktum der realen Welt verweist. Durst kann seine Überlegungen überhaupt nur deshalb anstellen, weil er sich auf Zeitreiseromane beschränkt, in denen genretypisch zwei oder mehr Versionen desselben Geschehens präsentiert und miteinander kontrastiert werden. Erstens aber bilden Zeitreiseromane nur einen kleinen und wenig repräsentativen Ausschnitt des Kanons parahistorischer, kontrafaktischer Literatur. Und zweitens kann auch bei Zeitreiseromanen nur dann sinnvollerweise von parahistorischen Texten gesprochen werden, wenn zumindest einer der dargestellten Stränge des Raum-Zeit-Gefüges auch tatsächlich mit der realweltlichen Historie übereinstimmt. Die schlichte Nebenordnung unterschiedlicher Versionen derselben Ereignisfolge in der Fiktion ergibt noch keine Kontrafaktik. Nach Dursts Definition müsste schließlich auch eine Erzählung, die von zeitreisenden Marsmännchen im Jahre 30.000 vor Christus handelt, als parahistorische Erzählung klassifiziert werden, da hier ja durchaus eine literarische Realität hypostasiert und dann in einem weiteren Schritt von selbiger abgewichen wird. ${ }^{310}$ Der Begriff parahistorisch - respektive kontrafaktisch - wäre in diesem Fall aber kaum mehr sinnvoll zu gebrauchen. Es bestätigt sich hier nur, was im Grunde schon begriffslogisch klar ist: Der Versuch, die Fakten aus der Kontrafaktik zu tilgen, kann nur scheitern. ${ }^{311}$

310 Zurecht betont Gordon B. Chamberlain: „A uchronia is not the same thing as an alternative or parallel universe. Earths where the human species, if it exists at all, coexists with dinosaurs, walking trees, or Norse gods do not branch from our historical tree." (Chamberlain: Afterword: Allohistory in Science Fiction, S. 281).

311 Ähnliche Einwände lassen sich übrigens gegen Uwe Dursts vielrezipierte Theorie der Fantastik vorbringen, in deren Rahmen der Autor versucht, Fantastik streng fiktionsintern-strukturalistisch, also ohne Rekurs auf realweltliche Realitätsannahmen zu definieren: „Literarische Bedingungen sind nicht anhand fiktionsexterner naturwissenschaftlicher Fakten zu untersuchen, denn die Literatur ist ein eigengesetzliches System. " (Uwe Durst: Theorie der phantastischen Literatur. Aktualisierte, korrigierte und erweiterte Neuausgabe. Berlin 2007, S. 90) Eine solche, von autonomistischer Kunstemphase beseelte Position ist fiktionstheoretisch jedoch schlicht unhaltbar. Zurecht stellt Johannes Odendahl an Dursts Theorieansatz die kritische Rückfrage: „Wenn [...] die Literatur von einer empirischen Realität grundsätzlich gar nichts weiß: woher wäre dann noch irgendein Kriterium zu nehmen, um ein realistisches von einem nicht-realistischen (also phantastischen) Erzählen zu unterscheiden?“ (Johannes Odendahl: Die Kunst des Möglichen. Über den Wirklichkeitsbezug phantastischer Literatur. In: Wirkendes Wort 65/2 (2015), S. 261-279, hier S. 266) Für eine Kritik an Dursts Ansatz siehe ebd.: S. 264-267, sowie Gerhard Haas: Literarische Phantastik. Strukturelle, geistesgeschichtliche und thematische Aspekte. In: Gerhard Härle / Gina Weinkauff (Hg.): Am Anfang war das Staunen. Wirklichkeitsentwürfe in der Kinder- und Jugendliteratur. Baltmannsweiler 2005, S. 117-134, hier S. 117-119. 


\subsubsection{Skopus: Kontrafaktische Welten, kontrafaktische Elemente, point of divergence}

So wie fantastisch erzählte Werke niemals in allen ihren Einzelelementen fantastisch sind, so sind auch kontrafaktisch erzählte Werke niemals in allen ihren Elementen kontrafaktisch. Wie die meisten fiktionalen Texte entwerfen auch Texte, in denen dezidiert amimetische Erzählverfahren wie Kontrafaktik und Fantastik zum Einsatz kommen, meist eine überwiegend realistisch gestaltete Diegese, in welcher dann vereinzelt Elemente vorkommen können, die mit allgemeinen Realitätsannahmen oder mit konkretem Faktenwissen unvereinbar sind. ${ }^{312}$ Entsprechend beruht die Rede von ,kontrafaktischen Welten' ebenso wie die Rede von ,kontrafaktischen Texten` oder auch von ,kontrafaktischen Genres‘ - etwa der Alternate History - auf einer metonymischen Generalisierung: Gemeint sind damit nicht solche Welten oder Texte, in denen ausschließlich kontrafaktische Elemente vorkommen (solche Welten und Texte dürften es vermutlich gar nicht geben), sondern Welten und Texte, in denen kontrafaktische Elemente besonders auffällig, häufig oder interpretatorisch signifikant sind.

Unter der Voraussetzung der in dieser Studie vorgestellten Theorie der Kontrafaktik, die ja grundsätzlich die Referenzstruktur einzelner Elemente in den Blick nimmt, besteht auch gar keine Notwendigkeit, komplette fiktionale Welten als kontrafaktisch, fantastisch oder ähnliches zu designieren. Stattdessen kann von einzelnen (variierenden) Realitätsreferenzen und ihrer jeweiligen Signifikanz für die Deutung des zu interpretierenden Werks ausgegangen werden. An die Stelle von Globalklassifikationen fiktionaler Welten tritt somit die Analyse kontrafaktischer Elemente. Damit wird nicht zuletzt die Möglichkeit eröffnet, kontrafaktische Elemente auch in solchen fiktionalen Werken zu analysieren, die insgesamt kaum dem Korpus der kontrafaktischen Literatur zugerechnet werden würden, da die Kontrafaktik hier wenig dominant ist oder aber mit anderen Erzählverfahren konkurriert.

Ein prominentes Beispiel für den isolierten Einsatz eines kontrafaktischen Elements findet sich zu Beginn von Franz Kafkas Romanfragment Der Verschollene:

312 Marie-Laure Ryan vertritt in einem vielrezipierten Aufsatz die These, dass fiktionale Welten nur hinsichtlich dessen, was in ihnen erklärtermaßen von der realen Welt abweicht, auch tatsächlich von der realen Welt differieren; in jeder anderen Hinsicht würden fiktionale Welten mit der realen Welt übereinstimmen. Ryan zufolge weichen fiktionale Welten also stets ,so wenig wie möglich` von der realen Welt ab. Vgl. Marie-Laure Ryan: Fiction, Non-Factuals, and the Problem of Minimal Departure. In: Poetics 9 (1980), S. 403-422. Zipfel konstatiert: „Fiktive Geschichten sind nie ganz und gar fiktiv.“ (Zipfel: Fiktion, Fiktivität, Fiktionalität, S. 79) Siehe auch Blume: Fiktion und Weltwissen, S. $83 \mathrm{f}$. 
Als der siebzehnjährige Karl Roßmann, der von seinen armen Eltern nach Amerika geschickt worden war, weil ihn ein Dienstmädchen verführt und ein Kind von ihm bekommen hatte, in dem schon langsam gewordenen Schiff in den Hafen von Newyork einfuhr, erblickte er die schon längst beobachtete Statue der Freiheitsgöttin wie in einem plötzlich stärker gewordenen Sonnenlicht. Ihr Arm mit dem Schwert ragte wie neuerdings empor und um ihre Gestalt wehten die freien Lüfte. ${ }^{313}$

Bei der „Freiheitsgöttin“, die im Gegensatz zu ihrem realweltlichen Vorbild, der Freiheitsstatue auf Liberty Island, ein Schwert und keine Fackel im Arm trägt, handelt es sich offenkundig um ein kontrafaktisches Element. Dieses einzelne kontrafaktische Element lässt sich, wie selbst oberflächlichen Kennern der Kafka-Forschung bekannt sein dürfte, auf produktive Weise in eine Deutung von Der Verschollene einbeziehen. ${ }^{314}$ Allein aufgrund dieses einen kontrafaktischen Elements wird man den Roman in seiner Gänze jedoch kaum als kontrafaktischen Roman klassifizieren können.

Tatsächlich unterscheiden sich kontrafaktische Werke mitunter beträchtlich in Grad und Umfang ihres Einsatzes kontrafaktischer Elemente. Diese schwankende Reichweite kontrafaktischer Realitätsvariationen kann mit einer Kategorie von Wilef Hoops als ,Skopus‘ bezeichnet werden. Hoops bindet die Kategorie des Skopus an die Frage, ,in welchen Wirklichkeitsbereichen ein bestimmter fiktionaler Text signifikant abweicht“. ${ }^{315}$ An Hoops anschließend formuliert Ansgar Nünning:

\footnotetext{
Zunächst stellt sich die Frage, wie detailliert und umfassend ein historischer Roman den notwendig begrenzten Geschichtsbereich schildert, der durch seine Selektionsstruktur konstituiert wird. Dieser Grad der Ausgestaltung soll mit dem Kriterium ,Skopus‘ bezeichnet werden, der sich auf die Reichweite und Bandbreite der historischen Realitätsreferenzen in einem Roman bezieht. ${ }^{316}$
}

Der Skopus speziell der Kontrafaktik hängt nun freilich nicht von der Darstellung der Realität - etwa der Realgeschichte - innerhalb eines fiktionalen Textes ab, sondern von dessen indirekten Realitätsreferenzen. Gefragt wird also nicht danach, welche realweltlichen Fakten innerhalb der fiktionalen Welt korrekt wiedergegeben werden; gefragt wird vielmehr danach, in welchem Ausmaß realweltliches Faktenmaterial einbezogen werden muss, um eine Aktualisierung kontrafaktischer Referenzstrukturen zu ermöglichen. Die Frage des Skopus kontrafaktischer Werke ist dabei nicht allein für den alternativgeschichtlichen

313 Franz Kafka: Der Verschollene. Textband hg. v. Jost Schillemeit. Frankfurt a. M. 2002 (= Schriften - Tagebücher. Kritische Ausgabe), S. 7.

314 Für Überlegungen zur interpretatorischen Relevanz dieses speziellen kontrafaktischen Elements siehe Kapitel 4.6. Signifikanz.

315 Hoops: Fiktionalität als pragmatische Kategorie, S. 302.

316 Nünning: Von historischer Fiktion zu historiographischer Metafiktion. Bd. 1, S. $241 \mathrm{f}$. 
Roman relevant, sondern lässt sich für alle Texte stellen, in denen kontrafaktische Realitätsreferenzen vorkommen. Für die Interpretation dystopischer Texte etwa ist es häufig von großer Wichtigkeit, welche konkreten Elemente innerhalb der fiktionalen Welt als kontrafaktische Variationen gegenwärtiger gesellschaftlicher Tendenzen angesehen und welche Elemente eher als realistische oder fantastische Beigaben ohne konkrete Realitätsreferenz verstanden werden.

Die Konzentration auf einzelne kontrafaktische Elemente sowie auf den Skopus der signifikanten Realitätsabweichung stellen gegenüber der bestehenden Forschung bedeutende Verschiebungen dar. In der Mehrzahl der bisherigen Arbeiten zur Kontrafaktik werden weniger einzelne kontrafaktische Elemente als kontrafaktische Texte in ihrer Gesamtheit diskutiert. Gefragt wird danach, wie sich insbesondere alternativgeschichtliche Welten ab einem bestimmten historischen Umschlagspunkt weiterentwickeln, sodass sich schließlich die im jeweiligen Werk beschriebene fiktionale Welt ergibt. Dieser historische Umschlagspunkt, für den sich in der Forschung die synonymen Begriffe ,point of divergence ${ }^{\text {' und }}$ ,point of departure etabliert haben, wird mitunter sogar als genrekonstituierendes Merkmal der Alternate History angesehen. ${ }^{317}$ So schlägt etwa Kathleen Singles die folgende Definition vor:

point of divergence: the moment in the narrative of the real past from which the alternative narrative of history runs a different course. The point of divergence is the common denominator and the trait that distinguishes alternate histories from other related genres. ${ }^{318}$

Die alleinige Bindung des Alternate History-Genres an den point of divergence wirft allerdings eine Reihe von Problemen auf. Indem nämlich der historische Umschlagspunkt als Genremerkmal der Alternate History angesetzt wird, richtet sich das interpretatorische Interesse fast notwendigerweise auf die Entwicklung, die zwischen diesem Umschlagspunkt und der Gegenwart der fiktionalen Welt liegt und damit auf Fragen der Kausalität, Plausibilität und der kohärenten fiktionalen Weltgestaltung (Singles’ Studie trägt bezeichnenderweise den Untertitel „Playing with Contingency and Necessity“). Diese Fragen sind nun in faktualen Kontexten, etwa mit Blick auf die kontrafaktische Geschichtsschreibung, zweifellos von Belang. ${ }^{319}$ Für die fiktionalen Werke des Alternate History-Genres jedoch kommt einer

317 Seltener ist von einem „Bifurkationspunkt“ die Rede. Vgl. etwa: Nicolosi / Obermayr / Weller: Kontrafaktische Interventionen in die Zeit und ihre erinnerungskulturelle Funktion. Einleitung, S. 3.

318 Singles: Alternate History, S. 7.

319 Evans etwa schließt einige der von ihm diskutierten Beispiele aus dem Korpus „kontrafaktische[r] Geschichtsdarstellungen“ mit der Begründung aus, dass diese „kein echtes Interesse an Ursachen und Wirkungen zeigen.“ (Evans: Veränderte Vergangenheiten, S. 149). 
solchen Entwicklungsbeschreibung oft nur eine untergeordnete Bedeutung zu. So liegt in Kingsley Amis' The Alteration oder in Christian Krachts Ich werde hier sein im Sonnenschein und im Schatten der historische point of divergence zum Zeitpunkt der Handlung bereits über hundert Jahre in der Vergangenheit. Eine detaillierte Beschreibung der Entwicklungen vom point of divergence bis zur Gegenwart der Romanhandlung wird in diesen Werken nicht gegeben; tatsächlich ist in Krachts Roman noch nicht einmal völlig klar, welches genau der historische point of divergence sein soll. ${ }^{320}$ Die Herleitung der Romangegenwart aus einer konkreten Ausgangssituation erweist sich für diese Romane als weitgehend unmöglich und auch interpretatorisch als wenig bedeutsam. Sehr viel relevanter als die Frage nach dem alternativgeschichtlich-genealogischen Zustandekommen der fiktionalen Welten ist für eine Interpretation dieser Werke die Bedeutung einzelner kontrafaktischer Elemente. Zum point of divergence unterhalten diese Elemente mitunter nur noch eine sehr geringe - oder auch gar keine - Verbindung mehr. So werden in The Alteration immer wieder Personen erwähnt, die in der weitgehend theokratisch regierten fiktionalen Welt des Romans völlig anderen Berufen nachgehen als ihre realweltlichen Vorbilder: Der existentialistische Philosoph Jean-Paul Sartre etwa ist in der Welt des Romans ein jesuitischer Pater. Die satirische Intention, die der Roman hier offenkundig verfolgt, ist von der lückenlosen Herleitung dieses kontrafaktischen Elements vom historischen point of divergence an weitgehend unabhängig.

Letztlich liefert das Vorliegen eines point of divergence nur eine schwache Indikation dafür, in welchem Grade kontrafaktische Elemente für die Interpretation eines jeweiligen Werkes von Bedeutung sind. ${ }^{321}$ Insbesondere bei solchen Werken des Alternate History-Genres, in denen der point of divergence zur Handlungszeit bereits lange zurückliegt, erfüllt die alternativgeschichtliche Konstruktion oftmals primär Alibifunktion für die Ausgestaltung einer weitgehend autonomen fiktionalen Welt. So ist die Handlung rund um den hochbegabten Chorsänger Hubert Anvil in Amis' The Alteration nur noch sehr vage vom lange zurückliegenden point of divergence - dem Ausbleiben der protestantischen Reformation und dem Aufstieg Martin Luthers zum Papst vor über 400 Jahren - abhängig. Will man in der Interpretation des Werkes die

320 Siehe Kapitel 11.1.1. Differenzverwischungen.

321 Auch Dannenberg weist darauf hin, dass eine Konzeptualisierung als ,Abzweigung von einem bestimmten Zeitstrahl der Eigenart kontrafaktischen Denkens kaum gerecht wird: ,[C]ognitive research into counterfactuals, specifically into historical ones, has demonstrated quite clearly that, contrary to their popular conception by the human mind as binary branching structures, counterfactuals do not create discrete and separate worlds but blend spaces." (Dannenberg: Fleshing Out the Blend, S. 125). 
kontrafaktische Dimension desselben betonen, so wird man sich neben der Gesamtanlage der fiktionalen Welt, die auf einer lange zurückliegenden kontrafaktischen Abweichung von der Realgeschichte beruht, vor allem auf einzelne kontrafaktische Elemente konzentrieren müssen. Tatsächlich jedoch spielen solche kontrafaktischen Elemente für den Roman in toto nur eine untergeordnete Rolle, sodass hier letztlich ein Alternate History-Roman mit relativ geringem kontrafaktischem Skopus vorliegt.

Die Problematik einer Bindung des Alternate History-Genres an den point of divergence und den konsekutiven Geschichtsverlauf wird besonders deutlich bei solchen Werken, die nicht genretypisch einen point of divergence als Konstitutionsbedingung ihrer fiktionalen Welt voraussetzen und ihn in Form einer analeptischen Beschreibung nachreichen - wie dies etwa in Amis' The Alteration, in Dicks The Man in the High Castle oder in Ransmayrs Morbus Kitahara der Fall ist -, sondern die stattdessen den point of divergence im Rahmen ihrer eigentlichen Handlung ausgestalten. Tarantinos kontrafaktische Spielfilme Inglourious Basterds und Once Upon a Time in Hollywood etwa geben bis ungefähr Dreiviertel ihrer Spielzeit keinen eindeutigen Hinweis darauf, dass es sich hier überhaupt um kontrafaktische Werke handelt. Das hohe Spannungspotenzial dieser Werke liegt gerade in dem Umstand begründet, dass man als Zuschauer - zumindest beim ersten Sehen - mehr als zwei Stunden lang davon ausgeht, man habe es mit einer realistischen Diegese zu tun, in der sich unausweichlich die realhistorischen Katastrophen - also das Überleben Hitlers bis zum Jahre 1945 respektive die Tate-Morde der Manson Family im Jahre 1969 - ereignen müssen, nur um dann in Form eines sonderbar befreienden, kontrafaktischen Gewaltexzesses die Autonomie der Fiktion sich behaupten zu sehen. Wollte man nun lediglich diejenige Zeitspanne innerhalb der fiktionalen Welt, welche jenseits des point of divergence liegt, als zum Alternate History-Genre zugehörig ansehen, so hätte man es hier strenggenommen mit Werken zu tun, die nur zu etwa einem Viertel diesem Genre zugeschlagen werden könnten. Derart kuriose Genreklassifikationen ergeben sich freilich nur dann, wenn die Genrezugehörigkeit allein anhand kohärenter kontrafaktischer Geschichtsverläufe und nicht anhand der Häufigkeit oder interpretatorischen Signifikanz kontrafaktischer Elemente bestimmt wird.

Die von Singles aufgeworfene Frage, ob in einer alternativgeschichtlichen Erzählung partiell und isoliert von historischen Fakten abgewichen wird, ohne dass der Geschichtsverlauf im Ganzen verändert würde, oder ob von einem gewissen Punkt an die fiktionale Geschichte einen dauerhaft von der Realgeschichte abweichenden Verlauf nimmt - und einzig im letztgenannten Fall spricht Singles von 
Alternate History ${ }^{322}$-, ist für eine referenztheoretische und verfahrensanalytische Betrachtungsweise der Kontrafaktik vorderhand ohne Belang. Eine solche Betrachtungsweise der Kontrafaktik erlaubt es nämlich, vom einzelnen variierten Faktum auszugehen und nach dessen Bedeutung im Kontext des jeweiligen Werks zu fragen, und zwar unabhängig davon, ob im Text insgesamt eine kohärente Abweichung von der Realgeschichte vorliegt oder nicht. Der Skopus einzelner kontrafaktischer Elemente - also ihre Häufigkeit innerhalb der fiktionalen Welt sowie der Grad ihrer Realitätsübereinstimmung und -abweichung - wird also im Rahmen präziser Einzelstellenanalysen bestimmt, die von der etwaigen Gesamtklassifizierung fiktionaler Welten oder ganzer Texte unabhängig sind.

Tatsächlich besteht zwischen dem Vorliegen eines point of divergence und dem Skopus individueller Realitätsvariationen kein zwingender Zusammenhang. So finden sich etwa im Genrebereich der Science-Fiction und des Horrors mitunter Erzählwelten, die ihre Genese zwar einem von der Realgeschichte abweichenden Geschichtsverlauf von einem bestimmten point of divergence an verdanken, die ansonsten aber kaum auf kontrafaktische Referenzstrukturen zurückgreifen (man denke an die zahlreichen filmischen Ausgestaltungen der Zombie-Apokalypse). Paradoxerweise liegen in solchen Fällen streng definitorisch betrachtet Werke des Alternate History-Genres vor, die jedoch einen sehr geringen kontrafaktischen Skopus aufweisen, die also kaum kontrafaktische Referenzstrukturen ausbilden, welche eine kontrafaktische Interpretation des jeweiligen Werks stützen könnten. Dass das Vorliegen eines point of divergence allein noch nicht ausreicht, um kontrafaktische Interpretationen eines bestimmten Textes plausibel zu machen, zeigt sich auch daran, dass man letztlich jede fiktionale und deutlich von der Realität abweichende fiktionale Welt als Ergebnis eines historisch bereits weit zurückliegenden point of divergence konzeptualisieren könnte. Allein dadurch jedoch, dass man etwa eine Variante des Märchens Rotkäppchen - um ein willkürliches Beispiel zu wählen - ersinnt, in welcher der diegetischen Handlung ein lang zurückliegender point of divergence, vorgeschaltet' ist, entstehen im bekannten Haupttext des Märchens noch keine kontrafaktischen Referenzstrukturen. Zugleich gibt es auch Werke ganz ohne point of divergence und ohne kohärent kontrafaktische Welt, die gleichwohl Einzelelemente mit sehr deutlichem kontrafaktischem Skopus enthalten. Ein Beispiel hierfür wäre wiederum die waffenbewährte Freiheitsgöttin in Kafkas Der Verschollene.

Es bleibt festzuhalten: Das Vorliegen eines point of divergence bildet weder eine notwendige noch eine hinreichende Bedingung für die Designation eines gegebenen Werks als kontrafaktisch. Der point of divergence ist zweifellos ein

322 Vgl. Singles: Alternate History, S. 78. 
bedeutendes Genremerkmal des Alternate History-Genres, sollte in seiner generellen Bedeutung für Werke der Kontrafaktik und ihre Interpretation allerdings nicht überbewertet werden. Die präzise Bestimmung eines point of divergence dürfte letztlich für den faktualen Diskurs der Geschichtswissenschaft von weit größerem Interesse sein als für den fiktionalen Diskurs der Kontrafaktik. Nur durch die möglichst lückenlose Herleitung einer zeitlich überschaubaren konjekturalhistorischen Entwicklung im Nachgang eines möglichst plausibel gewählten point of divergence kann die historiografische Kontrafaktizitätsforschung den eigenen Anspruch auf Wissenschaftlichkeit verteidigen. Für künstlerische Diskurse hingegen müssen derartige Kriterien als rein fakultativ gelten. Bei der Interpretation fiktionaler Werke der Kontrafaktik erweist sich die Analyse konkreter kontrafaktischer Elemente, ihres Skopus und ihrer Signifikanz für das jeweilige Werk häufig als sehr viel produktiver als die Analyse kohärenter Geschichtsverläufe ab einem bestimmten historischen Umschlagspunkt.

Für kontrafaktische Werke jenseits der Alternativgeschichte ist die Frage nach einem etwaigen point of divergence ohnehin hinfällig. (Tatsächlich darf man vermuten, dass die Konzentration der Forschung auf den point of divergence als Definitionsmerkmal kontrafaktischer Texte ein Grund dafür gewesen ist, dass kontrafaktische Erzählformen jenseits der Alternativgeschichte bisher kaum Beachtung gefunden haben.) Die Variationen biografischer Fakten im Rahmen der Autofiktion und des Schlüsselromans oder die kontrafaktischen Variationen gesellschaftlicher oder politischer Trends und Ereignisse im Genre der Dystopie lassen sich meist nicht plausibel aus einem bestimmten historischen Abweichungspunkt herleiten; und selbst wenn ein solcher Abweichungspunkt im Text angelegt ist - wie etwa in manchen dystopischen oder apokalyptischen Werken -, dient er häufig nur als Vorwand für die Gestaltung einer amimetischen Erzählwelt. Hermeneutisch produktiv ist auch in solchen Fällen weniger die Konzentration auf die binnenfiktionale Genese einer kontrafaktischen Welt, sondern vielmehr der Fokus auf die, wenn man so will, Aktual-Kontrafaktik konkreter kontrafaktischer Elemente.

\subsubsection{Fakten als Kontexte kontrafaktischer Interpretationen}

Die Frage, welche Rolle die alludierten Fakten für die Interpretation kontrafaktischer Werke spielen, lässt sich auf das allgemeinere Problem der Relevanz von Kontexten für die Interpretation literarischer Werke beziehen. Definiert man im Anschluss an Lutz Danneberg Kontexte als „[d]ie Menge der für die Erklärung 
eines Textes relevanten Bezüge“،323, so sollte offenkundig sein, dass sich die Fakten der Kontrafaktik in diesem Sinne als Kontexte verstehen lassen. Danneberg unterscheidet zwischen vier basalen, für die Literaturwissenschaft relevanten Kontextarten: intratextuelle Kontexte (auch Co-Texte, als „Beziehung eines Teiles eines Textes zu anderen Ausschnitten desselben Textes“), infratextuelle Kontexte („Beziehung eines Textes [...] zum Textganzen“), intertextuelle Kontexte und extratextuelle Kontexte. ${ }^{324}$ Da die Fakten der Kontrafaktik niemals vom Werk selbst gesetzt, sondern diesem vorgängig sind, handelt es sich hierbei um eine Manifestation extratextueller Kontexte. ${ }^{325}$

Dass Kontexte für die Interpretation literarischer Texte von Bedeutung sind, bildet mitnichten eine Eigentümlichkeit der Kontrafaktik: „Strenggesehen ist jede (bedeutungszuweisende) Untersuchung eines literarischen Werkes kontextbezogen. [...] Differenzierend wirken allerdings die Zwecke der Kontextverwendung. “326 Im Falle der Kontrafaktik besteht der basale Zweck der Relationierung von Fakt (Kontext) und Faktenvariation (Text) in einem Vergleich der beiden beziehungsweise in ihrer Kontrastierung: ${ }^{327}$ Die kategoriale Möglichkeit eines Vergleichs zwischen Fakt und Kontrafakt ist im Falle der Kontrafaktik notwendigerweise gegeben, da es sich hier gewissermaßen zweimal um dieselbe Information handelt; nur bleibt diese Informationen eben einmal unverändert und wird ein andermal kontrafaktisch

323 Danneberg: Kontext, S. 333.

324 Danneberg: Kontext, S. $333 \mathrm{f}$.

325 Die grundsätzliche Textualität jeglicher Art von Kontext stellt Moritz Baßler in seiner - vom New Historicism inspirierten - Kontext-Theorie heraus. Vgl. Moritz Baßler: Die kulturpoetische Funktion und das Archiv. Eine literaturwissenschaftliche Text-Kontext-Theorie. Tübingen 2005. Ein solcher, auf komplexen philosophischen Vorannahmen beruhender „textuelle[r] Monismus“ garantiert zwar theoretische Konsistenz, führt aber auch zu einer Reduktion intuitiver Nachvollziehbarkeit (Oliver Jahraus: Die Kontextualität des Textes. In: Journal of Literary Theory. 8/1 (2014), S. 140-157, hier S. 146). Dass Kontexte selbst oftmals textuell verfasst sind - oder es unter der Voraussetzung eines bestimmten strukturalistischen Verständnisses von Bedeutung sogar notwendigerweise sind -, spielt für die Kontrafaktik nur eine untergeordnete Rolle. Die relevante Unterscheidung zwischen Text und Kontext ist erneut eine pragmatische, die vorderhand keiner ontologischen Begründung bedarf.

326 Lutz Danneberg: Interpretation: Kontextbildung und Kontextverwendung. In: Spiel 9/1 (1990), S. 89-130, hier S. $101 \mathrm{f}$.

327 Hier könnte im Rekurs auf strukturalistische oder konstruktivistische Bedeutungstheorien eingewendet werden, dass ja überhaupt jede Bedeutung auf der Differenz zu anderen Bedeutungen und auf nichts anderem beruht. Zentral für die Bedeutungsgenese kontrafaktischer Elemente ist allerdings nicht allein die Differenz zu anderen Elementen, sondern die Differenz 
variiert. ${ }^{328}$ Häufig führt der für die Kontrafaktik konstitutive Vergleich von (realweltlichem Kontext-)Fakt und (fiktionalem) Kontra-Fakt dabei normative, evaluative oder politische Implikationen mit sich, wie bei der Diskussion des Zusammenhangs von Kontrafaktik und politischem Schreiben noch ausführlich erläutert werden soll. ${ }^{329}$

Die für das Erzählphänomen der Kontrafaktik konstitutive Abhängigkeit von extratextuellen Kontexten hat weitreichende Implikationen für die Möglichkeiten und Grenzen kontrafaktischer Interpretationen. Jørgen Sneis zufolge lässt sich ,Interpretation“ verstehen als „Zuweisung von Bedeutung an einen Text, indem man ihn mit etwas verknüpft, d. h. in einen Kontext stellt und vor diesem Hintergrund versteht. Dies wirft die Frage auf, was man jeweils unter Text und Kontext zu verstehen hat, aber auch welche Kontexte man beim Interpretieren als relevant gelten lässt. “330 Indem nun Werke der Kontrafaktik durch indirekte Realitätsreferenzen realweltliches Faktenmaterial als relevantes Kontextwissen selegieren, nehmen sie - bzw. nimmt der Leser - eine spezifische Form der „Text-Kontext-Verknüpfung“vor, die für die Bedeutungskonstitution und Interpretation des jeweiligen Werkes von großer Wichtigkeit ist. ${ }^{331}$ Voraussetzung für diese Text-Kontext-Verknüpfung ist selbstverständlich die Verfügbarkeit der relevanten Kontexte: Bereits eine vor-interpretatorische Strukturanalyse kontrafaktischer Texte - also eine bloße Auflistung möglicher kontrafaktischer Elemente - ist nur dann zu leisten, wenn die relevanten faktualen Kontexte zuverlässig zur Verfügung stehen, wenn also das inferentielle Interpretationswissen problemlos abrufbar ist. Dies wiederum hängt ab von komplexen epistemischen, historischen und individuellen Voraussetzungen. Ändern sich diese Voraussetzungen und werden kontrafaktische Texte in der Folge von ihren relevanten Kontexten ,abgeschnitten', so verändern sich notwendigerweise auch die Interpretationsmöglichkeiten (vormals) kontrafaktischer Texte.

eines realweltlichen Faktums zu einer Variation seiner selbst. Die basale Differenzformel der Kontrafaktik lautet also nicht $\mathrm{A} \neq \mathrm{B} \neq \mathrm{C} \ldots$, sondern $\mathrm{A} \neq \mathrm{A}$ '.

328 Siehe Kapitel 4.3.5. Transfiktionale Doppelreferenz.

329 Siehe Kapitel 9. Politische Kontrafaktik.

330 Jørgen Sneis: Phänomenologie und Textinterpretation. Studien zur Theoriegeschichte und Methodik der Literaturwissenschaft. Berlin / Boston 2018, S. 55.

331 Im Anschluss an Danneberg formuliert Sneis: „Als Bedeutungskonzeption wird eine bestimmte Art der Text-Kontext-Verknüpfung bezeichnet, die festlegt, was überhaupt als die zu eruierende Bedeutung gelten soll. Sie definiert einen Bereich von relevantem Kontextwissen und steckt so den ordo investigationis der Bedeutungsermittlung ab. In diesem Sinne liefert die Bedeutungskonstitution eine Richtschnur für die Interpretationskonzeption. “ (Sneis: Phänomenologie und Textinterpretation, S. 55) Siehe auch Lutz Danneberg: Zum Autorkonstrukt und zu einem methodologischen Konzept der Autorintention. In: Fotis Jannidis u. a. (Hg.): Rückkehr des Autors. Zur Erneuerung eines umstrittenen Begriffs. Tübingen 1999, S. 77-105, hier S. $101 \mathrm{f}$. 
Zwei Faktoren haben auf die Selektion von Faktenwissen als relevantem Interpretationskontext einen besonders großen Einfluss: erstens die Zugehörigkeit des Lesers zu einer bestimmten Kultur und zweitens seine zeitliche Verortung. Man könnte auch von Kultur-Relativität und Zeit-Relativität der Rezeption sprechen. Bei den Fakten der Kontrafaktik handelt es sich um hochgradig spezifische Einzelinformationen; sie stehen also nicht kulturübergreifend zur Verfügung, sondern bilden Teil einer spezifischen kulturellen Durchschnittsenzyklopädie. Entsprechend dürfte ein alternativgeschichtlicher Text über den amerikanischen Bürgerkrieg wie etwa Ward Moores Bring the Jubilee - zumindest was seine speziell kontrafaktische Dimension angeht - für einen durchschnittlichen US-amerikanischen Leser leichter verständlich sein als für einen durchschnittlichen deutschen Leser, einfach deshalb, weil das interpretationsrelevante Kontextwissen bei einem US-amerikanisch sozialisierten Leser mit größerer Wahrscheinlichkeit vorhanden sein wird. Die unausweichliche Kultur-Relativität kontrafaktischer Textdeutungen dürfte einen der Hauptgründe dafür bilden, dass die populärsten Beispiele kontrafaktischer Kunst sich auf realweltliches Faktenmaterial beziehen, welches auch transnational als bekannt vorausgesetzt werden kann, beispielsweise den Ausgang des Zweiten Weltkriegs (und nicht etwa die Landesgeschichte Brandenburgs).

Sieht man einmal von kontingent-individuellen Faktoren ab, so ist der Wissenshorizont eines potenziellen Lesers nicht nur abhängig von der Zugehörigkeit zu einer bestimmten Kultur respektive Wissensgemeinschaft, sondern auch vom Zeitpunkt der Rezeption. Da sich der epistemische Horizont einer Kultur in beständigem historischen Wandel befindet, kann es vorkommen, dass das Faktenwissen, welches für die erfolgreiche Aktualisierung des kontrafaktischen Potenzials eines Textes vonnöten ist, ab einem gewissen Zeitpunkt nicht mehr zuverlässig zur Verfügung steht. Ein kontrafaktischer Text jedoch, der sich nicht mehr auf der Folie jener Fakten bewegt, die er variiert, ist schlichtweg kein kontrafaktischer Text mehr, will sagen: wird nicht mehr als solcher wahrgenommen, sondern kippt gleichsam in den allgemeineren Bereich fiktionalen Erzählens. Als Beispiel mag hier Christoph Ransmayrs Morbus Kitahara fungieren. In diesem Roman wird der in der Realität nie umgesetzte Morgenthau-Plan kontrafaktisch ausgestaltet. Anders jedoch als im Falle historischer Großereignisse - wie etwa dem Ende des Zweiten Weltkriegs im Jahre 1945 - kann die Kenntnis einer vergleichsweise nachgeordneten historischen Information, als welche der Morgenthau-Plan heutigen Lesern erscheinen mag, bei wachsendem zeitlichen Abstand nicht mehr umstandslos vorausgesetzt werden. Entsprechend dürfte für den im neuen Jahrtausend geborenen Durchschnittsleser, der nicht mehr über Detailkenntnisse der Geschichte des Zweiten Weltkriegs verfügt, die kontrafaktische Dimension von Morbus Kitahara spontan kaum mehr zugänglich sein. 
Aus dieser Bindung kontrafaktischer Texte an den Wissenshorizont eines spezifischen historischen Zeitpunkts - für gewöhnlich an den Zeitpunkt der Entstehung - ergeben sich weitreichende Konsequenzen für die Rezeptionstemporalität der entsprechenden Texte. Da Einzelinformationen der Enzyklopädie dazu tendieren, mit wachsendem historischen Abstand gleichsam zu verwittern - sie also von immer weniger Menschen zuverlässig aufgerufen werden können -, handelt es sich auch bei der Kontrafaktik tendenziell um ein historisch flüchtiges Phänomen. Mit wachsendem historischen Abstand zur Entstehungszeit treten bei kontrafaktischen Texten Modell-Leser ${ }^{332}$ und empirischer Leser immer weiter auseinander, oder anders gewendet: Die empirische Leserschaft der Entstehungszeit eines kontrafaktischen Textes wird in aller Regel eine größere Nähe zum intendierten Modell-Leser des Textes aufweisen als alle späteren Lesepublika. So sind etwa die wenigsten heutigen Leser in der Lage, die kontrafaktischen Figurendarstellungen etwa in Dantes Divina Commedia zu erkennen und zu deuten. ${ }^{333}$ In vergleichbarer Weise lässt sich spekulieren, dass die zahlreichen kontrafaktischen What If Hitler Had Won-Romane des 20. Jahrhunderts für einen hypothetischen Leser im Jahre 4.000, der über den Ausgang des Zweiten Weltkriegs nicht mehr zuverlässig informiert ist, auch nicht mehr als kontrafaktische Romane erkennbar sein werden, sondern schlicht als freie Bearbeitungen eines im 20. und 21. Jahrhundert besonders beliebten literarischen Stoffes erscheinen mögen.

Theoretisch denkbar - wiewohl empirisch eher selten - ist auch der umgekehrte Fall der Rezeptionstemporalität, dass nämlich ein künstlerisches Werk, das ursprünglich nicht als kontrafaktisches Werk intendiert gewesen war, im Lauf der Zeit kontrafaktischer wird, in dem Sinne, dass es im Rahmen einer bewusst anachronistischen Lektüre plötzlich sehr plausibel als Werk der Kontrafaktik deutbar ist. In einem derartigen Fall würden sich die kontextuellen Rahmenbedingungen kontrafaktischer Interpretation und damit die Möglichkeit, überhaupt

332 Umberto Eco definiert den Modell-Leser als „ein Zusammenspiel glücklicher Bedingungen, die im Text festgelegt worden sind und die [zufriedengestellt - Übersetzung M. N.] sein müssen, damit ein Text vollkommen in seinem möglichen Inhalt aktualisiert werden kann.“ (Eco: Lector in fabula, S. 76) Die deutsche Übersetzung enthält an dieser Stelle im Übrigen einen Fehler: Anstelle des korrekten Begriffs „,zufriedengestellt“ steht der Begriff „zufriedenstellend“. Im Italienischen lautet die Stelle: „Il Lettore Modello è un insieme di condizioni di felicità, testualmente stabilite, che devono essere soddisfatte perché un testo sia pienamente attualizzato nel suo contenuto potenziale." (Umberto Eco: Lector in fabula. La cooperazione interpretative nei testi narrativi. Milano 1979, S. 62).

333 Eine Ausnahme bildet hier freilich Dante selbst, der ja in der Divina Commedia als Figur vorkommt. Zipfel weist darauf hin, dass die Einschreibung Dantes in seine eigene Erzählung sich als Vorstufe des modernen Konzepts der Autofiktion verstehen lässt. Vgl. Zipfel: Autofiktion, S. 302. 
eine solche Interpretation anzustrengen, erst geraume Zeit nach der Entstehung des jeweiligen Werks ergeben. Geschehen kann dies, wenn sich die epistemischen Kontextbedingungen auf eine solche Weise verändern, dass die Realität das relevante Faktenmaterial ,nachliefert', sodass dieses Faktenmaterial späteren Rezipienten innerhalb des jeweiligen Werks als gleichsam antizipierend variiert erschiene. Ein Beispiel hierfür ist das Katastrophenkino der 1990er Jahre - etwa Roland Emmerichs Independence Day aus dem Jahre 1996 -, welches im Nachgang der Anschläge auf das World Trade Center am 11. September 2001 bei manchem Beobachter den Eindruck hervorrief, es handele sich hierbei um einen antizipierenden künstlerischen Kommentar zu den realen Terroranschlägen. ${ }^{334}$ Ein ähnlicher Fall liegt vor bei Juli Zehs dystopischem Roman Corpus Delicti, der heutigen Lesern wie ein Kommentar zur Corona-Krise sowie den staatlichen Maßnahmen zu deren Eindämmung erscheinen mag, wenngleich der Text bereits 2009, also zehn Jahre vor Beginn der Corona-Krise, erschienen ist.

Abschließend ist festzuhalten, dass die rezeptionsseitig zu leistende Kontextverknüpfung der Kontrafaktik einen spezifischen kulturellen und historischen Index verleiht. Eine literarhistorische Betrachtung der Kontrafaktik wird folglich entweder streng historisierend verfahren müssen, indem sie ursprüngliche Rezeptionssituationen rekonstruiert und den kontrafaktischen Status fiktionaler Werke im Kontext ihrer jeweiligen Entstehung bestimmt. (Auf diese Weise wird in der vorliegenden Studie verfahren: Als kontrafaktisch werden solche Texte angesehen, die bereits bei ihrer Entstehung als kontrafaktisch intendiert gewesen waren oder deren Entstehungskontext doch zumindest eine solche kontrafaktische Interpretation plausibel erscheinen lässt.) Oder aber sie wird dem Umstand Rechnung zu tragen haben, dass unterschiedliche historische Lesepublika das kontrafaktische Potenzial eines Textes jeweils auf unterschiedliche Weise - oder auch gar nicht - aktualisieren, sodass eine Literaturgeschichte der Kontrafaktik als Geschichte der rezeptionsgeschichtlichen Querschnitte geschrieben werden müsste. Die Frage, welche Texte zu welchem Zeitpunkt als kontrafaktisch gelesen werden, kann dabei für die historischen Kulturwissenschaften von großem Interesse sein, sagt das Ensemble der Texte, die zu einem gewissen Zeitpunkt als kontrafaktisch angesehen werden, indirekt doch viel über den Wissens- und häufig auch den Wer-

334 Claas Morgenroth beschreibt die sonderbare Umkehrung der gewöhnlichen zeitlichen Abhängigkeit zwischen realen Ereignissen und künstlerischer Darstellung wie folgt: „Der 11. September steht da wie eine nachgeholte Referenz bisher referenzloser und daher als Kunst problemlos konsumierbarer Artefakte und überführt die menschliche Imagination in ihr Komplement: die Wirklichkeit.“ (Claas Morgenroth: Erinnerungspolitik und Gegenwartsliteratur: Das unbesetzte Gebiet - The Church of John F. Kennedy - Really ground zero - Der Vorleser. Berlin 2014, S. 201). 
tungshorizont einer bestimmten Epoche aus. Ihr kultureller und historischer Index respektive ihre unausweichliche, Gegenwartsverhaftung'verleiht der Kontrafaktik ein besonderes zeitdiagnostisches Erkenntnispotential und bildet nicht zuletzt eine Bedingung für ihre besondere Eignung als Verfahren politischen Schreibens. Anders als etwa realistische oder fantastische Erzählungen nehmen kontrafaktische Werke stets eine hochgradig spezifische Text-Kontext-Verknüpfung vor. Diese hohe Kontext-Sensitivität ermöglicht es der Kontrafaktik unter anderem, realweltliche Sachverhalte (kritisch oder politisch) zu kommentieren, indem sie diese Sachverhalte auf künstlerisch variierte Weise präsentiert.

\subsubsection{Mögliche Einwände}

Zum Abschluss der Faktendiskussion soll drei naheliegenden Einwände begegnet werden, die gegen das vorgestellte Faktenverständnis vorgebracht werden könnten. Es wird zu klären sein, ob die Kontrafaktik mit konstruktivistischen Wahrheitstheorien in Einklang zu bringen ist, was die Fakten der Kontrafaktik von Manifestationen ,ästhetischer Wahrheit' unterscheidet und wie die These, dass die Fakten der Kontrafaktik grundsätzliche aus der realen Welt stammen müssen, mit dem Umstand vereinbar ist, dass in manchen kontrafaktischen Werken die relevanten Fakten in Form von Paratexten mitgeliefert werden.

Im Rahmen der poststrukturalistischen und postmodernen Kritik am Essentialismus und Universalismus sind auch die Begriffe ,Wahrheit‘ und ,Wissen“ einer fundamentalen Kritik unterzogen worden. Dort, wo sie im Rahmen des postmodernen Diskurses überhaupt weiterhin verwendet wurden, geschah dies mit zum Teil deutlich veränderten Bedeutungen und Bewertungen. So ersetzt etwa Michel Foucault einen vermeintlich objektivistischen Wahrheitsbegriff durch eine ,Archäologie des Wissens' und gibt generell der Genealogie den Vorzug vor der Ontologie; Hayden White zieht mit seinen Studien zur ,Metahistory` die Möglichkeit einer objektiven Geschichtsschreibung in Zweifel; und Jacques Derrida stellt mit seiner Theorie der Dekonstruktion die Vermittlungsmöglichkeiten klarer Wissensansprüche in der Sprache in Frage. Gemeinsam ist den genannten und verwandten postmodernen Theorien ein konstruktivistisches Wahrheitsverständnis: Wahrheit - und zwar jede Form von Wahrheit - wird hier als ein subjektiv und historisch bis zu einem gewissen Grade kontingentes Konstrukt verstanden, dessen transzendentales Apriori nicht in den ,Dingen“ oder ,Tatsachen' der Welt zu verorten ist, sondern allenfalls noch in der Geschichte, in der Sprache oder in der individuellen Lebenswelt. Nicht selten gerät innerhalb derartiger Argumentationszusammenhänge die Kategorie der Wahrheit generell unter Ideologieverdacht. 
Im Kontext der Kontrafaktik-Diskussion stellt sich vor diesem Hintergrund allerdings die Frage, wie von ,Fakten“ abgewichen werden sollte, wenn unumstößliche Wahrheiten überhaupt nicht existierten? Untergräbt, so könnte man fragen, eine konstruktivistische Wahrheitstheorie nicht die Basis kontrafaktischen Erzählens, da im Rahmen einer solchen Theorie zwischen Fakt und Kontra-Fakt ja gar nicht mehr zuverlässig unterschieden werden kann?

Wie in der Forschungsdiskussion zur Postmoderne bereits ausgeführt wurde, besteht ein grundlegendes Problem postmoderner Wahrheitstheorien in ihrem oftmals allzu ausschließlichen Fokus auf diskursiv-formale oder, wenn man so will, textontologische Fragestellungen. Tendenziell ignoriert werden demgegenüber pragmatische Unterscheidungen sowie die referentielle Funktion der Sprache, wie sie für die Sprache in ihrer kommunikativen oder sprachhandlungstechnischen Funktion grundlegend sind. ${ }^{335}$ Zwar mag zutreffen, dass sich rein sprachlich zwischen fiktionalen und faktualen Diskursen nicht zuverlässig differenzieren lässt; pragmatisch jedoch, also mit Blick auf den realen Sprachgebrauch, lässt sich sehr wohl zwischen faktualen und fiktionalen Deutungsansprüchen unterscheiden.

In der Kontrafaktik hat man es nun gerade mit einer spezifischen Kombination derartiger faktualer und fiktionaler Deutungsansprüche zu tun. Vermittelt werden ein realweltlicher Sachverhalt - ein Wissenselement also, dem im Rahmen eines faktualen Deutungskontextes Gültigkeit zugesprochen wird - mit einer Variation desselben Sachverhalts innerhalb einer fiktionalen Welt. Die ontologische, metaphysische oder semiotische Begründbarkeit faktualer oder fiktionaler Deutungsansprüche ist dabei vorderhand ohne Belang.

Voraussetzung dafür, dass ein ,Fakt` zum Material des kontrafaktischen Erzählens werden kann, ist nicht sein Status als unzweifelhafte Tatsache, sondern lediglich sein (historisch spezifischer) realweltlicher Wissensanspruch ${ }^{336}$, der Um-

335 Remigius Bunia exemplifiziert dieses Problem mithilfe der folgenden Anekdote: „Der Konstruktivist würde sagen, es gebe keine ,Blume an sich' und dennoch beim nächsten Floristen, auf den einen oder anderen Strauß ,referierend', der geliebten Person ganz ohne schlechtes Gewissen eine Magnolie kaufen. Doch sollte er begründen können, weshalb dies ohne jeden Aufwand trotz seiner Ablehnung der ,Referenz' möglich ist. Es stellt sich bei der Debatte um Poststrukturalismus und die Gegenposition nämlich die Gretchenfrage: wie hältst du's mit der Metaphysik? mit Wahrheit? mit Referenz?“ (Bunia: Faltungen, S. 11).

336 Danneberg bemerkt im Hinblick auf das ,Wissen“ kontrafaktischer Imaginationen: „Aufgrund der angenommenen Veränderlichkeit meint in der Rekonstruktionssprache Wissen immer Wissensanspruch und als Wissensanspruch zu einer bestimmten Zeit sollen solche kognitiven Einheiten aufgefasst werden, über die man sich in der Zeit streiten konnte oder auch gestritten hat das schließt immer Stimmen ein, die bestimmte Wissensansprüche durch Ausgrenzung zu entproblematisieren suchten.“ (Danneberg: Überlegungen zu kontrafaktischen Imaginationen in argumentativen Kontexten und zu Beispielen ihrer Funktion in der Denkgeschichte, S. 74). 
stand also, dass das Faktum in der realen Welt von einer gewissen Gruppe von Sprechern als Faktum anerkannt oder zumindest ernsthaft zur Disposition gestellt wurde oder wird. Die vorgeschlagene Betrachtungsweise des kontrafaktischen Erzählens, die den Bezug auf ein realweltliches Faktum als Definiens der Kontrafaktik ansetzt, ist entsprechend nicht prinzipiell inkompatibel mit den Grundannahmen des Konstruktivismus, dessen Vertreter davon ausgehen, dass selbst noch die sogenannte ,reale Welt' Produkt einer - kognitiven, sozialen, semiotischen etc. - Konstruktion ist. Auch die meisten konstruktivistischen Theorien reden schließlich keinem nivellierenden Panfiktionalismus das Wort, sondern erlauben durchaus eine Differenzierung zwischen fiktionalen und faktualen Diskursen, zwischen Diskursen also mit oder ohne realweltlichen Wahrheitsanspruch, sowie auch zwischen Wahrheit und Lüge. ${ }^{337}$

Während also zwischen einem konstruktivistischen Wahrheitsverständnis und der Kontrafaktik kein notwendiger Widerspruch besteht, erweist sich die Verbindung von Kontrafaktik und Theorien ,ästhetischer Wahrheit‘ als problematisch. Die Fakten der Kontrafaktik sind tendenziell abzugrenzen von Formen der ,Wahrheit‘, ,Erkenntnis‘ oder ,Weisheit‘, die anhand genuin ästhetischer Verfahren vermittelt werden oder die einzig über die Kunst zugänglich sind. Eine Detaildiskussion der verschiedenen Konzeptionen ästhetischer Wahrheit kann an dieser Stelle nicht geleistet werden. ${ }^{338}$ Übergreifend und gewiss auch etwas vereinfachend kann zu sogenannten ,ästhetischen Wahrheiten' angemerkt werden, dass hier erstens unter ,Wahrheit' meist kein spezifisches, potenziell falsifizierbares Weltwissen gemeint ist, welches beispielsweise auch einer wissenschaftlichen Investigation zugänglich wäre (die Rede von ,ästhetischen Fakten' leuchtet kaum ein). In aller Regel werden (emphatische) ästhetische Wahrheiten von (kontingenten) Einzelinformationen über die reale Welt unterschieden. ${ }^{339}$ Zweitens sind ästhe-

337 Hierzu bemerkt Eva-Maria Konrad: „Selbst wenn der Bezug auf die Wirklichkeit selbst nicht möglich ist, lässt sich für fiktionale und faktuale Texte doch nach wie vor eine Referenz auf unterschiedliche Welten behaupten: entweder auf eine durch Konventionen etc. als ,real ${ }^{\text {* }}$ ausgezeichnete Welt oder auf andere, diesen Konventionen nicht entsprechende Welten. Die fiktiven Welten bzw. Konstrukte, auf die sich literarische Texte beziehen, sind also nicht alle in gleicher Weise fiktiv, erfunden oder ,gemacht', denn nur eine dieser Welten ist diejenige, die wir gewohnt sind, ,Wirklichkeit‘ zu nennen.“ (Konrad: Panfikationalismus. S. 245f.).

338 Siehe etwa zu den ästhetischen Wahrheitstheorien des 20. Jahrhunderts Achim Geisenhanslüke: Die Wahrheit in der Literatur. Paderborn 2015.

339 Diese Unterscheidung findet sich bereits in der Poetik des Aristoteles. Aristoteles zufolge ist ,es nicht Aufgabe des Dichters [...] mitzuteilen, was wirklich geschehen ist, sondern vielmehr, was geschehen könnte, d. h. das nach den Regeln der Wahrscheinlichkeit oder Notwendigkeit Mögliche. Denn der Geschichtsschreiber und der Dichter unterscheiden sich nicht dadurch voneinander, daß sich der eine in Versen und der andere in Prosa mitteilt - [...] -; sie 
tische Wahrheiten meist nicht solche, die dem Werk als implizite, inferentielle und realweltlich-faktuale Referenzfolie zugrunde lägen, wie es bei der Kontrafaktik der Fall ist. Das, was man als ,ästhetische Wahrheit' bezeichnet, wird meist aus dem Werk selbst abgeleitet, etwa indem ein Roman Einblicke in die Erfahrungswelt einer fremden Figur gewährt oder indem eine ästhetische Erfahrung - beispielsweise bei der Lektüre eines Kafka-Textes ${ }^{340}$ - den Leser dazu bewegt, die eigene soziale oder institutionelle Stellung in der Welt zu überdenken. Tendenziell liegt der Rede von der ,ästhetischen Wahrheit' ein monistisches Kunstmodell, inklusive einem werkimmanent-emphatischen Wahrheitsverständnis zugrunde. Ästhetische Wahrheiten sind also nicht auf konkrete Fakten der realen Welt angewiesen, sondern ,ereignen' sich gleichsam im Kunstwerk selbst; anstatt aus der realen Welt ableitbar zu sein, können sie allenfalls dazu beitragen, mithilfe fiktionaler Literatur - im Sinne einer Applikation - wiederum auf die reale Welt einzuwirken.

Der These schließlich, dass die Fakten der Kontrafaktik niemals aus dem fiktionalen Werk selbst stammen können, scheint der Umstand zu widersprechen, dass es kontrafaktische Werke gibt, in denen die relevanten Fakten in Form von Paratexten, also beispielsweise in Vor- oder Nachwörtern, mitgeliefert werden. Der Widerspruch ist allerdings nur ein scheinbarer, da auch der faktuale Geltungsanspruch eines Paratextes nicht allein anhand des jeweiligen Textes bestimmbar ist: Dass ein Paratext realweltliche Fakten zuverlässig präsentiert, kann dieser Paratext selbst nicht beweisen; hier ist erneut ein Abgleich mit multivialen Wahrheitsannahmen über die reale Welt vonnöten. ${ }^{341}$ Auch bei den Nachworten von Robert Harris' Fatherland oder Phlip Roths The Plot Against America, welche einen Teil der interpretationsrelevanten Fakten referieren, liegt also keine textimmanente Kontrafaktik vor (was, wie oben ausgeführt wurde, ohnehin eine contradictio in adjecto wäre ${ }^{342}$ ). Tatsächlich lassen sich diese Nachworte gar nicht zum kontrafaktischen, fiktionalen Haupttext der Romane hinzuzählen. Bereits textstrukturell sind sie vom eigentlichen Haupttext abgesetzt. Wichtiger jedoch ist der Umstand, dass es sich hier, wie

unterscheiden sich vielmehr dadurch, daß der eine das wirklich Geschehene mitteilt, der andere, was geschehen könnte. Daher ist Dichtung etwas Philosophischeres und Ernsthafteres als Geschichtsschreibung; denn die Dichtung teilt mehr das Allgemeine, die Geschichtsschreibung hingegen das Besondere mit.“ (Aristoteles: Poetik. Griechisch/Deutsch. Übersetzt und hg. v. Manfred Fuhrmann. Stuttgart 1994, 1451a-1451b / S. 29).

340 Dies ist eines der Lieblingsbeispiele Adornos: „Wen einmal Kafkas Räder überfuhren, dem ist der Friede mit der Welt ebenso verloren wie die Möglichkeit, bei dem Urteil sich zu bescheiden, der Weltlauf sei schlecht: das bestätigende Moment ist weggeätzt, das der resignierten Feststellung von der Übermacht des Bösen innewohnt.“ (Theodor W. Adorno: Engagement. In: Ders.: Noten zur Literatur. Frankfurt a. M. 1974, S. 409-430, hier S. 426).

341 Siehe Kapitel 4.3.3. Die reale Welt.

342 Siehe Kapitel 4.3.5. Transfiktionale Doppelreferenz. 
bei allen ernstgemeinten Paratexten, um Texte mit einem faktualen Geltungsanspruch handelt: Ihr Wahrheitsgehalt - etwa die realen Lebensdaten bekannter historischer Personen - ist nicht von der literarischen Fiktion abhängig; ihre Sprechinstanz ist nicht der Erzähler des fiktionalen Werks, sondern der reale Autor. In diesen Nachwörtern werden also keine ,Fakten` aufgestellt, die dann im Haupttext variiert würden; stattdessen werden in den Nachwörtern schlichtweg Fakten der realen Welt referiert, deren Richtigkeit sich auch unabhängig vom jeweiligen Einzeltext überprüfen lässt.

Freilich gibt es auch Paratexte, die selbst Teil des fiktionalen Werks sind, etwa Herausgeberfiktionen. So endet Ward Moores Alternate History-Klassiker Bring the Jubilee mit der Nachbemerkung eines Mannes, welcher den autodiegetisch erzählten Haupttext des Romans angeblich auf einem Dachboden gefunden hat und ihn nun der Öffentlichkeit zugänglich machen möchte. Allerdings ist leicht erkennbar, dass der Herausgeber und die von ihm erzählte Geschichte selbst Teil der fiktionalen Welt sind. Der Fiktionalitätsstatus derartiger pseudo-faktualer, de facto fiktionaler Paratexte unterminiert gerade ihre Zuverlässigkeit in Bezug auf die Präsentation von Weltwissen. Eigenständig realweltliche Fakten ,produzieren` können fiktionale Paratexte ebenso wenig wie alle anderen fiktionalen Texte.

Hinsichtlich der ,Fakten' in Paratexten kontrafaktischer Werke gibt es also zwei Möglichkeiten: Entweder werden Paratexte als fiktionale Texte rezipiert; in diesem Falle können sie keine zuverlässigen Informationen über die reale Welt bereitstellen (was freilich nicht ausschließt, dass die hier referierten Informationen im Einzelfall korrekt sein können). - Oder aber Paratexte werden als faktuale Texte betrachtet; in diesem Fall können sie nicht mehr eigentlich der Kontrafaktik zugeschlagen werden, die ja per definitionem nur in fiktionalen Medien vorkommt. In beiden Fällen behält also die These, die Fakten der Kontrafaktik dürften nicht vom fiktionalen Werk selbst gesetzt sein, ihre Gültigkeit. ${ }^{343}$

Selbstverständlich kann in der Literatur auch mit unterschiedlichen Einschätzungen hinsichtlich des Fiktionalitätsstatus von Paratexten gespielt werden. Eine solche kreative Paratextverwendung findet sich etwa zu Beginn von Timur Vermes’ 2012 erschienenem Roman Er ist wieder da: Mit „er“ ist Adolf Hitler gemeint, der in Vermes’ kontrafaktischer Polit- und Mediensatire aus unerklärlichen Gründen im Jahre 2011 mitten in Berlin wieder zum Leben erwacht und über den Umweg einer Karriere als vermeintlicher Hitler-Imitator neuerlich zur Macht aufsteigt. ${ }^{344}$ Auf der Impressumsseite des Buches heißt es:

Sämtliche Handlungen, Charaktere und Dialoge in diesem Buch sind rein fiktiv. Ähnlichkeiten mit lebenden Personen und/oder ihren Reaktionen, mit Firmen, Organisationen

343 Siehe zu den Paratexten kontrafaktischer Werke auch Kapitel 4.7. Markierung. 344 Siehe aus der Forschung Rosenfeld: Hi Hitler!, S. 219-225. 
etc. sind schon deshalb zufällig, da unter vergleichbaren Umständen in der Realität andere Vorgehens- und Verhaltensweisen der handelnden Figuren nicht vollständig ausgeschlossen werden können. Der Autor legt Wert auf die Feststellung, dass Sigmar Gabriel und Renate Künast nicht wirklich mit Adolf Hitler gesprochen haben. ${ }^{345}$

Vermes spielt hier offenkundig mit der Textgattung der Fiktionalitätsversicherung, wie sie häufig am Anfang von Romanen oder am Ende des Abspanns von Spielfilmen eingesetzt wird. So mag es zwar richtig sein, dass die „Handlungen, Charaktere und Dialoge“ in Vermes' Roman keine präzise realweltliche Entsprechung aufweisen; die historische Figur Adolf Hitler ist jedoch ebenso wenig fiktiv wie die im letzten Satz erwähnten politischen Persönlichkeiten Sigmar Gabriel und Renate Künast. Darüber hinaus legt der zweite Satz des Textes eine ironisierende Deutung nahe, da durch die Versicherung, es könne „nicht vollständig ausgeschlossen werden“, dass die Personen in der Realität sich anders verhalten als diejenigen im Buch, eben doch suggeriert wird, dass ein Verhalten in Übereinstimmung mit demjenigen der fiktionalen Figuren wahrscheinlich ist. Er ist wieder $d a$ stellt somit den eigenen satirisch-gesellschaftskritischen Charakter gewissermaßen bereits vor Beginn (oder mit Beginn?) des eigentlichen Haupttextes heraus. Damit wird freilich zugleich auch um einige Grade unwahrscheinlicher, dass es sich hier um einen ernstgemeinten, faktualen Paratext handelt, welcher zuverlässig Auskunft über die Fakten der realen Welt geben könnte.

\subsection{Material}

Laut der Minimaldefinition bilden realweltliche Fakten das ,Material' der Kontrafaktik. Der hier verwendete Materialbegriff knüpft dabei an ein übergreifendes, kunstwissenschaftliches Materialverständnis an: Tendenziell lassen sich in den Kunstwissenschaften zwei Konzepte von ,Material' unterscheiden, die man behelfsweise als ,physisch“ und ,inhaltlich“ bezeichnen könnte. Der Begriff des physischen Materials verweist auf „Werkstoff[e], Rohstoff[e] oder Hilfsmittel“, die zur Herstellung eines Kunstwerks vonnöten sind, also etwa der Marmor des Bildhauers oder die Farben des Malers; speziell für die Literatur bezeichnet Material in diesem Sinne „die stofflichen Gegenstände, auf deren Basis und mit deren Hilfe Texte erzeugt [...], aufbewahrt, vervielfältigt und verbreitet werden.“346 Davon tendenziell zu unterscheiden ist ein inhaltlicher Materialbegriff. Dieser bezieht

345 Timur Vermes: Er ist wieder da. Köln 2012, S. 4.

346 Dieter Burdorf / Christoph Fasbender / Burkhard Moennighoff (Hg.): Metzler Lexikon Literatur. Begriffe und Definitionen. 3., völlig neu bearbeitete Aufl. Stuttgart 2007, S. 480. 
sich auf Stoffe, Themen und Motive eines Kunstwerks. So können beispielsweise eigene Lebenserfahrungen des Autors zum ,Material‘ eines psychologischen Romans werden. ${ }^{347}$ Eine strikte Trennung zwischen diesen beiden Dimensionen des Material-Begriffs lässt sich dabei nicht in jedem Fall aufrechterhalten. So weist der Artikel im Metzler Lexikon Literatur darauf hin, dass es „etwa in der Dokumentarlit[eratur], bei den Verfahren der Collage und Montage sowie bei allen durch Aufführung geprägten Formen der Lit[eratur] wie Theater und Tanz, Berührungen, Überschneidungen und Übergänge zwischen diesen Bereichen [gibt].،348

Eine Übergängigkeit zwischen physischen respektive formalen Aspekten einerseits und inhaltlichen Aspekten andererseits lässt sich teilweise auch beim Faktenmaterial der Kontrafaktik beobachten: Der Begriff des Materials wird im gegebenen Zusammenhang vor allem deswegen als Erweiterung des Faktenbegriffs verwendet, weil er in besonderem Maße geeignet scheint, die Offenheit des für die Kontrafaktik relevanten Faktenverständnisses hervorzuheben. Konkret soll durch seinen Gebrauch darauf hingewiesen werden, dass die Variation jener Fakten, welche für das Phänomen der Kontrafaktik konstitutiv ist, sowohl inhaltliche als auch formale Aspekte dieser Fakten zu umfassen vermag. Es kann hier noch einmal an die obigen Ausführungen zum nicht exklusiv propositionalen Status der Fakten in der Kontrafaktik erinnert werden: Wahrheit, faktuale Richtigkeit oder Weltwissen lassen sich nicht allein in Form von (inhaltlichen) Propositionen bestimmen, sondern können auch andere Formen des Wissens wie Script- und Framewissen oder die Fähigkeit zur Identifikation spezifischer Sinneseindrücke miteinschließen. ${ }^{349}$ Entsprechend wird eine allgemeine Theorie der Kontrafaktik sich nicht auf inhaltlich-propositionale Faktenausprägungen beschränken dürfen, sondern auch die mehr formalen Aspekte realweltlichen Wissens zu berücksichtigen haben. Hierfür scheint der Begriff des Faktenmaterials eher geeignet als

347 Dass eine bestimmte Erfahrung oder ein realweltlicher Sachverhalt als Quelle oder Inspiration für eine fiktionale Darstellung fungiert, sagt noch nichts darüber aus, ob und in welcher Weise dieses Material in die Interpretation des jeweiligen Werks einbezogen werden sollte. So lässt sich aus dem Umstand, dass bei der Verfertigung eines Kunstwerks auf realweltliches Material zurückgegriffen wurde, keineswegs folgern, dass das Kunstwerk selbst auch auf dieses Material referiert. Peter Lamarque bemerkt hierzu: „In general it is helpful to keep apart different questions about the relation of fictions to the world; for example: (1) Where did the idea for such and such a fiction come from? (2) What people or things in the real world are the fictional characters similar to? (3) What properties are attributed to the characters in the fiction? (4) Who or what specifically does the author intend to refer to? These questions are significantly different; the method of investigation in each case is different, and each has a different bearing on the relation of fiction and reality.“ (Peter Lamarque: Fictional Points of View. Ithaca / London 1996, S. 41).

348 Burdorf / Fasbender / Moennighoff (Hg.): Metzler Lexikon Literatur, S. 480.

349 Siehe Kapitel 4.3.4. Das Faktenverständnis der Kontrafaktik. 
der blanke Faktenbegriff, welcher stets Gefahr läuft, im Sinne eines bloß propositionalen Wahrheitsverständnisses aufgefasst zu werden.

Am Rande sei bemerkt, dass sich die Möglichkeit eines Bezugs sowohl auf formale wie auch auf inhaltliche Aspekte zwar für die Kontrafaktik, nicht aber für die Fantastik eröffnet. Marianne Wünsch hat darauf hingewiesen, dass es sich beim Fantastischen stets um ein Phänomen auf der Ebene der histoire handelt. ${ }^{350}$ Eine bloß sprachlich-formale Fantastik ist nicht vorstellbar, weswegen etwa Tzvetan Todorov poetische oder allegorische Rede aus seiner Definition der Fantastik explizit ausschließt. ${ }^{351}$ Wenn beispielsweise in Joseph von Eichendorffs Mondnacht die Seele ,weit ihre Flügel ausspannt', so wird damit selbstverständlich kein fantastisches Fabelwesen beschrieben; es handelt sich hier vielmehr um ein Beispiel bildlicher Rede.

Anders als die Fantastik bezieht sich die Kontrafaktik jedoch nicht auf allgemeine Annahmen über die ontologische Beschaffenheit der Welt, sondern auf hochgradig spezifische Faktenannahmen. ${ }^{352}$ Da diese Faktenannahmen mitunter selbst sowohl eine inhaltliche als auch eine formale Dimension aufweisen, die potenziell beide in die Literatur überführt und dort variiert werden können, muss sich Kontrafaktik nicht notwendigerweise auf die Ebene der histoire beziehen, sondern kann potenziell auch Aspekte des discours mitumfassen. Die Möglichkeit einer primär formalen kontrafaktischen Variation ergibt sich für die Literatur vor allem dort, wo das kontrafaktisch zu variierende Weltwissen selbst an spezifische formale Ausprägungen der Sprache gebunden ist: So variiert etwa Kathrin Röggla in ihrer kreativ-dokumentarischen Prosaarbeit wir schlafen nicht den ,Sound' eines gesellschaftlichen Spezialdiskurses, nämlich den Jargon der Unternehmensberatung. Die kontrafaktische Variation betrifft dabei weniger das, was in einem bestimmten Diskurs ausgesagt wird, als vielmehr das wie seiner formalen Anlage. ${ }^{353}$

Der Materialbegriff wird schließlich auch verwendet, weil durch ihn angezeigt werden kann, dass die Fakten der Kontrafaktik nie unvermittelt aus der

350 Wünsch: Die Fantastische Literatur der Frühen Moderne (1890-1930), S. 16.

351 Vgl. Tzvetan Todorov: Einführung in die fantastische Literatur. Berlin 2013, S. $42 \mathrm{f}$.

352 Fraglich ist, ob im Fall der Fantastik überhaupt von ,Material' gesprochen werden kann; eine notwendige Bindung an spezifische außerliterarische Sachverhalte liegt bei der Fantastik anders als bei der Kontrafaktik - ja nicht oder zumindest nicht notwendigerweise vor. Zwar könnte man darauf hinweisen, dass etwa das Vampir-Motiv sich ursprünglich unter anderem aus der Adelskritik des 18. Jahrhunderts speist. Für das Verständnis der zahlreichen zeitgenössischen Vampir-Geschichten ist dieser Umstand allerdings ohne Belang, da sich die Semantik des Vampirs längst von den historischen Quellen emanzipiert hat. Vgl. Brittnacher: Zahnlos, blutarm, keusch - zur Kastration einer Metapher, S. 130-133.

353 Siehe hierzu Kapitel 13.1. Kathrin Röggla: wir schlafen nicht. 
realen Welt übernommen werden. Sobald die Fakten in die Literatur integriert werden, sind sie nicht mehr dieselben, sondern werden zum ,Material“ einer literarischen Bearbeitung, ein Material, dem gleichwohl seine Herkunft aus einem faktualen Kontext weiterhin eingeschrieben bleibt. Man kann hier zu Vergleichszwecken an das Material einer künstlerischen Collage denken, welches, indem es in das Kunstwerk eingefügt wird, seinen Status grundlegend verändert, gleichzeitig aber seinen ursprünglichen Herkunftskontext weiterhin erkennen lässt.

Die literarische Bearbeitung des Faktenmaterials umfasst im Falle der Kontrafaktik grundsätzlich zwei Dimensionen: Erstens wird ein Faktum aktiv variiert; hierauf beruht die spezifische Referenzstruktur der Kontrafaktik. Und zweitens wird dieses variierte Faktum im Rahmen des Kunstwerks neu kontextualisiert. (Dies geschieht freilich immer und überall, wenn ein Kunstwerk realweltliche Fakten aufnimmt: Unausweichlich beeinflusst der Kontext des Gesamtwerks das also, was Danneberg als ,infratextuellen Kontext' bezeichnet - die Deutung des einzelnen Elements. ${ }^{354}$ ) Tatsächlich könnte man das Verfahren der Kontrafaktik insgesamt als Variation und Rekontextualisierung von Faktenmaterial im Rahmen künstlerischer Werke charakterisieren.

\subsection{Variation}

In der Forschung hat sich bisher keine einheitliche Terminologie für das spezifische Verfahren kontrafaktischen Erzählens durchsetzen können. Die meisten Studien bescheiden sich mit eher deskriptiven Begriffen wie ,Abweichung‘ oder ,Umschreibung` - und zwar im speziellen Falle des historischen kontrafaktischen Erzählens einer Umschreibung des „faktischen Geschichtsverlaufs“355, des „tatsächlichen Geschichtsverlauf[s]“356 oder einer „Normalized Narrative of the Past““.357 Andreas Widmann hat darüber hinaus den Begriff „deviierendes historisches Erzählen“ für die historische Kontrafaktik vorgeschlagen. ${ }^{358}$

Im Rahmen der vorliegenden Studie wird statt von ,Abweichung، oder ,Deviation‘ von einer ,Variation‘ realweltlichen Faktenmaterials bzw. von ,realitätsvariierendem Erzählen' gesprochen. Der Begriff ,Variation‘ lässt sich dabei in Anlehnung an das Prinzip ,Thema und Variation` verstehen, wie es insbesondere aus musikali-

354 Danneberg: Kontext, S. 334. Siehe auch Kapitel 4.3.7. Fakten als Kontexte kontrafaktischer Interpretationen.

355 Helbig: Der parahistorische Roman, S. 31.

356 Rodiek: Ungeschehene Geschichte, S. 26.

357 Vgl. Singles: Alternate History, S. 43-48.

358 Vgl. Widmann: Kontrafaktische Geschichtsdarstellung, S. 18 (im Original gesperrt). 
schen Kontexten bekannt ist: Man denke an das kompositorische Verfahren der Variation, beispielsweise in Bachs Goldberg-Variationen, in denen sich sämtliche dreißig Variationen auf das anfängliche ,Aria'-Thema beziehen. Tatsächlich wurde das Prinzip der musikalischen Variation in der Forschung bereits vereinzelt mit dem kontrafaktischen Erzählen in Verbindung gebracht. So greifen die Psychologen Neal J. Roese und Mike Morrison zur Charakterisierung der Wirkung von kontrafaktischen Elementen in Erzählungen auf die Metapher „theme and variation“ zurück: „If reality is the theme, and counterfactual is the variation, then the juxtaposition of the two embodies a combination of the joy of recognition with surprise at something novel.“359 Auch in Kingsley Amis’ Roman The Alteration von 1976, einem der Klassiker des Alternate History-Genres, wird das Prinzip der Geschichtsvariation, welches der kontrafaktischen Erzählwelt des Romans zugrunde liegt, unter anderem mit der musikalischen Variation in Verbindung gebracht: Der Protagonist, ein junger, hochbegabter Sänger im Dienste der katholischen Kirche, denkt an einer Stelle des Romans über die Komposition eines auf Variationen beruhenden Musikstücks nach, wobei auch der für den Roman poetologisch zentrale Titelbegriff ,alteration“ fällt. ${ }^{360}$ Die ,Alteration“ respektive Variation im musikalischen Bereich wird somit in Verbindung gebracht mit der ,Alteration“ oder Variation der Realgeschichte im Genre der Alternate History.

Die musikalische Assoziation des Begriffs ,Variation“ ist im gegebenen Kontext auch deshalb wünschenswert, weil sich in diesem Begriff andeutet, dass die Faktenvariationen der Kontrafaktik nicht notwendigerweise auf inhaltlich-propositionale Aspekte beschränkt sind, sondern dass hier mitunter auch formale Aspekte eine Rolle spielen. ${ }^{361}$ Im Falle musikalischer Variationen - im Rahmen eines Mediums also, das eine Trennung von Signifikant und Signifikant nicht in vergleichbarer Weise zulässt wie sprachliche Zeichen - ist eine Differenzierung zwischen Inhalt und Form der Variation schließlich gar nicht sinnvoll durchführbar. Nicht zuletzt soll mit dem musikassoziierten Begriff der ,Variation“ auf die genuin künstlerische Natur der Kontrafaktik hingewiesen werden.

Auch jenseits der musikalischen Assoziation bietet der Begriff der ,Variation“ den Vorteil, den komparativen Charakter, welcher für die Kontrafaktik konstitutiv

359 Roese / Morrison: The Psychology of Counterfactual Thinking, S. 22.

360 Vgl. Kingsley Amis: The Alteration. Frogmore 1978, S. 37 f. Der Begriff ,alteration“ ist in Amis’ Roman mehrfach belegt: Neben dem Verfahren kontrafaktischen Erzählens, welches der Erzählwelt des Romans zugrunde liegt, und - damit zusammenhängend - dem musikalischen Prinzip von Thema und Variation bezeichnet der Begriff ,alteration“ auch die geplante Kastration, die an dem zehnjährigen Protagonisten vorgenommen werden soll, um auf diese Weise seine engelsgleiche Singstimme zu erhalten. Vgl. ebd., S. 49.

361 Siehe Kapitel 4.3.4. Das Faktenverständnis der Kontrafaktik. 
ist, in besonderem Maße zu betonen. Während eine ,Deviation“ oder ,Abweichung‘ auch schlicht resultativ verstanden werden kann (dadurch, dass von einem bekannten Weg ,abgewichen' wird, folgt nicht notwendigerweise, dass auf dem neuen Pfad noch irgendein starker Bezug zum ursprünglichen Weg fortbesteht ${ }^{362}$ ), ist es ein Definiens jedweder ,Variation‘, dass - ungeachtet aller etwaigen Veränderungen - ein Bezug zum ursprünglichen Thema, Motiv oder Material gewahrt bleibt. Mit dem Variationsbegriff soll also auch darauf hingedeutet werden, dass bei den Faktenvariationen der Kontrafaktik die alludierten, realweltlichen Fakten stets weiterhin ,mitgemeint` sind.

\subsection{Signifikanz}

Der Minimaldefinition zufolge muss die Veränderung von realweltlichem Faktenmaterial in der Kontrafaktik auf ,signifikante، Weise erfolgen. Signifikanz bildet dabei eine wesentlich hermeneutische Kategorie. Als signifikant werden solche Variationen des Faktenmaterials bezeichnet, die für die Deutung des jeweiligen Werkes in seiner Ganzheit von Bedeutung sind (statt von ,Signifikanz‘ könnte man auch von ,hermeneutischer Relevanz‘ oder ,Deutungsrelevanz' sprechen). Während eine Faktenabweichung möglicherweise auch isoliert und unabhängig von ihrem textuellen Kontext identifizierbar sein mag, wird ein Element erst dadurch zu einem eigentlich kontrafaktischen, dass seine Faktenvariation sich für die Gesamtdeutung des Textes als bedeutsam erweist. Signifikant oder deutungsrelevant sind kontrafaktische Elemente also nicht für sich allein genommen, sondern nur, indem sie in eine Gesamtdeutung des Textes integriert werden (ein und dieselbe Faktenabweichung kann in unterschiedlichen Texten unterschiedlich - oder auch gar nicht interpretiert werden, muss also nicht immer und überall als kontrafaktische Faktenvariation aufgefasst werden). Umgekehrt wird ein Werk erst dadurch eigentlich zu einem kontrafaktischen, dass man seinen kontrafaktischen Elementen im Rahmen einer Gesamtdeutung des Werkes besondere Bedeutung zuschreibt. Offenkundig liegt hier eine Manifestation des hermeneutischen Zirkels vor. ${ }^{363}$ Da es sich nun bei der Zuschreibung von Signifikanz um einen dynamischen und individuellen Deutungsprozess handelt, wird man nicht erwarten dürfen, dass sich allgemeingültige Kriterien für die Feststellung von Signifikanz angeben lassen. Wie stets bei hermeneutischen Prozessen kann eine Interpretation nur im Nachhinein plausibilisiert,

362 Eine primär resultative Variante kontrafaktischen Denkens liegt für gewöhnlich den „Was wäre, wenn ..."-Fragen zugrunde. Siehe Kapitel 2.1. Terminologie.

$363 \mathrm{Vgl}$. Eco: Lector in fabula, S. 148. 
nicht aber im Vorhinein - etwa auf der Grundlage mechanischer Deutungsregeln zuverlässig präjudiziert werden. ${ }^{364}$

Einen Teilaspekt der Definition der Kontrafaktik bildet Signifikanz deswegen, weil sie es ermöglicht, die Faktenvariationen der Kontrafaktik von anderen Formen der Faktenabweichung in fiktionalen Werken zu unterscheiden. ${ }^{365}$ Nicht jeder fiktionale Text, der erfundene Elemente enthält - und dies ist bei den meisten, wenn nicht gar bei allen fiktionalen Texten der Fall -, ist zugleich auch kontrafaktisch. Zurecht betont Catherine Gallagher: „[W]e don't read most novels as counterfactual conjectures; we intuitively make a distinction between the kind of hypothetical exercises involved in counterfactuals and mere fictionality. "366 Realistische Texte etwa enthalten in aller Regel Elemente, die zwar fiktiv, darum aber noch nicht kontrafaktisch sind. So hat es beispielsweise in der realen Welt nie einen Detektiv mit dem Namen und den präzisen Eigenschaften von Sherlock Holmes gegeben; ontologisch betrachtet ist Sherlock Holmes ein fiktives Objekt. Der Umstand jedoch, dass es ihn nicht gegeben hat, ist für eine Interpretation der Sherlock Holmes-Romane nicht relevant. Anders als bei der Fiktivität kontrafaktischer Elemente steht die Fiktivität von Sherlock Holmes nämlich in keinem offenkundigen Widerspruch zum Weltwissen des Lesers. Mithin ist sie als Fiktivität auch nicht signifikant. Im Falle fiktional-realistischer Texte wird der Frage der (Nicht-)Existenz bestimmter Objekte für gewöhnlich mit Gleichgültigkeit begegnet.

Nun gibt es aber auch Fälle fiktionaler Werke, bei denen eine Faktenabweichung gut erkennbar ist, diese Faktenabweichung aber dennoch ohne Relevanz für die Deutung des Textes bleibt. Dies ist etwa der Fall, wenn Faktenmaterial in einem literarischen Werk fehlerhaft wiedergegeben wird. Ein Fehler liegt beispielsweise vor, wenn innerhalb einer fiktionalen Welt eine Straße einen falschen Namen trägt, diese fehlerhafte Benennung für das in Frage stehende Werk aber hermeneutisch irrelevant ist. ${ }^{367}$ Fehler mögen also als Abweichung von Fakten-

364 Vgl. Kablitz: Theorie der Literatur und Kunst der Interpretation.

365 Auch Hoops unterscheidet „[s]ignifikant[e]“ Abweichungen in fiktionalen Texten von „Detailabweichungen oder zufälligen Irrtümer[n] von Autoren“ (Hoops: Fiktionalität als pragmatische Kategorie, S. 302, Anm. 106).

366 Gallagher: What Would Napoleon Do?, S. 333.

367 Das Vorliegen von Fehlern in fiktionalen Kontexten lässt sich, ebenso wie das Vorliegen kontrafaktischer Elemente, immer nur im Rahmen einer bestimmten Interpretation erschließen: „Ein Fehler im fiktionalen Kontext liegt [...] dann vor, wenn die selektierten Aspekte (in Bezug auf eine bestimmte Interpretation) auf willkürliche, unplausible oder unvollständige Weise aus ihrem jeweiligen Kontext gelöst und mit anderen kombiniert werden.“ (Wolfgang Huemer: Gibt es Fehler im fiktionalen Kontext? Grenzen der dichterischen Freiheit. In: Otto Neumaier (Hg.): Was aus Fehlern zu lernen ist in Alltag, Wissenschaft und Kunst. Wien / Münster 2010, S. 211-227, hier S. 226) Zum Zusammenhang von Signifikanz und „Reichweite 
material für den Leser erkennbar sein; wofern sie sich aber nicht sinnvoll in einen (hermeneutisch zu erschießende) Textsinn integrieren lassen, wird man hier nicht eigentlich von einem kontrafaktischen Element sprechen können. Bei kontrafaktischen Elementen handelt es sich nicht um zufällige Realitätsabweichungen, sondern um signifikante Realitätsvariationen, deren Identifikation und Deutung textuell intendiert ist.

Freilich kann die Frage, ob im Einzelfall ein Fehler oder ein kontrafaktisches Element vorliegt, selbst zu einem interessanten Streitfall der Interpretation werden. Dies liegt unter anderem daran, dass auch Fehler, die einem Autor bei der Produktion eines Textes unterlaufen, auf der Ebene der Rezeption unter Umständen als sinnvolle Aspekte der Werkintention angesehen werden können. Kafkas Romanfragment Der Verschollene etwa erfordert an diversen Stellen eine Entscheidung darüber, ob ein unbedeutender Fehler oder eine signifikante Faktenvariation vorliegt. So ist die bekannte Schilderung der „Statue der Freiheitsgöttin“ zu Beginn des ersten Kapitels, der zufolge die Freiheitsstatue statt einer Fackel ein „Schwert“ emporstreckt ${ }^{368}$, zweifellos als kontrafaktisches Element anzusehen: erstens deshalb, weil davon ausgegangen werden kann, dass Kafka sowie den meisten seiner Leser durchaus bewusst war oder ist, dass die reale Freiheitsstatue kein Schwert im Arm trägt; und zweitens, weil sich dieses Element sehr plausibel in eine Deutung des Romans integrieren lässt. ${ }^{369}$ Interpretatorisch schwerer zu bewerten ist hingegen eine spätere Stelle des Romans, an der Herr Green bemerkt, dass sich „San Francisko“ von New York aus gesehen „im Osten“ befinde, was realweltlich-geografisch natürlich inkorrekt ist. ${ }^{370} \mathrm{Ob}$ man diese Aussage lediglich als bedeutungslosen Fehler oder aber als textuell intendiertes, kontrafaktisches Element deuten möchte, wird letztlich davon abhängen, welche Signifikanz man diesem realweltlich fehlerhaften Detail im Rahmen einer Gesamtinterpretation des Romans zuschreibt. Beispielsweise ließe sich diese Aussage auf die Themen Bewegung, Architektur und fehlende Verortung im Raum beziehen, die in Kafkas Roman durchgehend eine Rolle spielen. ${ }^{371}$

der Abweichungen [von der Wirklichkeit]“ siehe auch Hoops: Fiktionalität als pragmatische Kategorie, S. 302. Das, was Hoops „Wirklichkeitsabweichungen in semantischer Funktion“ nennt, deckt sich weitgehend mit dem, was in dieser Studie als Kontrafaktik bezeichnet wird (vgl. ebd., S. 314).

368 Kafka: Der Verschollene, S. 7.

369 Siehe Kapitel 4.3.6. Skopus: Kontrafaktische Welten, kontrafaktische Elemente, point of divergence.

370 Kafka: Der Verschollene, S. 124.

371 Vgl. Michael Navratil: Mobile Machtgebilde. Bewegung und Architektur in Kafkas Roman „Der Verschollene“. In: Gerhard Neumann / Julia Weber (Hg.): Lebens- und Liebesarchitektu- 
Insgesamt lässt sich festhalten, dass die Designation eines Elements als kontrafaktisch sich nicht allein anhand der Fiktivität, also anhand des ontologischen Status des jeweiligen Elements wird durchführen lassen, sondern zusätzlich einer Zuschreibung interpretatorischer Relevanz bedarf. Einzig indem eine Realitätsvariation als hermeneutisch signifikant eingestuft wird, gerät das entsprechende Element zu einem eigentlich kontrafaktischen. Wird hingegen eine konkrete Faktenabweichung als nicht deutungsrelevant klassifiziert - etwa weil man sie als Erfindung im Rahmen der allgemeinen Fiktionalitätslizenzen, als Fehler oder als nebensächliches informationelles Fossil eines überkommenen Weltbilds ansieht -, so kann nicht sinnvollerweise von einem Fall der Kontrafaktik gesprochen werden. Derartige unbedeutende Faktenabweichungen sind eher als nebensächliche Störelement zu betrachten; sie werden von der ansonsten dominanten Textdeutung gleichsam absorbiert.

\subsection{Markierung}

Aus den Überlegungen zur notwendigen Signifikanz kontrafaktischer Realitätsvariationen folgt, dass nicht jede erkennbare Faktenveränderung innerhalb einer fiktionalen Welt auch als signifikante und mithin potenziell kontrafaktische Abweichung von realweltlichem Faktenmaterial zu bewerten ist. Erkennbarkeit allein ist also noch keine hinreichende Bedingung für Signifikanz. (Umgekehrt setzt Signifikanz natürlich Erkennbarkeit voraus: Von ,nicht-erkennbarer Signifikanz zu sprechen, wäre schlichtweg paradox.)

Nun gibt es allerdings Ausprägungen der Kontrafaktik, bei denen die kontrafaktische Faktenvariation innerhalb des Textes derart dezidiert herausgestellt wird, dass es geradezu unmöglich erscheint, der entsprechenden Faktenabweichung die Deutungsrelevanz abzusprechen. In solchen Fällen kann man von einer ,Markierung' der Kontrafaktik respektive von ,markierter Kontrafaktik' sprechen. ${ }^{372}$

ren. Erzählen am Leitfaden der Architektur. Freiburg i. Brsg. / Berlin / Wien 2016, S. 363-383, hier S. $378 f$.

372 In ähnlicher Weise schreibt Fotis Jannidis: „Immer ist das Kriterium für das Vorhandensein einer impliziten Information das ,wahrgenommene Fehlen' von etwas. Gerade umgekehrt können aber auch bestimmte Signale oder Hinweise im Text, insbesondere Andeutungen und Anspielungen, als Markierungen für implizite Informationen dienen.“ (Jannidis: Figur und Person, S. 69) Anstatt von ,Markierungen“ schreibt Zipfel von „Objekte[n], die aus der Wirklichkeit entlehnt sind, sich jedoch explizit und signifikant von ihren realen Entsprechungen unterscheiden.“ (Zipfel: Fiktion, Fiktivität, Fiktionalität, S. 97 - Hervorhebung M. N.) Der Begriff ,Explizitheit" hat allerdings den Nachteil, dass er das Vorliegen einer eindeutigen Markierung der Realitätsabweichung auf der Textoberfläche suggeriert. Da eine solche textuell manifeste 
Markierung stellt zwar keine notwendige Bedingung der Kontrafaktik dar und taucht entsprechend auch nicht in der Minimaldefinition auf. Gleichwohl hängt die Markierung kontrafaktischer Texte oder Textstellen eng mit der Frage nach der Deutungsrelevanz fiktionaler Faktenvariationen zusammen; auch ist die konkrete Gestalt etwaiger Markierungen für die Interpretation der jeweiligen Texte mitunter von großer Wichtigkeit, sodass eine gesonderte Diskussion markierter Kontrafaktik sinnvoll erscheint.

Um das Verhältnis von Signifikanz und Markierung zu verdeutlichen, kann auf eine Unterscheidung zurückzugegriffen werden, die Klaus W. Hempfer in einem vielrezipierten Aufsatz mit dem Titel $\mathrm{Zu}$ einigen Problemen einer Fiktionstheorie vorgenommen hat. In Zusammenhang mit der Frage, wie Texte auf ihren eigenen Fiktionalitätsstatus hinweisen können, unterscheidet Hempfer Fiktionssignale von Fiktionsmerkmalen:

Fiktionssignale sind kommunikativ relevant und damit notwendig historisch variabel, sie garantieren, daß ein Text von den Rezipienten bei adäquater Kenntnis der zeitgenössisch jeweils gültigen Diskurskonventionen als ein fiktionaler verstanden wird - Fiktionsmerkmale sind demgegenüber Komponenten einer Theorie, die ein solches Verständnis zu rekonstruieren versucht, indem sie explizit die Bedingungen formuliert, die vorliegen müssen, um einen Text als - mehr oder weniger - fiktional einzustufen. Diese Bedingungen gehen selbstverständlich über das explizit Signalisierte hinaus, sonst bräuchte man sie ja einfach nur von den Texten ,abzulesen', wobei Fiktionssignale als historisch unterschiedliche Realisationsformen von Fiktionsmerkmalen zu begreifen sind. ${ }^{373}$

Hempfers Überlegungen lassen sich auf die Markierung von Faktenvariationen im Rahmen der Kontrafaktik übertragen. Die Notwendigkeit einer signifikanten Abweichung von den Fakten ist im Falle der Kontrafaktik per definitionem und insofern unausweichlich gegeben. Die Signifikanz der Faktenabweichung bildet also ein notwendiges ,Merkmal' der Kontrafaktik im Sinne Hempfers. Dieses Merkmal muss allerdings nicht unmittelbar in Form eines einzelnen Elements auf der Textoberfläche ,abzulesen` sein: In welcher Weise sich die Faktenvariation im konkreten kontrafaktischen Text manifestiert, also über welche spezifischen ,Signale، das Erkennen der signifikanten Faktenabweichung sichergestellt wird, lässt sich nicht allgemeingültig bestimmen. Hier ist eine große Zahl an Realisierungsformen denkbar. Signifikanz, im Sinne eines Merkmals der Kontrafaktik, verweist also auf eine definierende Eigenschaft des Erzählphänomens, während Markiertheit, im Sinne eines manifesten Signals, mit dem das Vorliegen einer

Markierung bei Texten der Kontrafaktik manchmal, aber nicht immer vorhanden ist, wird der Begriff der Explizitheit zugunsten der präziseren Begriffe Signifikanz und Markierung vermieden.

373 Klaus W. Hempfer: Zu einigen Problemen einer Fiktionstheorie. In: Zeitschrift für französische Sprache und Literatur 100 (1990), S. 109-137, hier S. $121 \mathrm{f}$. 
kontrafaktischen Referenzstruktur betont wird, textuell auf unterschiedliche Weise - oder eben auch gar nicht - realisiert sein kann. Markierte Formen der Kontrafaktik liegen dort vor, wo sich in einem literarischen Text spezifische Eigenschaften identifizieren lassen, die eine kontrafaktische Interpretation dieses Textes provozieren. Anders formuliert: Markierungen begünstigen oder erzwingen die Einbeziehung von Faktenvariationen in die Interpretation eines Textes.

Zur Verdeutlichung und Präzisierung kann an dieser Stelle ein Seitenblick auf die Intertextualitätstheorie geworfen werden, die zum Teil mit ähnlichen Problemen wie die Theorie der Kontrafaktik befasst ist. Auch in der Intertextualitätstheorie wird davon ausgegangen, „daß eine literarische Anspielung, um etwas zu suggerieren, zumindest überhaupt als literarische Anspielung muß erkannt werden können“ “374 (freilich immer unter der Voraussetzung, dass man nicht von einem vage-poststrukturalistischen Intertextualitätsbegriff wie demjenigen Julia Kristevas ausgeht, sondern ein engeres Verständnis von Intertextualität - mit Allusionen auf konkrete Prätexte - anlegt). Prinzipiell bestehen nun zwei Möglichkeiten, um die Identifikation einer intertextuellen Anspielung sicherzustellen. Zu differenzieren ist zwischen ,unmarkierter und markierter Intertextualität“375: Entweder eine Anspielung wird spontan erkannt, weil der Leser über hinreichende Kenntnis des konkreten Prätextes verfügt. In diesem Fall würde es sich um einen Fall unmarkierter Intertextualität handeln. ${ }^{376}$ Oder aber es liegt eine textuelle Markierung vor, die eine intertextuelle Referenzbildung aktiv befördert oder provoziert. Im letztgenannten Fall sind zahlreiche Realisationsmöglichkeiten der Markierung denkbar, von der besonderen graphischen oder syntaktischen Hervorhebung der relevanten Textstelle über eine Betonung der Intertextualität durch eine inhaltliche Thematisierung literarischer Produktion und Rezeption bis hin zu paratextuellen Signalen. ${ }^{377}$

Auch im Falle der Kontrafaktik können markierte und unmarkierte Formen voneinander unterschieden werden. Unmarkierte Kontrafaktik liegt vor, wenn die Abweichung vom Fakt selbst die einzige Form der ,Markierung“ darstellt, wenn Abweichung und Markierung also gewissermaßen zusammenfallen. Als Beispiel unmarkierter Kontrafaktik lässt sich etwa Christoph Ransmayrs Roman

374 Gerhard Goebel: Funktionen des ,Buches im Buche‘ in Werken zweier Repräsentanten des ,nouveau roman'. In: Eberhard Leube / Ludwig Schrader (Hg.): Interpretation und Vergleich. Festschrift für Walter Pabst. Berlin 1972, S. 34-52, hier S. 45.

375 Vgl. Jörg Helbig: Intertextualität und Markierung. Untersuchungen zur Systematik und Funktion der Signalisierung von Intertextualität. Heidelberg 1996, S. 72-75.

376 Vgl. Helbig: Intertextualität und Markierung, S. 87-91, 155-161.

377 Für eine kommentierte Auflistung intertextueller Markierungsarten siehe Helbig: Intertextualität und Markierung, S. 83-142. 
Morbus Kitahara betrachten, in dem die Nachkriegsgeschichte deutlich vom realen Verlauf der Geschichte abweicht, oder auch Michel Houellebecqs Dystopie Unterwerfung, deren Darstellung einer islamischen Herrschaft als kontrafaktischer Kommentar auf zeitgenössische Debatten rund um Islam und Islamismus lesbar ist. Von markierten Formen der Kontrafaktik kann hingegen gesprochen werden, wenn die Signifikanz der Faktenabweichung mittels einer zusätzlichen Texteigenschaft explizit signalisiert wird. Markierte Kontrafaktik liegt beispielsweise in Harris' Roman Fatherland vor, der die Frage der Faktenvertuschung auch binnenfiktional an zentraler Stelle thematisiert und dessen Nachwort ferner die relevanten realgeschichtlichen Fakten nachträgt.

Die bestehende Forschung hat sich bisher fast ausschließlich mit unmarkierten Formen kontrafaktischen Erzählens befasst: In der einstweilen dominanten, wenn auch kaum jemals theoretisch ausformulierten Konzeption kontrafaktischen Erzählens wird davon ausgegangen, dass sich kontrafaktische Texte durch eine Abweichung von gut bekanntem, enzyklopädischem Wissen auszeichnen. Diese kontrafaktischen Realitätsvariationen können, so wird vorausgesetzt, vom Leser spontan identifiziert werden, einfach deshalb, weil sie zu eklatant sind, als dass man sie übersehen könnte. Folgt man etwa Widmanns Theoretisierung der kontrafaktischen Geschichtsdarstellung, so „lässt sich der für die Aktualisierung der Textinhalte adäquat ausgerüstete Modell-Leser [...] als Rezipient beschreiben, der über das notwendige enzyklopädische Wissen verfügt, um erkennen zu können, dass die in den Romanen vorgelegten Geschichtskonstruktionen nicht mit dem übereinstimmen, was aufgrund von Überlieferung und Konvention den Stellenwert historischer Fakten besitzt.“378 Eine solche Betrachtungsweise wird für die Mehrzahl der konventionellen Beispiele der Kontrafaktik gewiss hinreichend sein. Bei genauer Prüfung ergeben sich aus dem von Widmann formulierten und von den meisten anderen Forschern zumindest implizit mitgetragenen Modell allerdings eine Reihe weitreichender Konsequenzen - und zum Teil auch Probleme - für eine Ausdifferenzierung der Theorie der Kontrafaktik. Erstens: Im vorgeschlagenen Modell wird davon ausgegangen, dass der Leser bereits vor der Lektüre des kontrafaktischen Textes über eine einigermaßen vollständige Kenntnis der relevanten Fakten verfügt und dieses konventionelle Faktenwissen im Lektürevorgang dann als Vergleichsfolie permanent aktualisiert. Dynamische Prozesse der Wissensaneignung, die allererst durch die Lektüre eines - zunächst vielleicht noch gar nicht als kontrafaktisch erkannten - Textes angeregt werden, bleiben dabei unberücksichtigt. Solche dynamischen Prozesse der Wissensaneignung können sich etwa da ergeben, wo die entsprechenden Fakten von einem empirischen

378 Widmann: Kontrafaktische Geschichtsdarstellung, S. 38. 
Leser eigens im Lexikon oder auf Wikipedia nachgeprüft werden. Zweitens: Der Bezug auf enzyklopädisches Wissen präferiert einen ganz bestimmten Typ von Fakten als Basis der Kontrafaktik, nämlich solche, die in hohem Maße konventionalisiert, relativ statisch und in Form von Propositionen formulierbar sind. Unberücksichtigt bleiben dabei Formen des Skript-Wissens und prozessorale Wissensformen, stark spezialisiertes Welt- respektive Expertenwissen sowie die wandelbaren Bedingungen der Rezeption kontrafaktischer Werke, etwa bei wachsendem historischen Abstand zu ihrem Entstehungszeitpunkt oder bei Verpflanzung in einen kulturell alteritären Rezeptionskontext. Drittens: Die Abweichung von den Fakten in kontrafaktischen Texten muss dem vorgeschlagenen Modell zufolge nicht mehr eigens ausgestellt oder markiert werden, da diese Abweichung eklatant genug ist, um eine Identifikation zuverlässig erwartbar zu machen. Explizitere Formen der Markierung jedoch, die auf formale Mittel, auf paratextuelle Rahmungen oder auf innerdiegetische Meta-Kommentare zurückgreifen, werden von diesem Modell nicht abgedeckt.

$\mathrm{Zu}$ den ersten beiden Punkten ist anzumerken, dass der Grad der Konventionalisierung von Wissen im Rahmen der Kontrafaktik nicht notwendigerweise als starr angesehen werden muss. Zwar wird in den Standardbeispielen historischen kontrafaktischen Erzählens meist auf Weltwissen zurückgegriffen, das einen hohen Grad an Bekanntheit und intersubjektiver Verbindlichkeit aufweist und dessen künstlerische Variation mithin leicht identifizierbar ist. Gerade in den avancierteren Beispielen des Genres jedoch - etwa im alternativgeschichtlichen Erzählen Christian Krachts - gewinnt der unsichere Status der relevanten Faktenbasis selbst interpretatorische Relevanz. Mitunter erweist sich eine solche Faktenbasis als letztlich inexistent, oder aber sie muss erst im Laufe des Lektürevorgangs erschlossen werden. Gerade angesichts der spezifischen Bedingungen der Genese von Weltwissen in der Gegenwart wäre es reduktiv, die Kontrafaktik allein im Hinblick auf eine starre Enzyklopädie konzeptualisieren zu wollen. Schließlich zeichnet sich das digitale Zeitalter durch eine intrikate Mischung aus enormer Wissenspluralisierung und -partikularisierung einerseits und einer nie dagewesenen allgemeinen Verfügbarkeit von Informationen andererseits aus.

Was die spontane Erkennbarkeit der Faktenvariation angeht, so muss selbst im Hinblick auf einige Standardbeispiele der historischen Kontrafaktik konstatiert werden, dass die Autoren hier offenbar nicht immer auf die Fähigkeit ihrer Leserschaft zur spontanen Identifikation der jeweiligen Faktenvariationen vertrauen. Häufig wird der kontrafaktische Werkstatus - gleichsam sicherheitshalber - von den Autoren zusätzlich markiert. So stellt Robert Harris ans Ende seines Romans Fatherland ein Nachwort, in welchem er betont: „Many of the characters whose names are used in this novel actually existed. Their biographical details are correct up to 
1942. Their subsequent fates, of course, were different." 379 Es folgt eine Liste der realen Lebens- und Sterbeumstände der für den Roman relevanten Nazi-Persönlichkeiten (wobei ein Eintrag zu Adolf Hitler bezeichnenderweise fehlt. Offenbar setzt Harris die Kenntnis der zentralen Lebensdaten Hitlers auch bei seiner englischsprachigen Leserschaft voraus.). Auch Philip Roth liefert am Ende seines Romans The Plot Against America Kurzbiografien der handlungsrelevanten Persönlichkeiten (Hitler fehlt erneut, nicht aber F. D. Roosevelt, Joseph Goebbels oder Hermann Göring), führt die wissenschaftlichen Quellen an, auf die er bei der Recherche zurückgegriffen hat, und stellt eine Originalrede von Charles Lindbergh bereit. ${ }^{380}$ Paratextuelle Hinweise, in denen die Faktenbasis der Erzählung nachgereicht wird, finden sich in alternativgeschichtlichen Texten mit einiger Regelmäßigkeit; solche paratextuellen Markierungen können als der klassische Fall markierter Kontrafaktik angesehen werden. ${ }^{381}$

Eine weitere verbreitete Markierungsart der Kontrafaktik sei erwähnt: Nicht selten spielen in kontrafaktischen Werken Themen wie Geschichtsfälschung, Propaganda, politische Ideologien sowie andere Formen der (faktualen) Faktenverfälschung eine zentrale Rolle. Kontrafaktische Werke, die ja selbst bereits einen einigermaßen komplexen Fiktionsstatus aufweisen, thematisieren in derartigen Fällen also selbst wiederum Fragestellungen rund um Fiktionalität, Fiktivität und Lüge innerhalb ihrer fiktionalen Welten. Solche immanenten Faktenreflexionen bilden ein Spezifikum kontrafaktischer Werke; sie können geradezu als eine Genrekonvention der Alternate History angesehen werden (man denke etwa an die Holocaust-Verheimlichung in Harris' Fatherland oder an den Versuch der Geschichtsklitterung in Tarantinos Inglourious Basterds). Da derartige binnenfiktionale Faktenreflexionen in ihrer interpretatorischen Relevanz mitunter weit über die Funktion einer bloßen Markierung der Kontrafaktik hinausgehen, sollen sie noch ausführlich im Kapitel zur Metafaktizität diskutiert

379 Harris: Fatherland, S. 385.

380 Dass Philip Roths Werk ungeachtet seiner gut recherchierten Faktenbasis zweifellos ein Werk der (künstlerischen) Kontrafaktik und keines der Historiografie ist, stellt der Autor zu Beginn seiner abschließenden Leserhinweise heraus: „The Plot Against America is a work of fiction. This postscript is intended as a reference for readers interested in tracking where historical fact ends and historical imagining begins.“ (Philip Roth: The Plot Against America. Boston / New York 2004, S. 364).

381 Eine vollständige Liste der Markierungsformen kontrafaktischer Texte soll an dieser Stelle nicht geliefert werden. Es ist auch kaum wahrscheinlich, dass sich eine solche Liste überhaupt erstellt ließe, ergeben sich Markierungen doch mitunter aus einem komplexen Zusammenspiel textstruktureller, inhaltlicher und kontextueller Aspekte, sodass - zumindest theoretisch - unendliche Markierungsvarianten der Kontrafaktik denkbar sind. Bei den Möglichkeiten zur Markierung intertextueller Anspielungen ist dies im Übrigen nicht anders. 
werden. ${ }^{382}$ Im Rahmen der aktuellen Überlegungen zur Markierung der Kontrafaktik sei allerdings festgehalten, dass durch die werkimmanente Wahrheitsproblematisierung das Augenmerk der Leser mitunter überhaupt erst auf die vorgängigen Konstitutionsbedingungen der kontrafaktischen Diegese gelenkt wird (ohne dass diese werkimmanente Wahrheitsproblematisierung deswegen selbst notwendigerweise kontrafaktisch wäre - häufig haben metafaktische Elemente eher den Status von politischen Lügen oder Fake News ${ }^{383}$ ).

Die Frage, ob eine markierte Form der Kontrafaktik vorliegt oder nicht, kann je nach Markierungsart und Rezeptionskontext durchaus unterschiedlich beantwortet werden. Ein Paratext, der eindeutig auf den kontrafaktischen Status des Haupttextes verweist, stellt eine der wenigen eindeutigen Manifestationsformen kontrafaktischer Markierung dar (wobei das oben diskutierte Beispiel aus Vermes' Er ist wieder da zeigt, dass selbst hier Komplikationen möglich sind ${ }^{384}$ ); eine ähnlich explizite Markierungsform wären beispielsweise Fußnoten im Text, welche die einschlägigen Fakten zur jeweiligen fiktionalen Faktenvariation nachreichen. Weniger eindeutig wird die Identifikation von Markierungen - oder besser: der Eindruck der Markiertheit - hingegen da ausfallen, wo die Erkennbarkeit der kontrafaktischen Faktenvariation von inhaltlichen Aspekten, Interpretationsleistungen und den epistemischen Voraussetzungen des Lesers - also von dynamischen, individuellen oder kontextuellen Faktoren - abhängt. Hierin gleicht die Kontrafaktik wiederum dem Phänomen der Intertextualität: Auch im Falle der Intertextualität ist die Bewertung des Grades von Markiertheit mitunter abhängig von der Einschätzung des jeweiligen Rezipienten. ${ }^{385}$

Besonders schwer zu beantworten erweist sich die Frage, ob eine markierte oder eine unmarkierte Form der Kontrafaktik vorliegt, im Falle solcher Faktenvariationen, die sich nicht auf inhaltliche Aspekte, sondern primär auf formale oder sinnliche Eigenschaften beziehungsweise auf Eigenschaften des discours beziehen. Wenn etwa Kathrin Röggla in wir schlafen nicht den Jargon der Unternehmensberatung sprachlich abwandelt, so ist es kaum möglich, eine einzelne Texteigenschaft oder Proposition zu isolieren, die es erlauben würde, die in diesem Text präsentierte (pseudo-)dokumentarische Sprachform als realitätsvariierend einzustufen. Stattdessen kommt hier ein ganzes Set verfremdender Verfahren zum Einsatz, welche insgesamt dazu führen, dass sich der Eindruck des Nicht-Realitätsanalogen respektive der ,verschobenen“ Realitätsreferenz einstellt (es wird noch zu diskutieren sein, welche Funktion just diesem je ne sais quoi

382 Siehe Kapitel 5.4. Metafaktizität.

383 Vgl. Navratil: Lying in Counterfactual Fiction.

384 Siehe Kapitel 4.3.8. Mögliche Einwände.

385 Siehe hierzu Helbig: Intertextualität und Markierung, S. 161-168. 
des sprachlich-klanglichen (Nicht-)Wiedererkennens in Rögglas Texten zukommt ${ }^{386}$ ). Tendenziell scheinen im Falle einer Fokussierung formaler Aspekte eines Werkes die Erkennbarkeit der kontrafaktischen Variation und die Markierung derselben nicht immer deutlich voneinander unterscheidbar zu sein. Darüber hinaus erstreckt sich in primär formvariierenden Ausprägungen der Kontrafaktik wie dem kreativen Dokumentarismus und bestimmten Beispielen des kontrafaktischen Comics - die relevante Formvariation oftmals auf den gesamten Text, sodass das Vorliegen etwaiger Markierungen der Kontrafaktik hier nicht isoliert (also elementbezogen), sondern nur pauschal festgestellt werden kann.

\subsection{Rekapitulation: die Minimaldefinition der Kontrafaktik}

An dieser Stelle seien die zentralen Begrifflichkeiten der Minimaldefinition noch einmal in aller Kürze zusammengefasst. Zur Erinnerung sei auch die Minimaldefinition ein weiteres Mal angeführt:

Kontrafaktik bezeichnet signifikante Variationen realweltlichen Faktenmaterials innerhalb fiktionaler Medien.

Begriffe, denen systematische Bedeutung zukommt, werden im Folgenden kursiv gesetzt.

Kontrafaktik bezeichnet das kontrafaktische Erzählen oder Denken in fiktionalen (insbesondere fiktional-künstlerischen) Medien, also etwa in der Literatur, im fiktionalen Film oder im fiktionalen Comic. Kontrafaktik ist charakterisiert durch eine spezifische Referenzstruktur, bei der innerhalb eines fiktionalen Werks indirekt auf einen realweltlichen Sachverhalt Bezug genommen wird. Dies geschieht dadurch, dass dieser Sachverhalt innerhalb des Werkes nicht unverändert, sondern in variierter Form dargestellt wird. Kontrafaktische Elemente zeichnen sich also durch faktenkontrastierende, transfiktionale Doppelreferenzen aus, die sich direkt auf die fiktionale Welt, indirekt auf die reale Welt beziehen.

Fiktionalität bezeichnet eine bestimmte Form des pragmatischen Umgangs mit Texten (und anderen Medien); ein Text wird dadurch zu einem fiktionalen, dass er in Übereinstimmung mit den Konventionen der ,Institution' Fiktionalität rezipiert wird. Eine zentrale Vorgabe der Institution Fiktionalität besteht darin, dass fiktionale Texte von der Verpflichtung auf realweltlich wahre Aussagen ausgenommen sind. Das literarische fiktionale Erzählen kreiert fiktionale Welten, die allein über eine Interpretation der literarischen Darstellungsgesamtheit zugänglich sind.

386 Siehe Kapitel 13.1. Kathrin Röggla: wir schlafen nicht. 
Die Fakten der Kontrafaktik sind insofern realweltlich, als über ihre faktische Richtigkeit nur mit Blick auf die reale Welt eine Aussage getroffen werden kann. Die Fakten der Kontrafaktik - verstanden als deutungsrelevante Kontexte der Interpretation - werden also nicht von den kontrafaktischen Werken selbst gesetzt, sondern sind diesen vorgängig.

Als potenzielle Fakten der Kontrafaktik können alle Annahmen oder Aussagen über die reale Welt gelten, denen ein positiver Wahrheits- oder Richtigkeitswert zukommt. Das bedeutet, dass Abweichungen von diesem Wahrheits- oder Richtigkeitswert von einer bestimmten Gruppe von Rezipienten, die dieselben epistemischen Voraussetzungen teilen, als eindeutig unwahre oder inkorrekte Aussage über die reale Welt klassifizierbar sind. Der Faktenbegriff der Kontrafaktik ist insofern ein konventionalistischer oder pragmatischer; er verweist vorderhand auf keine spezifische ontologische Fundierung und auf keinen spezifischen epistemologischen Rahmen.

Als Material der Kontrafaktik bieten sich sämtliche Ausschnitte und Aspekte des Weltwissens an, die im jeweiligen fiktionalen Medium auf eine solche Weise abgewandelt werden können, dass sich eine eindeutige Nicht-Übereinstimmung mit faktualen Wahrheitsannahmen ergibt. Diese Nicht-Übereinstimmung kann dabei sowohl inhaltliche als auch formale Aspekte des jeweiligen Faktenmaterials umfassen. Der Begriff des Materials wird - in Anlehnung an andere künstlerische Verfahren - gebraucht, um sowohl die kontrafaktische Veränderung als auch die künstlerische Neukontextualisierung der realweltlichen Fakten im Rahmen des kontrafaktischen Werks anzuzeigen.

Auch durch den Begriff der Variation wird - in Anlehnung an das musikkünstlerische Verfahren der Variation - der genuin künstlerische Anwendungsbereich der Kontrafaktik betont. Die Begriffe Fakten- oder Realitätsvariation bezeichnet eine solche Abweichung von realweltlichem Faktenmaterial, die dasjenige Faktenmaterial, von dem abgewichen wird, nach wie vor erkennen lässt. Die Faktenvariationen der Kontrafaktik werden dabei niemals rein resultativ verstanden, sondern stehen stets in dialektischer Spannung zu denjenigen Fakten, die sie variieren.

Kontrafaktik liegt nur dann vor, wenn Faktenvariationen in einem fiktionalen Werk als signifikant oder deutungsrelevant für die Interpretation des jeweiligen Werks angesehen werden. Diese erkennbare und hermeneutisch relevante Abweichung von den Fakten unterscheidet die Kontrafaktik von anderen Ausprägungen der Faktenabweichung in fiktionalen Texten, beispielsweise von fiktiven Elementen, die kein realweltliches Pendant aufweisen - etwa fiktive Elemente in realistischen Texten -, oder von interpretatorisch irrelevanten Fehlern.

Ein Erkennen der signifikanten Faktenvariationen kann bei der Kontrafaktik auf einer mehr oder weniger offensichtlichen Inkongruenz zwischen realer 
und fiktionaler Welt beruhen (unmarkierte Kontrafaktik) oder aber durch Verfahren der Markierung zusätzlich befördert werden (markierte Kontrafaktik). Typische Formen der Markierung kontrafaktischer Texte sind faktenreferierende Vor- und Nachwörter oder der Einsatz metafaktischer Elemente, welche die Thematik von Wahrheit und Unwahrheit noch einmal auf binnenfiktionaler Ebene aufgreifen. 